University of South Florida

DIGITAL COMMONS

@ UNIVERSITY OF SOUTH FLORIDA
Digital Commons @ University of

South Florida

3-1-2005

\title{
Strategies for an Intra-Urban Circulator System
}

CUTR

Follow this and additional works at: https://digitalcommons.usf.edu/cutr_nctr

\section{Recommended Citation}

"Strategies for an Intra-Urban Circulator System," National Center for Transit Research (NCTR) Report No. CUTR-NCTR-RR-2004-08, Center for Urban Transportation Research, University of South Florida, 2005. DOI: https://doi.org/10.5038/CUTR-NCTR-RR-2004-08

Available at: https://scholarcommons.usf.edu/cutr_nctr/181

This Technical Report is brought to you for free and open access by the National Center for Transit Research (NCTR) Archive (2000-2020) at Digital Commons @ University of South Florida. It has been accepted for inclusion in Research Reports by an authorized administrator of Digital Commons @ University of South Florida. For more information, please contact digitalcommons@usf.edu. 


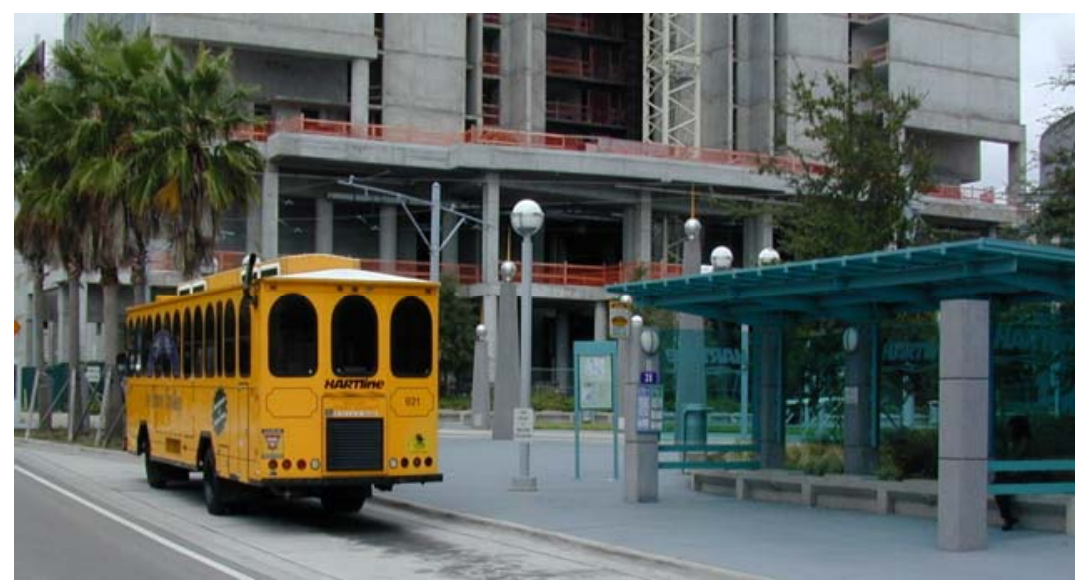

STRATEGIES FOR AN INTRA-URBAN

CIRCULATOR SYSTEM

November 2005

Final Report

BD-549-11 


\begin{tabular}{|c|c|c|c|}
\hline $\begin{array}{l}\text { 1.Report No. } \\
\text { NCTR 576-08 } \\
\text { FDOT BD-549-11 }\end{array}$ & \multicolumn{2}{|c|}{ 2. Government Accession No. } & 3.Recipient's Catalog No. \\
\hline \multirow{2}{*}{\multicolumn{3}{|c|}{$\begin{array}{l}\text { 4.Title and Subtitle } \\
\text { Strategies for an Intra-Urban Circulator System }\end{array}$}} & $\begin{array}{l}\text { 5.Report Date } \\
\text { November } 2005\end{array}$ \\
\hline & & & 6.Performing Organization Code \\
\hline \multicolumn{3}{|c|}{$\begin{array}{l}\text { 7.Author(s) } \\
\text { Victoria Perk, Senior Research Associate } \\
\text { Martin Catalá, Senior Research Associate } \\
\text { Joel Volinski, Director, NCTR } \\
\text { Jennifer Flynn, Graduate Research Assistant } \\
\text { Marlo Chavarria, Graduate Research Assistant }\end{array}$} & 8.Performing Organization Report \\
\hline \multirow{2}{*}{\multicolumn{3}{|c|}{$\begin{array}{l}\text { 9.Performing Organization Name and Address } \\
\text { National Center for Transit Research } \\
\text { Center for Urban Transportation Research } \\
\text { University of South Florida } \\
\text { 4202 E. Fowler Avenue, CUT } 100 \\
\text { Tampa, FL 33620-5375 }\end{array}$}} & 10. Work Unit No. \\
\hline & & & $\begin{array}{l}\text { 11.Contract or Grant No. } \\
\text { DTRS98-G-0032 }\end{array}$ \\
\hline \multirow{2}{*}{\multicolumn{3}{|c|}{$\begin{array}{l}\text { 12.Sponsoring Agency Name and Address } \\
\text { Office of Research and Special Programs } \\
\text { U.S. Department of Transportation, Washington, D.C. } 20690\end{array}$}} & $\begin{array}{l}\text { 13. Type of Report and Period } \\
\text { Final Report }\end{array}$ \\
\hline & & & 14.Sponsoring Agency Code \\
\hline \multicolumn{4}{|c|}{$\begin{array}{l}\text { 15.Supplementary Notes } \\
\text { Supported by a grant from the Florida Department of Transportation and the U.S. Department of Transportation }\end{array}$} \\
\hline \multicolumn{4}{|c|}{$\begin{array}{l}\text { 16.Abstract Currently, there are several urban communities that have implemented trolley/circulators or are in the } \\
\text { process of developing such services. In general, proponents of central business development and smart growth have been } \\
\text { some of the supporters of circulator systems in downtown cores. Because of nostalgia and their historical experiences, } \\
\text { one of the most favored modes has been the trolley (fixed and non-fixed guideway). However, while several urban } \\
\text { communities have recently implemented trolley services, or are in the process of developing one, currently there are no } \\
\text { such guidelines to use in the implementation and operation of the service. Therefore, the case studies in this report } \\
\text { identifying key elements of successful practices can be an important resource for these entities. This study develops a } \\
\text { synthesis of existing circulator systems in Florida and other select systems around the country. The study further } \\
\text { identifies key characteristics for developing an effective circulator system as well as critical operating strategies. } \\
\text { Finally, general guidelines are provided from which individual Florida communities and others across the country or } \\
\text { elsewhere can develop systems unique to their needs. }\end{array}$} \\
\hline $\begin{array}{l}\text { 17.Key Words } \\
\text { Circulator System } \\
\text { Commuter Assistance Programs } \\
\text { Parking Strategies, Public Transit, } \\
\text { Rider Benefits, Transportation } \\
\text { Demand Management }\end{array}$ & \multicolumn{3}{|c|}{$\begin{array}{l}\text { 18.Distribution Statement } \\
\text { Available to the public through the National Technical Information Service } \\
\text { (NTIS),5285 Port Royal Road, Springfield, VA } 22181 \text { ph (703) 487-4650 } \\
\text { http://www.ntis.gov ,and through the NCTR web sit at http://www.nctr.usf.edu/. }\end{array}$} \\
\hline 19.Security Classif. (of this report) & $\begin{array}{l}\text { 20.Security Classif. (of } \\
\text { this page) } \\
\text { Unclassified }\end{array}$ & $\begin{array}{l}\text { 21.No. of pages } \\
91\end{array}$ & 22. Price \\
\hline
\end{tabular}

Form DOT F 1700.7 (8-69) 


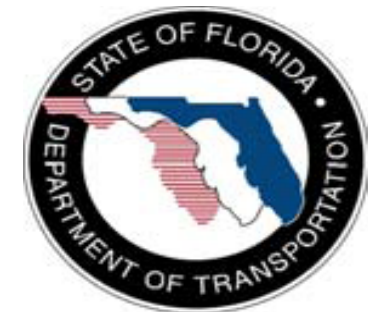

\section{State of Florida Department of Transportation}

Public Transit Office

605 Suwannee Street

Tallahassee, FL 32399-0450

(850) 414-4500

Project Manager:

Tara Bartee

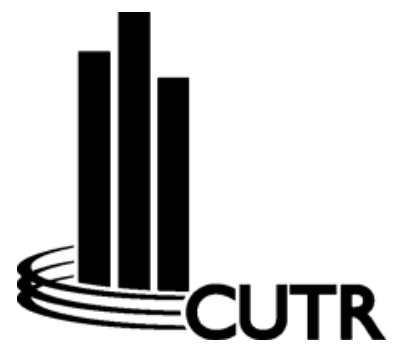

\section{National Center for Transit Research Center for Urban Transportation Research \\ University of South Florida \\ 4202 E. Fowler Avenue, CUT 100 \\ Tampa, FL 33620-5375}

(813) 974-3120

Project Staff: Victoria Perk, Senior Research Associate

Martin Catalá, Senior Research Associate

Joel Volinski, NCTR Director

Jennifer Flynn, Graduate Research Assistant

Marlo Chavarria, Graduate Research Assistant

The opinions, findings and conclusions expressed in this publication are those of the authors and not necessarily those of the U.S. Department of Transportation or the State of Florida Department of Transportation. 


\section{Executive Summary}

Currently, there are several urban communities that have implemented trolley/circulators or are in the process of developing such services. Some organizations in Florida that operate circulators (such as St. Petersburg and Tampa) have specifically expressed interest to obtain a resource that identifies key features for successful performance of such a system. Similarly, a commuter assistance organization in Boston area has expressed interest in characteristics of successful systems.

In general, proponents of central business development and smart growth have been some of the supporters of circulator systems in downtown cores. Because of nostalgia and their historical experiences, one of the most favored modes has been the trolley (fixed \& non fixed guide-way). Developers view such systems as means for increasing access to downtown businesses while smart growth proponents view it as a means of revitalizing the downtowns to slow the rate of sub-urbanization. However, while several urban communities have recently implemented trolley services, or are in the process of developing one, currently there are no such guidelines to use in the implementation and operation of the service.

The study develops a synthesis of existing trolley/circulator systems in Florida and other select systems around the country. The study further identifies key characteristics for developing an effective circulator system as well as critical operating strategies. Case studies identifying key elements of successful practices are included and will be an important resource for those interested in learning about successful strategies for circulator system implementation. The final report provides general guidelines from which individual Florida communities and others across the country or elsewhere can develop systems unique to their needs.

During the course of this research project, a comprehensive literature review of circulator systems was conducted. From the literature review, different goals and objectives of such systems, as well as characteristics of successful systems, were revealed and presented. In addition, through contacting several operating agencies throughout the country, current practices of evaluating circulator systems were identified and are included in the report. From the review of current practices, the major determinant of success is whether the circulator service is effectively serving the public purpose for which it was established. What is acceptable to one community in terms of performance might be totally unacceptable to another community, depending on the goals they are trying to achieve. Also from the review of current practices, several circulator systems were identified as "notable" based on remarkable success and/or other unique circumstances or experiences, and these are also described in the report. Three in-depth case studies are also presented, representing the Florida cities of St. Petersburg, Tampa, and Coral Gables.

From the tasks described above, several strategies for success were developed and encompass the following factors: service goals, service characteristics, fares, service delivery method, connectivity, identity, marketing, partnerships, and funding. From the research compiled for this report, it is clear that there is no "one size fits all" approach to the successful planning and operation of intra-urban circulators, as each system and operating environment is unique. Thus, in terms of circulator system performance, it may not be very effective to compare statistics such 
as ridership against other communities' circulators. Rather, the community should determine how the performance will be measured, such as by comparing the results to the stated goals or purpose. Key characteristics that make other transit modes successful, such as frequency and reliability, also are important for intra-urban circulators. Whether a part of the primary transit service in the area or not, it is also important for the intra-urban circulator to have good connections to other existing transit service as well as other modes such as pedestrian friendly areas and parking facilities. Along with appropriate marketing efforts, the circulator can become integral to the community. The research conducted for this report has shown the importance of local partnerships in the planning, development, and operation of intra-urban circulators. It is beneficial to incorporate business development concerns in the early planning process, and these relationships can also be fostered and continued as the service is implemented. Such partnerships can also be important for securing funding.

This research synthesis establishes effective development and operational strategies for intraurban circulator systems. Because of growing interest in reintroducing trolleys and circulators in downtown cores, it is essential that urban communities, both large and small, are provided with ample information on potential strategies from which to develop their own system objectives. The results of this study should be of interest to transit service providers, transportation professionals, downtown developers and businesses, transportation funding agencies, and other similar entities.

In addition to intra-urban bus circulators, the research includes current findings on streetcar systems, which often serve as circulators and share many of the same market and service characteristics as their bus counterparts. It is anticipated that by examining bus and streetcar systems concurrently, this report has produced a more comprehensive set of indicators for a successful circulator system. 


\section{TABLE OF CONTENTS}

Executive Summary ............................................................................................................................... vii

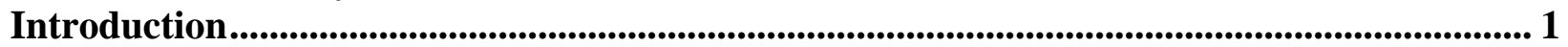

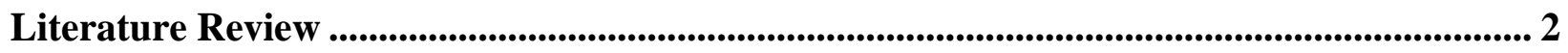

Goals and Objectives of Circulator Systems ……………................................................. 2

Characteristics of Successful Circulators.......................................................................... 4

Current Practices ............................................................................................................................. 9

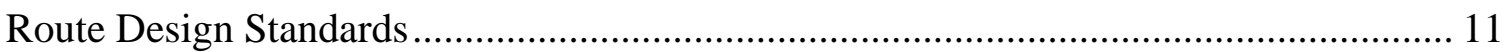

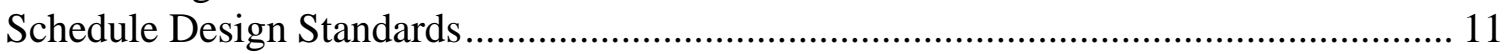

Economic and Productivity Standards ...................................................................... 12

Service Delivery Standards........................................................................................ 12

Passenger Comfort and Safety Standards ................................................................... 12

Route Design Standards ............................................................................................ 13

Schedule Design Standards............................................................................................ 16

Economic and Productivity Standards ............................................................................ 19

Service Delivery Standards...................................................................................... 20

Passenger Comfort and Safety Standards ...................................................................... 21

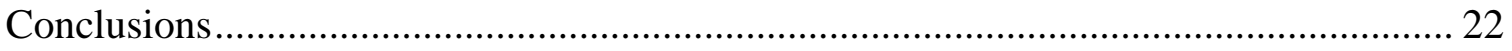

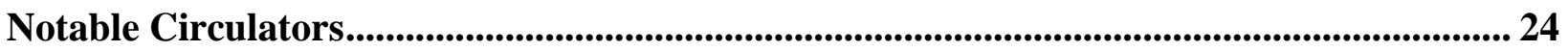

Ann Arbor LINK- Ann Arbor, Michigan .......................................................................... 24

Eureka Springs Trolley Bus- Eureka Springs, Arkansas ..................................................... 25

Chattanooga Electric Bus- Chattanooga, Tennessee ………………………………….... 28

M-Line Streetcar- Dallas, Texas ...................................................................................... 32

Portland Streetcar- Portland, Oregon ................................................................................. 33

Case Studies ................................................................................................................................... 36

Case Study 1: Tampa Downtown Circulators - Routes 96 and 98................................... 36

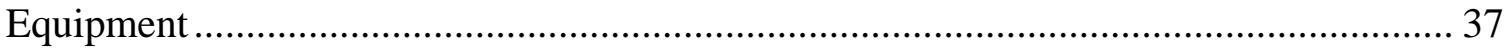

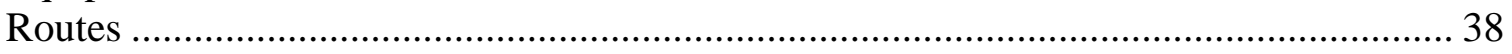

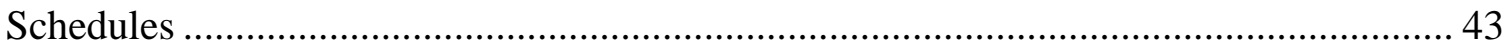

Case Study 2: St. Petersburg Looper ………………………........................................ 53

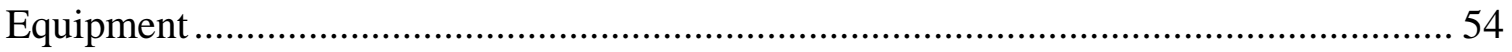

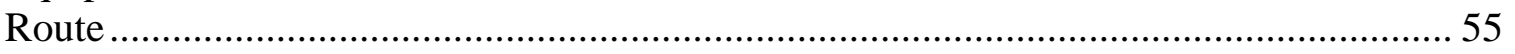

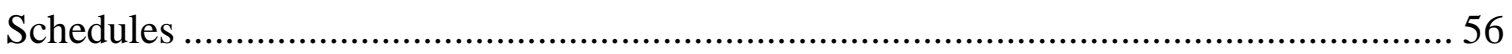

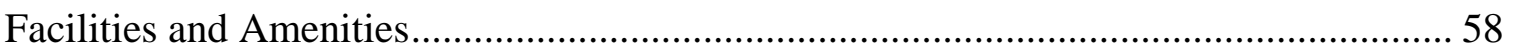

Case Study 3: Coral Gables Circulators.......................................................................... 65

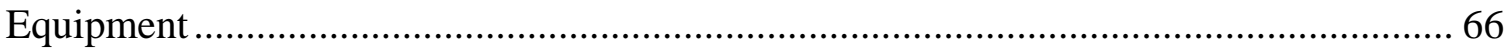

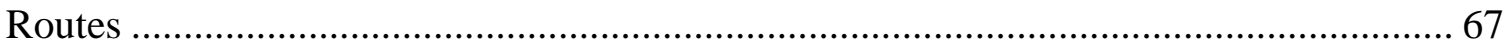

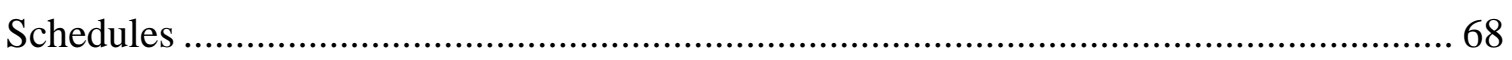

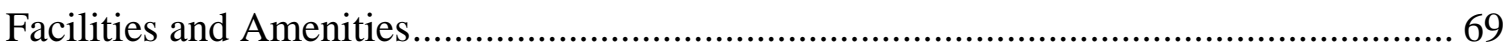

Findings and Conclusions .............................................................................................................. 78

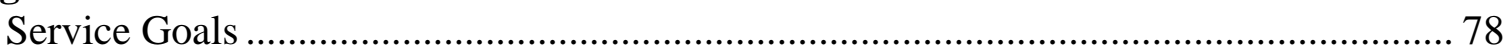

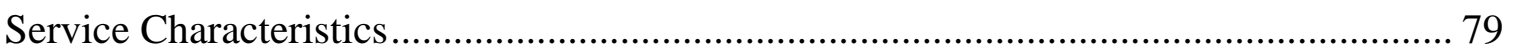

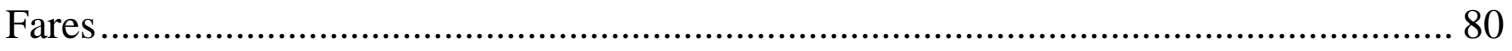

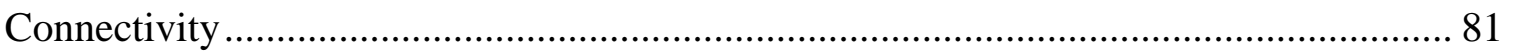

Service Delivery Method ....................................................................................... 81

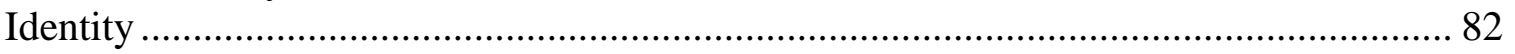




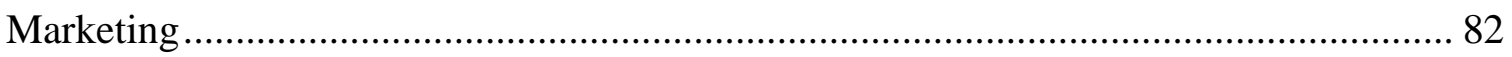

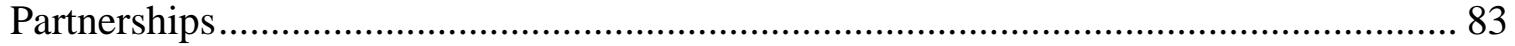

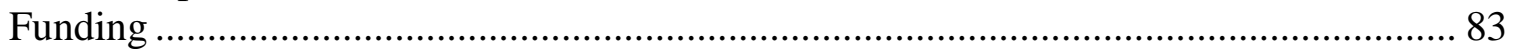

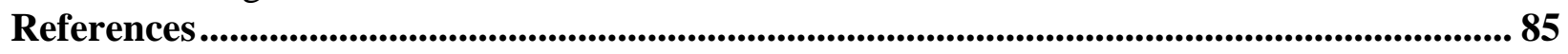




\section{Introduction}

The objective of this research synthesis is to establish effective development and operational strategies for intra-urban circulator systems. Because of growing interest in reintroducing trolleys and circulators in downtown cores, it is essential that urban communities, both large and small, are provided with ample information to develop plans for success. The results of this study should be of interest to transit service providers, transportation professionals, downtown developers and businesses, transportation funding agencies, and similar others. Systematic criteria for evaluation of intra-urban circulator systems were developed by drawing upon:

1. A comprehensive review of research literature,

2. A broad overview of representative circulator systems throughout the U.S.,

3. A detailed illustration of noteworthy systems facing unique challenges or employing innovative solutions, and

4. An in-depth analysis of three case studies in Florida.

This research further seeks to create an operational framework for maximizing ridership and serving commuters in downtown areas with efficient, timely, and well-planned circulator service. In addition to formulating improved strategies in the planning and operation of circulators, the CUTR research team collaborated with the public sector and downtown development parties to identify potential sources of funding. In addition to intra-urban bus circulators, the research examined below includes current findings on streetcar systems, which often serve as circulators and share many of the same market and service characteristics as their bus counterparts. It is anticipated that by examining bus and streetcar systems concurrently, this report has produced a more comprehensive set of indicators for a successful circulator system.

Currently, there are several urban communities that have implemented trolley/circulators or are in the process of developing such services. Some organizations in Florida that operate trolleys (St. Petersburg, Sarasota and Tampa) have specifically expressed interest in obtaining a resource that identifies key features for successful performance of an urban circulator. In two recent studies, Local Municipal Transit Circulator Policy Study, and Miami Surface Shuttle Service: Feasibility Study for transit Circulator Services in Downtown Miami, Brickell, Overtown and Airport West, Miami-Dade County aimed at determining factors for improving the quality of its existing circulator system. Similarly, a commuter assistance organization in the Boston area has expressed interest in characteristics of successful systems. 
In general, proponents of central business district development and smart growth have been some of the supporters of shuttle systems in downtown cores. Because of nostalgia and their historical relevance, one of the most favored modes has been the trolley (fixed and non-fixed guideway). Developers view such systems as a means for increasing access to downtown businesses while smart growth proponents view them as a means of revitalizing downtowns and slowing the rate of suburbanization. Some use them for internal circulation purposes, while others use them as a parking management tool by connecting the circulator to outlying park-and-ride lots.

However, while several urban communities have recently implemented trolley or other circulator services, or are in the process of developing such services, there are currently no such guidelines to use in the implementation and operation of the service. Therefore, case studies identifying key elements of successful practices are an important resource for these entities.

The first section of this report summarizes existing literature regarding intra-urban circulator systems. The next section provides a comprehensive summary of the current practices related to planning and operating a circulator system. More than 30 agencies were contacted as a part of this section. From this section on current practices, several interesting findings were revealed, and these "notables" are explored more fully in the next section of the report. Even more indepth research and analysis was conducted in the next section, which summarizes three case studies that closely examine the planning, implementation, and operation of circulator systems in three Florida cities: Tampa, St. Petersburg, and Coral Gables. Lessons learned from the experiences of these cities are also discussed. Finally, from all of the tasks conducted for this study, a set of findings and conclusions is presented, which consist of general observations as well as more specific strategies for the successful implementation of an intra-urban circulator system.

\section{Literature Review}

\section{Goals and Objectives of Circulator Systems}

Due to a growing interest in downtown circulator systems in large and small urban areas across the U.S., many communities are considering or are in the process of developing such services. In general, proponents of central business development and smart growth have been some of the supporters of shuttle systems in downtown cores. Developers view such a system as a means of increasing access to downtown businesses, while smart growth proponents view it as a means of revitalizing downtowns and slowing the rate of suburbanization. Although there seems to be a general consensus that circulators are a positive contribution to the vibrant, pedestrian-friendly 
downtowns that spur cultural and economic development, specific goals and perceived benefits of circulators vary according to location.

One common goal of implementing an intra-urban circulator is to create a linkage between the downtown area and the larger transit system. In its Downtown Circulator Implementation Plan for Washington D.C. ${ }^{2}$, the Downtown Circulator Partner Group outlines a detailed plan for a new downtown circulator service. The goal of the service is to improve connectivity and create a complete transportation network adequately linking all public transportation modes in the Washington CBD. Similarly, Circulator-Downtown Boise proposes a downtown circulator that would serve as a pilot program to a comprehensive commuter rail system. Boise planners see the effective linkage of the regional transit system to the downtown circulator loop as a key component in connecting commuters to homes, workplaces, shopping, dining and health care, thereby offering a compelling alternative to the car. The Milwaukee Downtown Plan-Transit Connector ${ }^{4}$ goes a step further by highlighting the possibility of a positive relationship between economic development and the linkage of circulators to the transit system. The plan calls for coexistence of pedestrian and transit movement with the proposed circulator, ensuring pedestrianfriendly streets through greater carrying capacity and curbside parking. The intention is that stops and transfers will become points of interaction, thus improving the city's commercial potential by increasing the opportunities for services and retail.

Another objective, cited by two proposals for enactment of CBD circulators, the Downtown Hartford Circulation Project ${ }^{1}$ and the aforementioned Milwaukee plan, is to improve downtown vehicle and pedestrian mobility by reducing the arrival of single occupancy vehicles. In addition to proposing a downtown circulator, the Milwaukee plan also proposed a "neighborhood" circulator that would connect the downtown area to surrounding neighborhoods, providing a means for workers to get to places of employment and for students and the elderly to have access to commercial centers. In its study of mobility in downtown Boise ${ }^{10}$, the Boise Downtown Circulation Working Group advised that introducing a new downtown circulator system would improve pedestrian mobility and could help address the challenge of Boise's great diversity of land use and needs.

Congestion mitigation was also referenced as a primary objective throughout much of the literature, including a feasibility study of three proposed circulator systems for the downtown Miami area. This study, prepared by Perk and Volinski for the Miami-Dade MPO, predicted an increase in congestion due to further downtown development, underscoring the beneficial role a circulator could play in encouraging mode shifts among commuters. The Circulator-Downtown Boise study emphasizes that reduction of pollution and congestion, aside from being worthy 
goals in their own right, may lead to further gains in the standard of living by reducing the costs of health risks associated with pollution and auto accidents. In addition to noting the potential benefit of easing traffic congestion and pollution, the Local Municipal Transit Circulator Study ${ }^{3}$ also points to the opportunity for providing transportation to mobility-deprived citizens, such as the elderly and low income members of the community.

The Central Salem Streetcar Feasibility Study, performed by Nelson/Nygaard Consulting Associates, notes a need for improved circulation within the downtown area due to the restrictive radial pattern of the existing bus network. This study, however, as well as the Seattle Streetcar Network and Feasibility Analysis ${ }^{12}$, focus more on the revival of fundamental community and economic development principles as fueling renewed interest in streetcars. Both studies note that streetcars have also been a favored mode for downtown circulators because of their historic relevance and ability to engender a sense of nostalgia. The following benefits, although associated with streetcars in these two studies, could possibly be applied to bus circulators as well:

- Development of core city services and retail, with special attention to store-front retail;

- Demand for living in mixed-use, pedestrian-friendly neighborhoods; and

- Convenient access to transportation

\section{Characteristics of Successful Circulators}

\section{$\underline{\text { Geographic Context }}$}

Densely populated areas with mixed land uses play a key role in the feasibility and success of a circulator, as evidenced by several reports. In their Local Municipal Transit Circulator Study ${ }^{3}$, Kimley-Horn and Associates find the climate for a feasible circulator system to be densely populated areas with mixed uses, citing that a mixture of residential and nonresidential land use facilitates transit usage by creating clear trip origins and destinations in the same area. In support of a proposed downtown circulator in Boise, the downtown mobility study mentioned above cites that, as a leading urban center in the Treasure Valley, Boise needs to integrate mixed uses and activities in the downtown area to make them a more interesting place for its citizens to live, work and shop. In agreement with this recommendation, the 1999 TCRP Report, Guidelines for Enhancing Suburban Mobility Using Public Transportation, prepared by Urbitran Associates, Inc., states that mixed-use land patterns permit circulators to serve trips for shopping and dining and that a fairly dense service area ensures reasonable travel times and definite 
demand for service. The Electric Transit Circulator Feasibility Study, prepared by CUTR, likewise identifies the high levels of pedestrian and transit activity characteristic of densely populated areas as necessary conditions for implementation of an electric minibus circulator.

\section{$\underline{\text { Socioeconomic Context }}$}

Throughout the literature, a ridership base of transit-dependent users, including seniors, students, and low-income workers, as well as a relatively high percentage of rental housing is recommended. Here it is worth noting that although lower incomes usually imply transit dependency, Kimley-Horn and Associates found circulator services to be more widespread in higher-income municipalities where there is greater likelihood of subsidy with local funds.

\section{$\underline{\text { System Elements }}$}

Much of the existing research presents clear recommendations for the linkage of an intra-urban circulator to the main transit system. Kimley-Horn and Associates emphasize ease of transfer for circulator users as crucial in effectively linking to the regional transit network. Urbitran Associates, Inc. stresses the particular importance of these "coordinated intermodal connections" for circulators serving commuters. However, in the Downtown Hartford Circulation Project, Team Hartford Transport cautions that linkage will not be effective without a regional transit system that is complementary to the circulator.

\section{Vehicle Appearance and Marketing}

For the proposed downtown circulator service in Washington, D.C., the Downtown Circulator Partner Group establishes several criteria for vehicles. In appearance, vehicles should be linked to an attractive marketing campaign when possible, and should have an interesting look, providing an innovative, aesthetic sense to the riders. The report cites examples of unique vehicles used in other cities, such as retro-styled trolleys or low-floored buses using hybrid engines, compressed natural gas, or other clean fuel technologies. Interestingly, the report also recommends large, clear windows that allow people on the street to see the presence of passengers using the service, as well as for riders to see attractions along the route.

In their feasibility study of Miami surface shuttles, Perk and Volinski find that the best type of vehicle for achieving cost effectiveness, efficiency, and environmental friendliness appears to be a conventional (versus low floored) minibus using electricity as fuel. However, the authors point out that these vehicles have disadvantages as well. For instance, the presence of an electric run shuttle system often becomes an attraction itself, sparking the curiosity of visitors and residents of the town and leading to overcrowding. As a result, people waiting at the designated stops may 
be passed by. Also, proper storage facilities present a challenge because they must be in close proximity to the shuttle system's route for expediency of battery switching.

\section{$\underline{\text { Public Information }}$}

Washington D.C.'s Downtown Circulator Partner Group recommends the provision of adequate public information regarding the service, such as pocket-sized guides and eye-level information at stops and stations. Although only two of the systems reviewed in the D.C. implementation plan provided real-time information to passengers, several of the parties interviewed for the report viewed such information as a highly desirable addition to service.

\section{Funding and Organizational Structure}

In regard to agency organization and funding sources, the position taken throughout much of the literature is perhaps reflected best in the comments of Perk and Volinski, who note that many factors come into play in the development of an intra-urban circulator, and there will always be trade-offs between costs, service coverage, and service frequency. Although the ideal circulator system would be low cost, frequent, and direct, many needs must be satisfied and the most practical means to meet them must be employed. This may entail a "thinking outside of the box" approach that is often best achieved by pooling creative resources through the formation of unique partnerships.

To ensure coherence in the provision of downtown circulator service, Perk and Volinski advocate identifying key strategies for securing funds by working with all parties involved, such as local transportation agencies, the business community, and existing transit service providers. In agreement with this line of thinking, the Stone Consulting and Design Team held six meetings and conducted interviews with key stakeholders for a feasibility report on a proposed downtown circulator in the historic district of Savannah ${ }^{5}$. To increase the chances of developing a successful circulator system, Perk and Volinski also recommend designating a lead agency such as a Transportation Management Association to facilitate discussion between stakeholders.

Along similar lines, CUTR's Electric Transit Circulator Feasibility Study identified key conditions for implementation of an electric minibus circulator, including an environment where there is promise of interlocal service agreements and a synergistic sharing of resources and major facilities. The study states that these considerations are necessary given the high capital costs associated with electric minibuses and the grave scarcity of funds allocated. This shortage in funding gives way to the following discussion of possible sources of financial support. 


\section{Funding}

Funding sources cited for transit circulators generally fall into the categories of general municipal, county, state and federal programs. Attesting to the need for additional funding, the average fare box recovery for Florida transit systems is generally 20\%-30\%. The following sections outline some of the sources that may be available for funding the capital and operational costs of downtown circulators. It should be noted that throughout most of the literature reviewed, a mixture of funding from several federal, state, local, and private sources is the recommendation.

\section{Capital Costs}

In the circulator implementation plan for Washington, D.C., the Downtown Circulator Partner Group notes that although the FTA can cover up to $80 \%$ of the cost of purchasing vehicles, many cities must be creative in obtaining the remaining 20\%. As an example, the study cites at least five funding sources for the Miami Beach Electrowave, including the Clean Cities Coalition and the Florida EPA, and \$350,000 worth of supporting equipment donated by the Florida Power and Light Corporation. The Miami Beach TMA noted the value of developing partnerships and pursuing various grants for the start-up of a circulator system.

\section{Operating Costs}

While the FTA may be a good place to start for capital funding, the federal government usually does not provide funding for ongoing bus operations. Furthermore, these programs only cover a period of a few years, after which the transit agency is on its own to come up with funding for continued service. Perk and Volinski's study of Miami surface shuttle services identifies funding opportunities from agencies such as MPOs, city and county governments, development and business interests, and state departments of transportation. The Downtown Circulator Partner Group suggests that sales taxes, parking fees, and downtown property taxes are all good operational funding sources because the people paying these monies tend to be the ones who will reap the benefits of the service. The following list provides a brief summary of the funding sources identified in the literature review: 


\section{Public funds}

- Farebox revenue

- Transit agency operating funds

- Federal Transit Administration

- $\quad$ State DOTs

- Parking fees

- Downtown property tax

- Sales tax

- City funds

\section{Private funds}

- Business improvement districts (BID)

- Develop impact fees

- Museums and cultural attractions

- Advertising revenue

- Convention and visitors bureaus

- Shopping malls and casinos

The next section of this report details current practices related to intra-urban transit circulator planning, implementation, and service evaluation. 


\section{Current Practices}

This section reviews current practices of service evaluation in the transit industry with the goal of identifying evaluation standards suitable for circulator services. Because different types of routes are specifically designed to provide various levels and characters of service, equal standards for evaluating a circulator route, an express route, and a fixed route are inadequate. Accordingly, evaluation of circulators should take into account that such services are typically designed for short, direct trips, focusing on promptness and short headways, with little or no fare charged.

However, separate service standards and evaluation practices designed specifically for circulators would seem to require a common definition of such a service. One must bear in mind that many types of circulators exist, serving many diverse purposes. For instance, services intended primarily for commuters will have different peak hour and headway considerations than services designed with tourists in mind. Similarly, although circulators are designed for directness, it may be necessary for a "loop" route to travel a circuitous path, depending on local geography. Thus, there is no one-size-fits-all method for evaluating such services.

Still, some general service standards and methods of evaluation can be drawn, provided that those in leadership roles do not lose sight of the original intent of the service or the context of local circumstances and needs. Kimley-Horn and Associates recommend this broad approach for developing and assessing the performance of a circulator service in Local Municipal Transit Circulator Policy Study. The study emphasizes that the type of circulator route developed should be dictated by a community's unique transit needs, which in turn are determined by the community's geographic and socioeconomic character.

According to Kimley-Horn, public involvement is critical, because it defines the role of the circulator in relationship to the needs of a community. To ensure that the public is adequately served, the report stresses that regular evaluation, on an annual basis at the least, is necessary. The study also advises that regular assessments may provide guidelines for adjustments in route efficiency and effectiveness, such as adding or modifying routes or adjusting headways. Moreover, planned evaluations are often a requirement for financial support programs.

More detailed information regarding bus route evaluation standards, including current industry practices used to employ such principles, is provided in Synthesis 10 of the Transit Cooperative Research Program (TCRP). TCRP Synthesis 10 is a compilation of information from numerous sources into a single resource, intended to aid transit agency staff in dealing with issues and problems related to evaluation at the route level. The report outlines existing activity and 
identifies some new standards that have been implemented in the area of route and schedule design, economics and productivity, service delivery, and passenger comfort and safety. Synthesis 10 does not specifically address evaluation of circulator routes; however, because several of the performance criteria in the report directly apply to conditions and elements of service typical of circulators, they may be appropriate for evaluation of such services.

According to Synthesis 10, there is an emerging trend in service evaluation that is moving beyond peer analysis, which historically focused on comparison by transit agencies to "peer" systems of comparable size. As evaluation has become increasingly geared to the viewpoint of the customer, a growing number of transit operators are using comparisons to agencies of various sizes and across different modes of transportation. In addition, there has been a gradual evolution toward more discrete (as opposed to system-wide) service standards. This trend is forecast to continue, especially in the area of service reliability, as route-level data collection and reporting technology such as automatic vehicle location (AVL) and automatic passenger counting (APC) become more sophisticated.

Given the increased emphasis on route-level analysis, the authors of Synthesis 10 anticipated that transit systems will begin to examine the relationship between individual routes and the 1990 Clean Air Act Amendments (CAAA). Standards relating to congestion and pollution mitigation are particularly appropriate for evaluation of intra-urban circulators because such services are likely to operate in areas of high density and poor air quality. Furthermore, such measures often play a role in the requirements of funding programs, and should not be overlooked as a means to achieving financial support.

According to TCRP, there has also been a notable shift toward comparison to other industries that seek to decrease wait times. Agencies commonly judge themselves against other transportation modes, such as an airline, taxi, or commuter train, or even other service industries, such as banks. Service standards geared to customer satisfaction may have particular significance for circulator routes, which typically aim for frequent and reliable service with straightforward, user-friendly scheduling. The report points out that, although customer service standards are often applied to evaluation at the system level, transit is experienced by riders on a route-by-route basis. Likewise, for a comprehensive evaluation it is recommended to appraise service at the route level when possible.

Through a survey of 120 transit agencies in the U.S. and Canada, TCRP Synthesis 10 identifies the following five categories of bus route evaluation standards: route design, schedule design, economic and productivity standards, service delivery standards, and passenger comfort and 
safety standards. Route and schedule design are concerned with standards that guide the design or redesign of a service. Economic and productivity standards deal with criteria that assess the performance of an already existing service. Service delivery standards are not concerned with the design of service, but with its reliability in actuality, e.g. on-time performance and headway adherence. Passenger comfort and safety standards measure the quality of the bus system environment experienced by riders. The performance criteria for each category are listed in the following summary, identical to that contained in the TCRP report:

\section{Route Design Standards}

- Population density

- Employment density

- Spacing between other bus routes and corridors

- Limitations on the number of deviations or branches

- Equal (geographic) coverage throughout the local tax base

- System design considerations such as enhancement of timed transfers

- Streamlining/reduction of routing duplications

- Network Connectivity

- Service equity

- Route directness

- Proximity to residences

- Proximity to non-residential generators

- Limitation on the number of transfers required to riders

- Bus stop siting requirements

- Bus stop spacing requirements

\section{Schedule Design Standards}

- Differing levels of service, e.g., local service versus express service

- Differing character of service, e.g., crosstown versus feeder

- Maximum number of standees

- Maximum intervals

- Standees versus no standees

- Duration of standee time

- Timed meets, or time to be spent waiting at a transfer point

- Use of clock-face schedules

- Span of service 


\section{Economic and Productivity Standards}

- Passengers per hour

- Cost per passenger

- Passengers per mile

- Passengers per trip

- Passenger miles

- Revenue per passenger per route (either in absolute dollars or as a percentage of variable cost)

- Subsidy per passenger

- Route level minimum variable cost recovery ratio

- Route level minimum costs that also include semi-variable and/or fully allocated/fixed costs

- Route level performance relative to other routes in the system

\section{Service Delivery Standards}

- On-time performance

- Headway adherence (evenness of interval)

\section{Passenger Comfort and Safety Standards}

- Passenger complaints

- Missed trips

- Unscheduled extra buses or trips

- Accidents

- Passenger environment conditions (e.g., vehicle cleanliness, vehicle condition, missing stanchions, blank destination signs)

- Special information (or special intervals) in areas where riders do not feel secure waiting for buses

As evidenced by the many different evaluation criteria employed by transit operators as reported in Synthesis 10, there is great variation in the industry. Standards and methods of service evaluation vary according to region, system size, and the organizational structure of the transit agency. In addition, evaluation practices may be formal or informal and processes of internal assessment often differ from those intended for public reporting purposes. However, some criteria were reported more consistently than others and could reasonably be considered 'fundamental' industry standards. Following is an overview of the criteria that emerge from Synthesis 10 as particularly applicable to conditions and elements characteristic of circulator services. However, this overview is not exhaustive; selection of specific criteria will depend on 
the service's unique purpose and circumstances, and should accompany any other criteria deemed appropriate.

\section{Route Design Standards}

These criteria are used in design or redesigning a route and help in determining and introducing the path that will be taken by the bus.

\section{Population Density}

Population density is the number of residents per square mile. According to the report, population density is "the best representation of the potential, in terms of daily trips, at the point of origin” (9). As much of the literature on circulators suggests that densely populated areas are key to the success of a circulator service, it is only natural to evaluate proposed routes according to this measure. Data for this criterion are found in the U.S. Census and may be supplemented by data from local planning agencies. Depending on the intent of the service, other demographic characteristics may be used in this analysis. For instance, if the proposed circulator is intended to provide transit to mobility-deprived citizens, measures such as auto ownership, proportion of elderly residents, and student population should be considered.

\section{Employment Density}

Employment density is the number of jobs per square mile. On average, work trips account for well over half of all transit ridership. Employees of central business districts comprise a large segment of the ridership market for many downtown circulators, and some services, such as employer shuttles, are designed solely for employees. With the exception of neighborhood circulators, employment density should be a basic consideration for an intra-urban circulator. Typically, metropolitan planning organizations (MPOs) or other regional sources provide employment data at a resolution appropriate for detailed route planning.

\section{$\underline{\text { System Design Considerations }}$}

Although similar to "network connectivity," described below, system design considerations focus on the design of a new route with respect to existing routes in the transit system. Network connectivity, discussed below, is concerned with the entire system. To forecast how a passenger might actually use a new route in relation to other routes, this criterion considers design elements such as enhancement of timed transfers at route intersections and the sharing of common terminals and bus loops. Given the many recommendations for the linkage of intra-urban circulators to the main transit network, system design criteria should be taken into account when 
designing such services. After all, effective linkage to the regional transit network cannot occur without effective linkage between routes. As discussed earlier in the literature review, efficient intermodal connectivity and ease of transfer are crucial for connecting a circulator to the main transit system.

\section{Network Connectivity}

Network connectivity, although clearly associated with "system design considerations," refers to the physical connection of a new route to the entire system. Rather than focusing on any specific route or group of routes, this criterion looks at opportunities to strengthen the system as a whole. Design should maximize resources and efficiencies, for instance by streamlining two poorly

performing routes into one stronger route. Similarly, when introducing a new route, its ability to enhance the whole system must be considered. Here it is useful to recall the suggestion by Nelson/Nygaard that improved circulation in the downtown might help alleviate the restrictive radial pattern of Seattle's existing bus network. This also supports Team Hartford Transport's caution that a circulator must be complementary to the route network in order to effectively link to the entire transit network.

\section{Service Proximate to as Many Residences as Possible}

The intention of this criterion is to run transit service as close as possible to a passenger's residence without undue inconvenience to other passengers. Thus, it is an appropriate consideration for neighborhood circulators, or downtown circulators that traverse a mixture of residential and nonresidential land use. As there is no standard mathematical definition of "proximate," this criterion depends on the subjective definition of individual transit agencies. Applying this criterion will involve trade-offs between factors such as population density, target market (e.g., income and auto ownership of prospective riders, and their destinations), and the ability of the vehicle to navigate streets. Even in high-density neighborhoods, smaller buses or shuttles may be necessary to accommodate residential street configurations. Thus, standards for this criterion will vary depending on the intent of the circulator.

\section{$\underline{\text { Service Proximate to as Many Non-Residential Trip Generators as Possible }}$}

As with the previous criterion, there is no mathematical definition of "proximate;" the term must be defined by each individual agency. Standards for this criterion will also vary depending on the intent of the circulator. The goal of this criterion is to run transit service as close as possible to a passenger's non-home destination without undue inconvenience to other passengers. This seems an appropriate consideration for any circulator with significant commuter ridership. Although the main point of negotiation in this compromise is employment density, target market 
and vehicle navigation apply as well. For instance, smaller buses or shuttles may be necessary to accommodate the pattern of streets in suburban office parks.

\section{Bus Stop Siting}

Bus stops need to be in places that generate the highest demand for circulator service. The stops should provide at least some fundamental amenities such as protection from the elements. Although they might be appropriate in certain instances, it is not necessary for shelters to be elaborate and expensive. It would be appropriate to locate stops where there are overhangs from nearby buildings that allow passengers to wait in the event of rain or extreme heat from the sun. Since downtown circulators tend to run frequently, it is unlikely that large crowds of waiting passengers will block adjacent buildings and frustrate business owners.

It is generally accepted that bus stops should be placed on the far side of traffic lights in order to allow other traffic to flow through those intersections, and to provide the bus that is trying to reenter traffic with a light that stops oncoming traffic. It is preferable for the bus stop to be located out of the lane of traffic for the sake of safety for passengers and other vehicles. On the other hand, in locations where parking space is limited, the need for adequate stop length may lead to an inclination toward nearside location of stops. Nearside stops with $80-\mathrm{ft}$ lengths do not consume as much curbside parking as that needed to accommodate $105-\mathrm{ft}$ farside stops. In addition, nearside stops may enable the bus to make use of the intersecting street width for pullout and lane merging.

\section{Bus Stop Spacing}

This criterion, which refers to the distance between adjacent stops of a particular route, represents a compromise between passenger convenience (easy walking distances) and speed. Interestingly, the results of the TCRP survey of transit agencies reveal "almost as many practices as there are operators" (13). This may be due in part to the issue of convenience versus speed, which is controversial because both sides of the argument appear to be mutually exclusive. When deciding which factor is of highest priority, the purpose and ridership market are significant issues. For instance, if the circulator is meant to promote retail and service activity through pedestrian-friendly interactions, spacing of stops should favor pedestrian convenience. Likewise, while easy walking distances may be a main concern for tourists, a lunchtime circulator will need to get downtown office employees to lunch and back in the shortest amount of time possible. However, because circulators typically provide short trips with minimal route deviation, any trade-off between speed and convenience may in fact be nominal. 
It should also be noted that because downtown circulators are often designed to be more attractive than walking or driving, such services are likely to have frequent stops. If a person must walk too far to get to a stop, he or she will be tempted to keep walking or use a car to make the trip. Since there will be frequent stops, the transit agency should do everything it can to make dwell times at stops as minimal as possible. This means that buses should be low floor to allow faster entry, and fare transactions should be as simple as possible. Free fares help speed the boarding process, but fares are often necessary to avoid the problems experienced when anyone can ride for free. If a fare is charged, it should be a flat fare, and a small one to help prevent people needing to search for different forms of change.

\section{Schedule Design Standards}

These criteria cover the basic interval, hours and days, and departure times for a route. Scheduling is an aspect of service that encompasses customer satisfaction, which is the emerging trend in bus service evaluation. Issues of customer satisfaction may be particularly pertinent to circulator services marketed to the choice rider, who will simply choose another travel option if public transit is found to be inadequate or unattractive.

\section{Differing Character of Service}

This criterion refers to the fact that there are different standards for different characters of service. Some systems have guidelines that vary according to character of service, such as feeder, radial, crosstown, and circulator services. As discussed earlier, equal standards are inadequate for assessing routes designed for different purposes. Thus, standards based on character of service may help ensure that evaluation of a circulator service is not at odds with the goals and objectives of the service.

\section{$\underline{\text { Maximum Standees }}$}

Downtown circulators are usually used by people making short trips, and while all passengers would prefer to sit rather than stand, it is not fatal to the success of a downtown circulator if passengers stand for a portion of their trip. Since there is a considerable amount of stopping where passengers board and deboard, there are usually opportunities for those who do stand to ultimately take a seat before their trip is over. The general rule of thumb is to allow 150 percent of load capacity to stand. If standees are anticipated, the interior of the vehicle should be equipped with bars or straps that standing passengers can hold to make their trip safer. However, if passenger counts show that buses are consistently running at 150 percent capacity, it would be wise to consider adding more capacity to the route, either through a larger vehicle, or additional 
vehicles. Again, people definitely prefer to sit if at all possible, and the transit provider does not want to operate under the image of an overcrowded system.

\section{$\underline{\text { Peak Periods vs. Off-peak Periods (Rush Hours that are Different from Non-rush Hours) }}$}

According to the TCRP survey, many transit agencies use load standards that vary by time of day, i.e., guidelines for peak periods will differ from those for off-peak periods. This criterion would apply to circulators that operate in downtown business districts or are designed to serve commuters, as these services are particularly prone to crush loads during rush times. In addition to varying load standards, it may likewise be advisable to adjust maximum standee guidelines during rush hours.

\section{$\underline{\text { Maximum Intervals }}$}

Maximum intervals, the most frequently used schedule design criterion, is the maximum time allowed to elapse between scheduled buses. With the risk of stating the obvious, this criterion is clearly germane to evaluation of circulator services, which are usually characterized by short, direct trips, with prompt and frequent service. Furthermore, along with minimum intervals (mentioned below), the effectiveness of this criterion will either facilitate or impede connection to the greater transit network. As mentioned earlier, achieving linkage to the regional transit system has been cited in much of the literature as a necessary ingredient for the success of a circulator system.

However, during off-peak hours, circulator services aren’t as necessary as during rush times. Thus, effective interval planning must strike a balance between headway consistency for the sake of passenger convenience and intensity of use at various times of the day. Obviously, the commute rush hour and the lunch hour are times when most downtown circulators are needed at their highest frequency, with much less use during mid-morning and mid-afternoon. However, it depends on the purpose, market, and prominence of the service. For instance, if a circulator is designed to encourage remote parking on the outskirts of the downtown, or if the area served is a tourist destination, there may be a large market of mid-day passengers. Similarly, if a circulator is the only major public transit service in a particular area, it may not reflect the more common peak and off-peak ridership patterns. 


\section{$\underline{\text { Minimum Intervals }}$}

This is the guiding principle used to specify the minimum amount of time required between scheduled buses. Few agencies reported using minimum interval criteria. However, the value of this criterion for evaluating services that emphasize frequency and schedule reliability must not be overlooked. This criterion is particularly relevant to services that are susceptible to bunching, as in the case of circulators with simple route geometries (such as loops) that cover a small geographic area. Setting appropriate minimum intervals may prevent the frustration felt by a passenger who has waited long past the scheduled arrival of the bus, only for three to arrive simultaneously. Promoting the efficient flow of passengers through appropriate interval standards may enhance overall linkage to the entire transit system.

\section{Timed Meets, or Time Spent Waiting at Transfer Points}

This involves the scheduled meeting of two or more trips on different routings, with the intent of facilitating transfers between routes. Buses are scheduled to converge at the transfer point to meet at the same time, commonly known as a pulse meet or timed transfer. Timed meets will ease passenger transfers, which may in turn improve "system design considerations" and "network connectivity," creating improved linkage to the system as a whole. However, if the frequency of the shuttle is high enough, perfect connectivity might not be as much of an issue. For instance, if service is provided every ten minutes or better, then transfers will not be as problematic as they might otherwise be. Additionally, the benefit of this criterion should be weighed against the caveat that the difficulty of implementing timed transfers tends to increase with the size of the transit system.

\section{$\underline{\text { Use of Clock-Face Schedules }}$}

"Clock-face" or "memory" schedules use intervals of time that divide evenly into 60 minutes, so that buses will arrive at the same number of minutes past every hour. From a marketing perspective, clock-face scheduling is a powerful tool for the promotion of a transit service, as arrival times are straight-forward and easy to remember, allowing for simpler trip planning. However, clock-face schedules are simply too expensive when running times are inconsistent, as with long routes that encounter numerous intersections. Nonetheless, the simple configurations and short round-trips typical of circulators are rather amenable to clock-face scheduling. Also, considering the markets typically served by circulators, the value of user-friendly scheduling may be greater than it appears at first glance. Tourists planning itineraries in an unfamiliar setting do not need the added hassle of trying to decipher a complicated schedule. Convenient, service that is easy to understand is a necessity for capturing the choice rider market. However, 
if the frequency of a circulator is high enough, clockface schedules are less important. As long as riders know a bus will arrive every ten minutes or less, it will not matter as much whether the schedule is clock-face. When the frequency becomes greater than every 10 minutes, then clockface headways become a definite advantage.

\section{Span of Service (the Hours at which Service Runs)}

As is usually the case, transit agencies should consider the nature of the community being served when making decisions regarding span of service. For instance, peak hours in a tourist town may be on Friday and Saturday nights when more people come out for work or leisure. But they also have demand throughout the day. Furthermore, while most downtowns deal primarily with daytime activities, some places are becoming 24-hour cities, and if there is a demand for service later in the evening or on weekends, then the service provider needs to take that into account. Also, if the circulator is the only form of public transportation in the downtown, it will have to extend its hours of service longer than most other downtown circulators.

\section{Economic and Productivity Standards}

Transit agencies often base service objectives and requirements on system-wide performance goals. However, the TCRP survey has identified several economic and productivity standards used by transit agencies to ascertain economic and ridership performance at the route level. The following two criteria are particularly applicable for evaluation of intra-urban circulators.

\section{$\underline{\text { Passengers per Mile }}$}

This criterion refers to the number of passengers carried in one bus mile, and is identified by TCRP as one of the most effective measures of productivity for routes with high turnover and frequent stops, such as circulators. Most of the agencies that participated in the survey reported using unlinked passenger trips (counting each time a person boards the bus as a completed trip, regardless of whether transfers were necessary) and revenue miles (counting only the hours that a bus is actually in service).

\section{Passengers per Hour}

This criterion is defined as the number of passengers carried in one bus hour. Passengers per hour helps determine how productive a transit system is with its time and route configuration. For instance, you might have a bus that carries a lot of people on a ten mile route, but finishes 15 minutes ahead of schedule. In order to stay on a one-hour headway, the bus waits until the start of the hour to begin its trip again. The bus might have done very well in terms of passengers per 
mile, but since it sat idle for 15 minutes, it did not perform as well in terms of passengers per hour. Although this is an unlikely scenario for a downtown circulator, it is worth noting as a secondary check for productivity purposes. It should also be noted that as a general rule, approximately $10 \%$ of a route's round trip time is built into the schedule as "recovery," allowing the bus to remain on schedule in the event of an unexpected delay.

\section{Route Level Performance Relative to Other Routes in the System}

For this criterion, the routes in a transit system are ordered according to percentile ranking of performance, i.e., a route's performance is measured against the performance of other routes in the same system. Yet circulators have unique service and performance characteristics. To avoid comparing apples to oranges, it may be useful to use a two-tiered approach when applying this measure. After a system-wide rank ordering, comparing a circulator to other routes with similar characters of service may provide a more comprehensive measure of productivity. In situations where this is not possible, agencies should be mindful of service goals and circumstances unique to the circulator.

While it doesn't provide a perfect way of measuring effectiveness, an agency should also establish the level of productivity that is reasonable to expect from its circulator route, probably in the range of at least 12 passengers per hour or 1.5 passengers per mile as a minimum. The route should then be measured against that performance over time, rather than comparing it to the performance of other routes that don't have the same characteristics.

\section{Service Delivery Standards}

Service delivery standards are concerned, not with supposed service delivery according to schedule design, but with the actual reliability of service delivered to the passenger. In short, these criteria measure the ability of a route to meet the service standards proposed in its design. Service delivery standards underlie the trend toward customer service-oriented evaluation, and have particular significance for choice riders, who compose a large share of the ridership market for circulators.

\section{On-Time Performance}

In general, this criterion is concerned with discrepancies between scheduled and actual running times. For a passenger, if service does not conform to scheduling, a timetable is of little value. In addition to dependable on-time performance, day-to-day consistency plays a strong role in the customer's perception of service delivery. For instance, if a certain bus is always five minutes late, this is preferable to that bus being 10 minutes early one day and then five minutes late the 
next. With the advent of automated technology such as automatic vehicle location (AVL), it has become much easier to monitor this issue.

Similar to other schedule and service delivery standards, on-time performance grows in significance as headway lengths increase. When service is provided at a frequency of 20 minutes or longer, people tend to follow schedules more closely. If a bus is missed, riders will be waiting considerably longer to catch the next one. If headways are relatively short, i.e., 10 minutes or less, people are not so concerned about perfect schedule adherence because they know a bus will be arriving relatively soon. Also, it should be noted that buses should never run "hot" (early). If a bus arrives before it is expected, it will pass stops before passengers get to those stops. Generally speaking, the definition of “on time” means arriving at the stop within one minute before schedule or up to 5 minutes after the schedule. These parameters may vary depending on the frequency of service.

\section{Headway Adherence (Evenness of Interval)}

Headway adherence refers to the interval of service, regardless of whether the trip conforms to properly scheduled runs. Arrivals are monitored at a certain location, without concern for whether the bus that arrived was actually scheduled for that time slot. Headway adherence is concerned with consistency, which, from a customer's perspective of service reliability, is actually more important than on-time performance. For instance, if individual buses are each about as late as the scheduled headway, and the scheduled headway is greater than the transit agency's on-time benchmark, buses will appear to arrive according to schedule. According to the customer, the bus has showed up in accordance with the advertised frequency and perhaps even when the schedule said it would; whether or not it is the exact bus the agency intended is of little importance. In this scenario, it is possible for on-time performance to be at 100 percent from a rider's point-of-view and 0 percent from the agency's perspective. As with on-time performance, AVL technology has encouraged greater consideration of this matter.

\section{Passenger Comfort and Safety Standards}

Passenger comfort and safety standards assess the quality of the bus system environment experienced by riders. The transit industry has generally become more concerned with issues of customer satisfaction in recent years; thus, agencies should consider such issues when evaluating any service. The following two criteria apply more specifically to circulators. 


\section{$\underline{\text { Unscheduled Extras }}$}

Unscheduled extras are the trips that are added to the schedule, not including routine schedule changes. This criterion may be of use to agencies that want to expand carrying capacity of a circulator route during special events such as sports or holiday events. Keeping track of unscheduled extras may help in planning the most efficient number of extra trips to run during special events.

\section{Passenger Environment Conditions}

This criterion assesses the physical surroundings encountered by a customer when using transit service, such as vehicle condition, missing bus stop markers, and blank destination signs. Obviously, passenger environment conditions are directly related to perceptions of service quality and will either encourage or discourage repeat customers. As discussed above, circulators are often designed with the goal of luring the choice rider out of his or her car, something that is unlikely if a pleasant service environment is lacking. Data on this standard are usually collected through market research, formally structured traffic surveys, or on-board surveys.

\section{Conclusions}

All transit services, whether they are regional or local, should have some metrics established to determine whether or not they are "succeeding" in their purpose. Success may be defined differently by different communities, depending on the public purposes being served by the circulators. For instance, some circulators might be designed to play a significant role in transforming a major arterial running through the downtown into a transit mall, creating a pedestrian-oriented, walking environment where there will be numerous sidewalk restaurants and businesses and a traffic-free, but busy ambience (e.g., Denver). Other circulators might be intended to operate in mixed traffic, but provide convenient alternatives for residents or employees who can choose to leave their cars parked while they travel within the boundaries of the area served by the circulator (Miami Beach), thereby minimizing the number of vehicles on the street. Another scenario might be that the city has taken the steps to restrict parking in the downtown area to remote parking garages. Here, the transit circulator may be the best way for people to get around downtown and then back to their own private vehicle. Other circulators might be established primarily for tourists as a way of giving them a relaxed and entertaining way of seeing the sites in the city. The same circulator might even be designed to serve a multitude of the above functions. The real determinant of success is whether the circulator service is effectively serving the public purpose for which it was established. What is acceptable 
to one community in terms of passengers per mile or per hour might be totally unacceptable to another community, depending on the goals they are trying to achieve.

Within whatever parameters have been decided upon for measuring success in terms of public purpose, measures that monitor service in terms of reliability and quality from the customer's point of view should be used as well. People will only continue to use the circulator if it is clean, comfortable, safe, reliable, accessible, easy to use and understand, and if personnel are accommodating and friendly. The ridership markets that are intended to be served must be understood well enough to know what will be attractive to them, and parameters such as frequency, span of service, and size and types of vehicles, should be developed accordingly. 


\section{Notable Circulators}

This section describes in detail some circulator systems that stand out as examples of particular interest. CUTR research staff has identified these as noteworthy systems facing unique challenges or employing innovative solutions. This system includes technical and anecdotal information gathered from transit agency websites, newspaper articles, publications for transit and urban planning practitioners. It should be emphasized that no two cities are exactly alike. When using peer information from one city to predict results in another, it is important to understand the issues underlying both the differences and the similarities between the two cities.

\section{Ann Arbor LINK- Ann Arbor, Michigan}

Ann Arbor's downtown circulator route, the LINK, is a prime example of the unique partnerships, collaborative solutions, and steadfastly committed leadership that resulted in success. Due to shortfalls in funding, it became necessary to temporarily discontinue the popular LINK circulator service. However, funds from a new bus advertising program, and partnering with the University of Michigan (U-M) and the Downtown Development Authority (DDA) have made it possible for the Ann Arbor Transportation Authority (AATA) to revive the service.

The initial LINK service, which was introduced in September 2003, connected Ann Arbor's four main retail areas: Main Street, State Street, Kerrytown, and South University. The route, which traveled within one block of all major parking facilities, was designed to ease transfer to other AATA routes and the University of Michigan shuttle routes. Initial ridership was mediocre, but skyrocketed during the 2004-05 fall and winter semesters, equaling the average for the entire AATA system, and consequently meeting its productivity goals.

During its 20-month trial, the LINK quickly established itself as an extremely popular alternative to driving. In November 2004, the LINK achieved a daily trip average of 625, which was more than triple the number for the same month the previous year, and the number of daily trips continued to increase during the first four months of 2005, averaging 800. Yet overwhelming ridership success alone was not enough to guarantee continuation of the service. The LINK was suspended from operation in April of 2005 due to the expiration of the Congestion Mitigation Air Quality (CMAQ) grant that had been its primary source of funding. The amount remaining from the initial federal grant from August of 2003 was insufficient to further finance the route for any significant time period.

In August 2005, the LINK combined its route with the day and evening segments of the U-M Oxford/Trotter Shuttle. The service, which is being funded through April 2006, has a new, 
published schedule, and remains free of charge to all passengers. As before, the LINK will connect the four major downtown shopping and dining areas to the U-M main campus, expanding its route to replace the day and evening segments of the U-M Oxford/Trotter Shuttle. Headways have been increased from approximately every eight minutes to every fifteen minutes. Service will run Monday-Friday from 7 a.m. to 6 p.m., and will continue from 6 to 11 p.m. along the portion of the route previously served by the U-M Shuttle. Late evening service to these areas will be provided from 11 p.m. until 2 a.m. by U-M Transportation Services. There are twenty-four stops, each listing points of local interest and equipped with a message board that provides an estimated time of arrival for the next bus based on real time information.

The revival of the LINK service would likely not have been possible without the new solutions that were generated through AATA's collaboration with the U-M and the DDA. By extending service to the main campus, AATA and the U-M were able to find a mutually beneficial, costeffective solution that became feasible when resources were pooled. In addition, the DDA's monetary support of the LINK exhibits its firm commitment, both in word and deed, to encouraging alternative transportation whenever possible. Furthermore, the amount of money needed from U-M and the DDA to re-introduce the route was greatly reduced by the revenue generated through AATA's new bus advertising program.

The costs of operating the route will be covered by $\$ 57,800$ remaining from the CMAQ grant, along with $\$ 101,900$ in state revenue, $\$ 60,000$ in AATA bus advertising revenue, $\$ 71,900$ from U-M and $\$ 22,600$ from the DDA, for a total of $\$ 314,200$ in direct operating costs. According to Greg Cook, Executive Director of AATA, the revised service is predicted to be successful, but will definitely continue to require innovation and the continued support of local partners, both public and private.

\section{Eureka Springs Trolley Bus- Eureka Springs, Arkansas}

The story of the Eureka Springs Trolley demonstrates that with creative flexibility, a circulator can successfully respond to unique local mobility needs, even in the face of complex challenges. Cooperative partnerships with the local business community, progressive state transportation policies, and inventive solutions have enabled Eureka Springs Transit to respond to the transportation needs of visitors and residents alike, while still preserving the historic character of the area. Eureka Springs also provides an example of the benefits a circulator can provide to a small town lacking the adequate infrastructure necessary to support its heavy tourism. 
In this quaint Victorian-era town of 2,200 people, historic hotels, antique craft shops, and the picturesque scenery of the Ozarks attracted almost one million tourists in 2002. In a place like Eureka Springs, where tourism is absolutely vital to the local economy, the ability of visitors to navigate the town safely and conveniently is an economic necessity. In this regard, several aspects of the area's local geography interact to compound transportation challenges.

Not only are there winding roads in Eureka Springs, a difficulty faced by many mountainous regions, but many of these roads were constructed during the Victorian era and are extremely narrow. To complicate matters more, there are no traffic signals in the entire town. In response to increasing distress from local business owners and residents about streets teeming with tour buses, as well as concern from tourists and the hospitality industry regarding the negative effect of traffic congestion on visitor experiences, Eureka Springs Transit was created by the city of Eureka Springs in 1978.

In order to provide modern public transit without detracting from the area's historic feel, local officials decided to use trolley buses consistent with the Victorian theme. Planning focused on five routes used to circulate tourists from a common tour bus staging area not only through the historic district, but also to lodging and other services located throughout the larger area. With the introduction of the trolley service, people have been able to "leave their cares with their cars,” says Lamont Richie, director of Eureka Springs Transit. “They don't have to deal with looking for a parking place or with trying to squeeze their 2004-size vehicle through a street built in the late 1800s." The overwhelming success of the Eureka Springs Trolley, which provided more than 600,000 trips in 2002, can be credited to several factors.

First, the trolley system was adopted in a collaborative spirit with the local business community, including tour bus operators. In addition to providing a quality service to tourists, the trolley operation has also been a boon to the local economy. When speaking of the hospitality industry, which generates the most jobs and revenue in the area by far, Richie says, "Building the service on a strong relationship with those players was critical to implementing the transit service, and making it a successful one, at that." One of the primary goals of the trolley was to disperse tour buses out from the town center to reduce congestion. Tour operators and local businesses immediately viewed this as an improvement of their product.

In addition to the indirect payback from an improved environment, local businesses directly benefit from the trolley system through financial incentives and commissions of selling tickets. Of the sixty local businesses that sold over 31,000 trolley tickets in 2003, ten realized more than $\$ 4,000$ in ticket sales each. Indeed, this income is seen by several local businesses as an 
important part of their profits. Local business owners realize that feeding riders to the trolleys ultimately benefits local businesses, as trolleys deliver the customers back to merchants.

At the same time, the trolleys are a valuable asset in the daily journeys of the citizens of Eureka Springs. A monthly unlimited ride pass that can be purchased for \$5.00 is especially popular with residents; in fact, nearly the entire population of Eureka Springs takes advantage of this benefit. Locals use the five routes that pass through the city to get to the downtown area without their cars adding to the congestion. Many historic district employees walk from home to the closest trolley route to get to work, and senior citizens have cited the trolley service as a crucial aspect of their mobility.

Another critical component in the success of the trolley has been its funding strategy. As a condition of securing federal rural transportation investment in 1985, Eureka Springs Transit was required to acquire a local match in funding to cover administrative and operating costs. Because ticket sales usually cover only a fraction of this match, local governments nationwide have traditionally sought non-fare revenue, such as city general funds, rental income, and parking fees. Arkansas, however, has one of the most ground-breaking state transit investment programs in the nation. The Arkansas Public Transit Trust Fund, passed by the Arkansas State Legislature in 2001, uses revenue from the state tax on car rentals, providing essential investment for local systems, including Eureka Springs. The Arkansas Public Transit Trust Fund allows Eureka Springs Transit to maintain a certain level of autonomy from the city administration. Thus, the trolley system is freed from the uncertainty of operations tied to the shrinking budgets characteristic of many local governments.

While the trolleys enjoy a certain amount of stability, the transit system remains proactive in terms of expanding its sources of funding. It charges fees for parking at its depot on the edge of the historic district, and collects rent from the Chamber of Commerce, which is located there as well. Also, because a good number of visitors arrive independently, without a tour operator, the performance of on-board ticket sales is increasing. To this end, the transit agency has involved the drivers more in the process of improving sales on the trolleys.

Eureka Springs Transit charges a fare well above most other downtown circulators, which are typically free-of-charge or exact only a small fare. In addition to the $\$ 4.00$ fee at the parking depot, passengers can buy an all-day pass for $\$ 4.00$, a two-day pass for $\$ 6.00$, or a one-ride pass for $\$ 2.00$. A child's daily pass (age 7-11) can be purchased for $\$ 1.00$. The trolley system is able to charge a premium for its services, but remains overwhelmingly successful. This may be due to several factors, the first being that Eureka Springs provides a unique situation where riding the 
trolley may actually be a more comfortable, attractive option than navigating a personal vehicle through winding roads. This is especially true for seniors, who compose a large segment of the area's tourist market. Furthermore, because of its Victorian theme, many tourists may view the trolley as an attraction in its own right. Four dollars may not seem too much to spend for what is perceived as a more authentic historic experience. Lastly, aside from tour buses, the trolleys are the only public transit option. For those who prefer an itinerary less regimented than that offered by a tour bus, the trolley may be seen as the best option for experiencing the town in a more spontaneous fashion.

In addition to its successful funding strategies and partnership with the local business community, Eureka Springs Transit has come up with inventive solutions to some small-town challenges that may not be common in larger cities. The urban form of Eureka Springs, beset with sharp turns and steep hills, does not facilitate precise scheduling. The town's roads can be difficult to navigate even under the most ideal circumstances. To sidestep this problem, each trolley route simply guarantees ten-minute headways at each stop. To boost rider confidence, the transit agency installed a color-coded clock for each route in the trolley depot. When a trolley departs the depot, the clock for that route is reset by the driver, so that tourists will have a more accurate idea of when the next vehicle will arrive. To help visitors understand these unusual aspects of service, the system has developed informational products, including a video that plays hourly on the local access station on hotel televisions.

Also key to its success is the trolley system's high level of adaptability. It is not unusual for large groups to arrive in Eureka Springs unexpectedly. In such situations, trolleys often need to be switched between routes or stand-bys put into action on short notice. Since the trolley's beginning, its staff has worked to improve its response times in scenarios of this type. The trolley system has worked so well over the years due in large part to its flexibility, a trait which has always been a defining feature of rural transit planning. For this, Richie gives credit to his innovative staff, saying, "We have a good crew here. We always look at how we operate, and never do so in a vacuum. That involves being aware of the needs that we are responsible for, and constantly trying to make improvements.”

\section{Chattanooga Electric Bus- Chattanooga, Tennessee}

The history of Chattanooga's electric bus program is an inspiring account of the virtual renaissance that took place in a city grappling with three interrelated problems: mounting traffic congestion compounded by a restrictive urban geography, the ensuing negative reputation of a city plagued by increasing pollution problems, and the general decline of its downtown. 
In 1969, Chattanooga was identified as the city with the worst particulate air pollution in the nation. In response, the city made a solid commitment to improving air quality and the overall quality of life in the area. Three short years later, after enacting strict clean air regulations, Chattanooga became one of the cleanest cities in the U.S. The dedication of local officials to environmental and quality of life issues continued, and in 1984 was embodied in a project called Vision 2000, which emphasized revitalization of Chattanooga's dying downtown.

Improving public transportation in the central city was one of the most challenging goals proposed in the Vision 2000 plan. Chattanooga's downtown is divided into three districts: the south-end shopping district, the central business district, and the north-end riverfront entertainment district. The area has a long and narrow geography restricted by interstates. The two plus mile length of the major downtown corridor was too lengthy to walk, while the city's width, in some places only four blocks, forced traffic onto only one of three streets traversing the city. Parking lots were flooded to capacity with short-term parking, and more than 65 percent of downtown land was set aside to accommodate automobiles.

Although the geography of the city was a nightmare for automobiles, its configuration proved to be ideal for transit service. Achieving downtown revitalization required city planners to conceptualize a new form of downtown transportation, which they did by exploring the idea of a downtown circulator system. In collaboration with city officials and community organizations, the Chattanooga Area Regional Transportation Authority (CARTA) identified several objectives for the circulator. The proposed circulator would need to become a permanent and unique fixture in the city's landscape, promote development, be easy to use, dependable, integrated with other transportation options, and an attraction in and by itself. While remaining committed to the first five objectives, CARTA officials focused on the sixth: the circulator had to be unique, innovative, and visually attractive in order for the ride itself to be a fond memory of a visit to one of America's most scenic cities. The circulator also needed to be effective in transporting employees and visitors in the downtown area; thus, the service had to operate in the heart of the business district, have many stops, and be frequent and free of charge.

Although the concept of reintroducing trolleys was considered, city leaders desired a system that focused on the future instead of the past. The Vision 2000 planning process allowed CARTA to consider cutting-edge technologies. After learning about electric buses operating in Santa Barbara, California, CARTA officials began to develop plans for an electric shuttle, which they believed would fit the model of a unique, innovative, attractive, and environmentally-friendly vehicle. 
CARTA began an international search to determine if electric vehicle technology existed that would support CARTA's operational requirements, if such a vehicle was being manufactured, and if not, whether the vehicle could be made in Chattanooga. CARTA soon found that the technology did exist, but unfortunately, there was no current manufacturer for the type of vehicle required by the city at that time. As a result, Advanced Vehicle Systems, Inc. (AVS) was created locally with the sole purpose of building electric shuttle buses for CARTA and other transit operators worldwide. Concurrently, CARTA and other partners created the Electric Transit Vehicle Institute (ETVI), a non-profit organization charged with promoting the design, production, and utilization of battery-powered electric buses. CARTA, ETVI, AVS, and the Tennessee Valley Authority (TVA) have formed a "living laboratory" for electric vehicle technology, identifying and addressing needed improvements by putting newly-built vehicles directly into revenue service.

In 1992, the Electric Shuttle was implemented by the Chattanooga Area Regional Transportation Authority and began operation in the downtown corridor. The project included the purchase of three intercept parking garages to provide funds, not only for the costs of operating the shuttle, but also for the capital costs of acquiring new vehicles. Thus, in addition to supporting all six objectives of the downtown circulator and investing locally in emerging technology consistent with the progressive efforts of the city, CARTA's final plan would become economically selfsufficient. With the estimated revenue from the garages, CARTA would have the funds to operate the shuttle without federal, state, or local funding.

By 1993, six vehicles were running, with free five minute service between the Tennessee Aquarium and the Chattanooga Choo Choo hotel. The Electric Shuttle became an immediate success, providing the transportation link that had been identified as one of the top goals of Vision 2000. Ridership increased on a daily basis as residents, tourists, and local business leaders began to use the shuttle. Passenger preference for the clean, quiet shuttles was soon evidenced by reports of riders allowing diesel buses to pass in order to ride the electric shuttle.

Since its inception, CARTA's electric bus operation has continued to grow. In August 1994, the Shuttle Park South (SPS) garage opened, followed the next year by the largest electric vehicle battery charging station in the U.S., and Shuttle Park North (SPN) in June 1996. Today the CARTA Electric Shuttle operates a free service along a 1.5-mile route and has a fleet of 23 lowfloor minibuses, the largest operation of electric buses in the United States. With eleven electric and hybrid-electric buses on order from AVS, CARTA's commitment to electric vehicles remains strong and the success of its popular Downtown Shuttle continues to grow. 


\section{Miami Beach ELECTROWAVE- Miami Beach, Florida}

The Miami Beach Transportation Management Association (MBTMA) began its investigation of alternative fuel vehicles because of their small size and clean, quiet operation, which seemed a promising solution to the escalating problems of limited parking, traffic congestion, and air pollution in Florida's second largest tourist area- South Beach. Because of the service-based economy, many residents have a relatively low income and could benefit from the mobility option of public transit. However, Miami-Dade Transit's large diesel buses were not amenable to the many sidewalk cafes and intense pedestrian activity typical of the area's high-density, mixed-use land development. Electric shuttle buses were the ultimate choice because their advanced technology made them the quietest, most environmentally-sound, cost-effective transit alternative for South Beach.

After traveling to AVS in Chattanooga to learn more about the production and operating process of electric vehicles, the MBTMA and other local leaders agreed to purchase seven 22-foot AVS electric shuttles. In 1998, the ELECTROWAVE became the first electric shuttle bus system in Florida. The service began operating along a 1.7 mile circulator route through Miami Beach's Art Deco District. The immediate success of the circulator, patronized by more than a million passengers during the first 35 weeks of its operation, reassured city commissioners and others who had initially been hesitant to support the service.

According to MBTMA, the success of the ELECTROWAVE would not have been possible without the strong support and involvement of the Miami Beach community and the committed leadership of local officials. The ELECTROWAVE was developed by MBTMA and the City of Miami Beach through funding partnerships with the Florida Department of Transportation, Florida Power and Light, Florida Alliance for Clean Technologies, The Clean Cities Coalition, the Florida Department of Environmental Protection, and the International Council for Local Environmental Initiatives (ICLEI). These funding partnerships provided over \$3.5 million of support for operating and capital expenses in the first year of operation. The goals and objectives of the project were:

- reductions in parking and traffic congestion,

- integration with the existing transit system operated by the county,

- development of a park-and-ride system,

- reductions in "cruising” for parking,

- reduction in auto air emissions,

- energy conservation, and 
- creation of a community partnership supporting the project throughout its development and into the future with funding, in-kind services, marketing and advertising support, and project equipment needs.

Interestingly, MBTMA chose to do without purchased advertising on the ELECTROWAVE. In place of wrap-around advertising, local artists chosen by the city's Art in Public Places Committee transformed the fleet of electric shuttles into moving murals. The unique eyecatching designs produced a tropical feel, lending a distinctive character and local brand appeal to the service. Full-page ads donated by major businesses were included in publications provided to every hotel room in the area. In addition, local businesses along the route distribute colorful, multi-lingual ELECTROWAVE brochures.

The ELECTROWAVE operated on headways of 10-15 minutes, 18-20 hours per day, 365 days per year, supporting over 3,500 municipal parking spaces along the route, and has a small fare of only $\$ 0.25$. The service resulted in a significant reduction in private automobile use by residents and employees in the service area. Because of its tremendous popularity in Miami Beach, the ELECTROWAVE provided a valuable test case for the operation of electric shuttles in areas of high humidity, salt air from the ocean, unusually hot road surfaces, and high demand operating schedule. It should be noted that the City of Miami Beach recently reached an agreement with Miami-Dade County in which the County agreed to take over responsibility for the ELECTROWAVE. The service will continue as a part of Miami-Dade Transit's operation and will be know as "The Local.”

\section{M-Line Streetcar- Dallas, Texas}

Perhaps the only thing more remarkable than the public-private cooperation that produced the McKinney Avenue Trolley is the fact that the operation is run by volunteers. With the exception of a paid chief operating officer and office manager, the McKinney Avenue Transit Authority (MATA), a private, nonprofit 501(c)(3) company, is overseen by an unpaid team of enthusiasts committed to the history and preservation of authentic vintage trolley systems. The entire staff is responsible to a chairman and board of directors composed of prominent members of the Dallas business community. These dedicated volunteers have aligned with local business owners to achieve strong support from the City of Dallas.

When original trolley tracks were discovered under 20-year-old layers of pavement along McKinney Avenue, members of the business community donated funds to study if restoring trolley service to the original tracks was feasible, and if there was enough community support to 
back the idea. An unexpected degree of local interest in the proposal led to the incorporation of MATA, which began to pursue funding. The final cost of the plan endorsed by the City of Dallas in 1984 was \$5.9 million. The City provided \$200,000, local businesses and other supporters contributed $\$ 3.25$ million, and the Federal Transit Administration (FTA) provided \$2.5 million in grants. Four vintage streetcars were soon purchased or donated and then restored; one came from Portugal, one from Australia, and the other two had originally run in Dallas during its trolley years.

In June of 1989 the M-Line Streetcar began the 365-day a year service for which MATA is known. Although the standing room only cars of the service's initial months far surpassed all expectations for success, the opening wave of ridership was followed by a lull in business, forcing MATA to devote more time and energy to marketing the new line. This spurred a successful collaboration with the area's tourist and convention agencies and local businesses along the line. MATA also allocated more resources to promoting special events, such as charters, birthdays, fraternity and sorority parties, rehearsal dinners, and even weddings on the historic streetcar line.

Although these efforts helped, costs of operating the system were higher than originally projected and finances remained tight. Originally managed by a paid staff, in 1991 operation of the streetcar line was granted to the supporting non-profit group which exists today. To ensure continuing financial support and strengthen its bond with the local community, MATA incorporated a Public Improvement District (PID), providing an extra \$150,000 in support annually.

With the 1996 inception of Dallas's new light rail system, MATA began planning extensions that would link both ends of the trolley system with the light rail stations. Today the M-Line streetcars offer free service seven days a week every 15 minutes during peak and lunch hours, and every half hour during off-peak times and weekends. The line connects Dallas's Arts District with historic Uptown, a vibrant neighborhood of restaurants, sidewalk cafes, galleries, boutiques, museums, and theaters. By operating restored vintage electric streetcars, MATA recreates the aura of an authentic trolley system of the early to mid-twentieth century, while also providing an integral component of modern public transit in Dallas.

\section{Portland Streetcar- Portland, Oregon}

In recent years, streetcars have garnered national attention as the transportation mode most suitable for encouraging high-density, mixed-use development in urban and suburban 
downtowns. The revived interest in streetcars is due in large part to the incredible success of the Portland Streetcar, the first modern streetcar line to open in decades, and one of the most booming urban revitalization projects in the U.S. When successful, streetcars allow developers to provide less parking and devote more resources to quality design, construction materials, and amenities. When planned well, they may enable residents to give up car ownership, freeing a significant amount of income for housing costs.

Portland began a vintage trolley operation in 1991 that served as a circulator between downtown and a shopping center across the Willamette River. The vintage trolleys ran on the MAX light rail track, a dedicated travel lane segregated from street traffic. Encouraged by the success of the vintage trolleys, the Portland community soon began to envision a streetcar line that would run within the downtown. Supporters predicted that extending a streetcar line into the central city would stimulate higher-density residential development in neighborhoods transitioning from past industrial uses. Proponents also wanted a "true" streetcar that would share the city's streets with car and foot traffic. Tri-Met, the regional transit agency, was dismissive of the new streetcar, claiming that any such system could never operate efficiently in downtown traffic congestion. But city officials disagreed and financed the line on their own by selling sponsorships of the stops and cars, a tactic that had been successful in funding the vintage trolleys.

In recognition that the two-car MAX light rail trains, although efficient, were also intimidating to pedestrians, backers of the Portland Streetcar were set on designing the system to fit the scale and traffic patterns of the neighborhoods it would serve. The streetcar planning process identified the following goals:

- connect neighborhoods with a convenient and attractive transportation alternative;

- suit the scale and traffic patterns of existing neighborhoods;

- attract new transit ridership through quality service;

- reduce short inner-city auto trips, parking demand, traffic congestion, and air pollution; and

- encourage residential and commercial development in the central city.

Instead of using more vintage replicas, the Portland Streetcar is ultra-modern. The cars are manufactured by Skoda-Inekon in Plzen of the Czech Republic for $\$ 1.8$ million apiece. The vehicles are eight feet wide and 66 feet long, about 10 inches narrower and 1/3 the length of a MAX (TriMet's light rail system) double car train. They run in mixed traffic and accommodate existing curbside parking and loading. 
The system was also able to minimize neighborhood disruption during the building process. New track construction methods cut excavation depths to just over a foot, an almost 50 percent decrease from the digging required for most conventional track systems. This further cut costs by avoiding utility relocation, and track construction took a mere three weeks per block. The total cost was $\$ 12$ million per mile, a fraction of that required for most light rail systems. The Portland Streetcar initiated service in 2001 and has been a great success, with weekday ridership averages of 5,800. This figure is quite impressive, considering that current minimum headways on the line are thirteen minutes.

But it is the streetcar's ability to leverage private investment that has perhaps been the strongest selling point for Portland. The building of the Streetcar line connected two formerly vacant 120acre parcels of land to the north and south of downtown. Since the 2001 commencement of the Portland Streetcar, 4,600 housing units and 2.2 million square feet of commercial development have been built to the north, within two blocks of the line, attaining the 20-year housing goal for the entire city in just seven years. According to Rick Gustavson of Portland Streetcar, Inc., another 5,000 housing units are expected to be built to the south during the next five to ten years.

This revitalization was born out of a fruitful agreement between the City and a local developer, who agreed to upzone his property from 15 to 125 dwelling units per acre. The resulting expansion was so impressive that other builders soon followed suit, adding to the density of the neighborhood. The arrangement has been such a success that Portland has partnered again with the same developer, who has agreed to build a neighborhood around an aerial tram that will link the Oregon Health and Science University in the north to Portland State University downtown. The proposed linkage is projected to provide 3,000 housing units and 6,000 jobs. Encouraged by the positive impact of the streetcar on Portland's urban development, Tri-Met, which had initially discounted the streetcar concept as unfeasible, has had second thoughts and is now the system operator.

Today, Portland's vibrant downtown is one of the most admired in North America, and serves as a model for central cities seeking possible solutions to loss in population, businesses and investment. Many factors have contributed to Portland's vitality, but one key ingredient has been cooperative planning for transportation and land uses with a focus on public transit. The Portland Streetcar system is one more element that has enhanced Portland's thriving downtown while helping to accommodate new residential and business growth. 


\section{Case Studies}

To more closely examine the aspects of planning, implementing, and operating an intra-urban circulator system, this research includes three comprehensive case studies. The selected case study sites are in Tampa, St. Petersburg, and Coral Gables, all in Florida. These cities were selected primarily for their geographic location, which made extensive contact and site visits from the CUTR researchers feasible. In addition, these cities have proven to be solid examples for this report and each provide a unique set of lessons learned from which others can benefit.

\section{Case Study 1:}

\section{Tampa Downtown Circulators - Routes 96 and 98}

\section{Background}

Various public and private stakeholders in the downtown area of the City of Tampa have worked together since the mid 1990s to plan and implement transit circulator services. Downtown Tampa is in many ways a classic modern downtown, serving as a government center for city and county functions, an area of concentrated office development, a center for the arts, and the location of the county's convention center with a number of hotels within a half-mile of that facility. In addition, new residential developments have occurred very close to the downtown business core on Harbor Island, located within a half-mile of downtown offices, while other new residential development will soon be rising along the TECO Streetcar Line in the Channelside area. A major sports arena has also been built in the downtown that hosts a National Hockey League team (the league champion in 2004!) as well as major concerts. Downtown Tampa serves as the largest transit hub in Hillsborough County, with much of Marion Street dedicated to transit vehicles as they progress on a north-south path through the downtown.

The initial impetus for considering the establishment of circulator services in downtown Tampa began in the mid-1990s as stakeholders in the city realized it was in competition with every other major city in the country that were all trying to attract conventions and meetings at major hotels. A more concerted effort to establish circulator services coincided with the termination of an automated People Mover system that connected downtown Tampa with Harbor Island, where a major hotel and residential development was located across the water from the Tampa Convention Center and the rest of the downtown. With the discontinuance and demolition of that facility, discussions about alternative ways to transport people between Harbor Island and downtown Tampa led to additional talks of how a more comprehensive circulator system might 
benefit downtown development. Circulators seemed to be popping up in downtowns all across the country, creating more interest in the idea for Tampa. The idea of creating an overheadelectric streetcar connecting the historic Ybor district to the east of downtown gained momentum as the developer of the People Mover agreed to pay a considerable amount of money toward construction of a streetcar system if he was allowed to discontinue operation of the severely money-losing People Mover. These conditions ultimately resulted in the establishment of a rubber wheeled trolley service in 1999 that is described in more detail below.

\section{Characteristics of the Rubber Wheeled Trolley Service in Downtown Tampa}

\section{Equipment}

The downtown Tampa circulator system uses the rubber wheel trolleys that are becoming familiar in many downtowns throughout the country. These vehicles, though owned, operated, and maintained by the Hillsborough Area Regional Transit Agency (Hartline), are distinctly different in appearance from the rest of the agency's transit fleet that is composed primarily of standard urban transit buses produced by the Gillig Corporation. The distinctly different look of these vehicles provides a visual cue that they are circulators, since these types of vehicles are being used for those purposes in so many cities in the country.

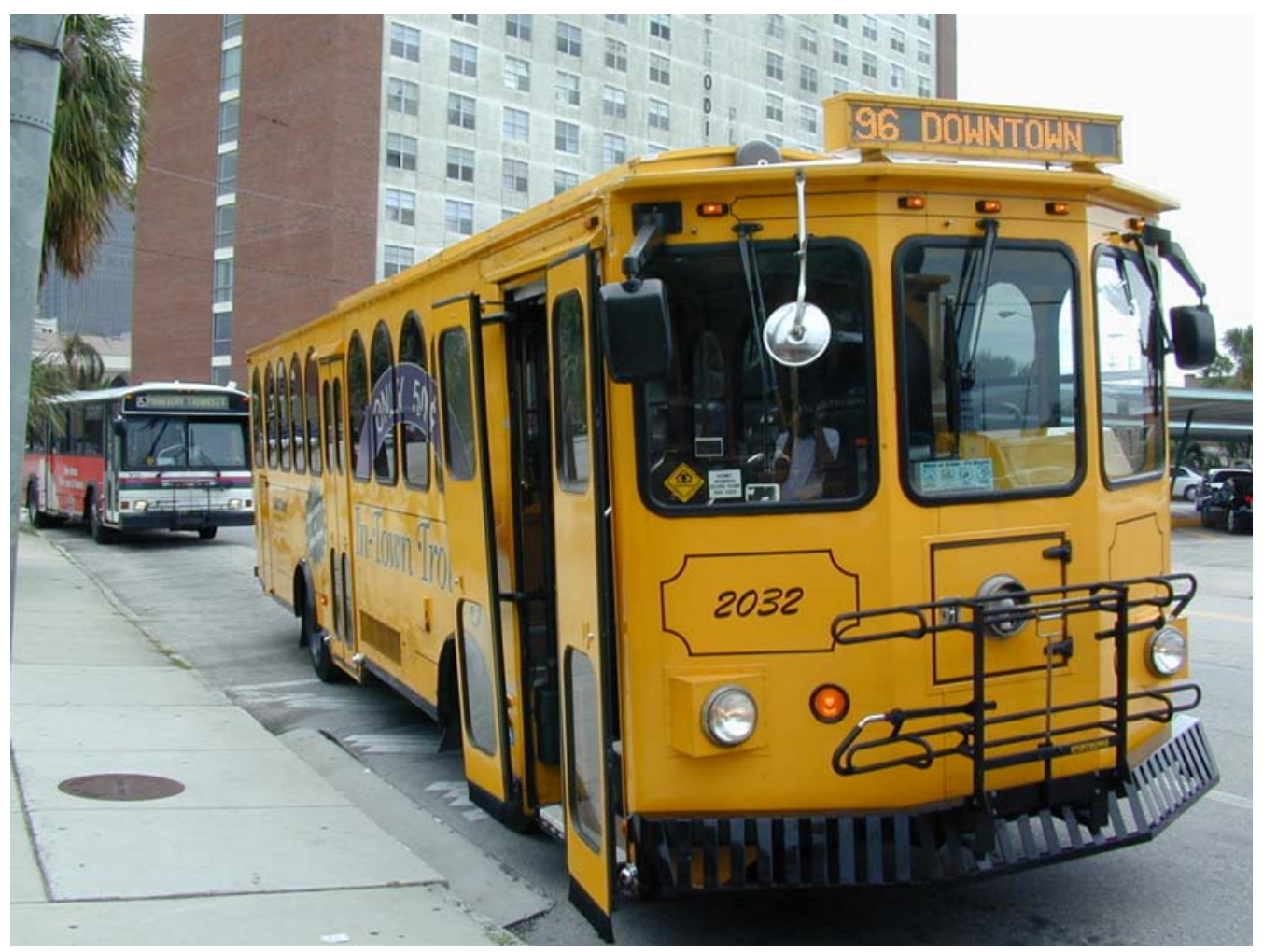

Downtown Tampa Trolley with Hartline Regional Bus behind it. 
The trolleys that are used are regarded as "seven year" vehicles in accordance with Federal Transit Administration classifications, and the ones in use at the present time were purchased between 1998 and 2000. These vehicles are wheelchair lift equipped, and range in size from 29 feet to 35 feet. They seat between 23 and 25 passengers. The interiors feature wooden seats and brass columns, evoking a nostalgic feel of travel from a long past era. Cushions are provided on the wooden seats to make the ride a bit more comfortable, and perhaps less slippery. Music is now played inside the vehicles as well. The intent is to make it a distinctly different experience from riding a regular public bus, and to provide a more relaxing, fun atmosphere.

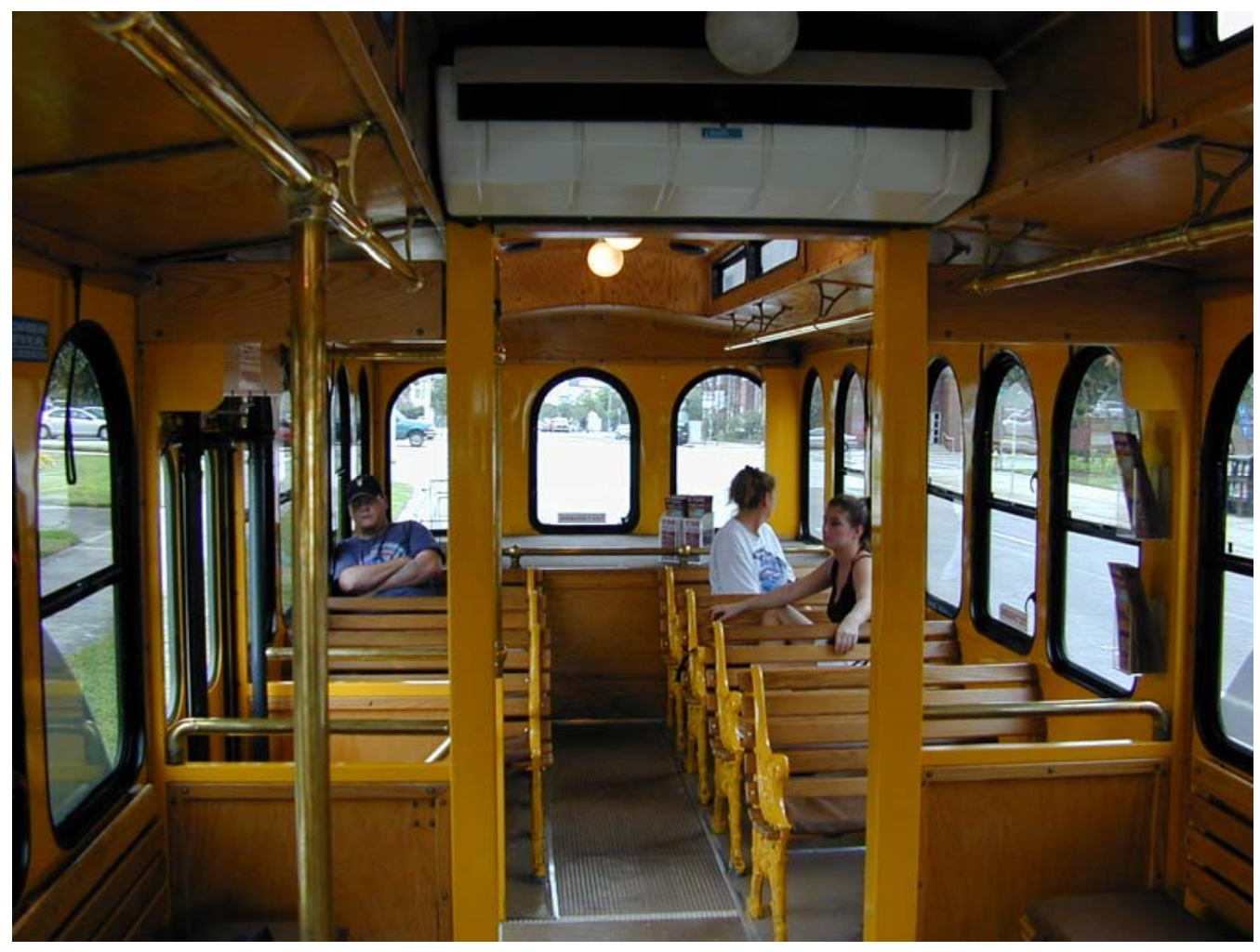

Interior of Hartline Downtown Rubber Wheel Trolley used on Route 96.

\section{Routes}

Downtown Tampa is now served by two circulator routes. The longest standing circulator is known as the In-Town Trolley Downtown. It is also known as Hartline's Route 96. This route has been in place in essentially the form shown below since 1999. This route provides service primarily in a north-south direction through downtown Tampa. At its northern end, Route 96 connects with many other Hartline bus routes at the Marion Transit Center, a relatively new and 
attractive facility where transit passes may be purchased and transit system information is provided. The route first covers the northwestern portion of downtown Tampa by traveling to the Main Library and the Performing Arts Center before proceeding southbound on Tampa Street. Along Tampa Street, which operates one-way southbound, the trolley passes a number of hotels, surface parking lots, office towers, and other public and private buildings as it makes its way toward Franklin Street. At Franklin Street, the route begins service along a two-way roadway that leads to the Convention Center and the Southern Transportation Plaza where connections can be made with the current end point of the TECO Streetcar Line that takes passengers eastward to Channelside and historic Ybor City, both entertainment venues with restaurants and shops. It is anticipated that as many as 5,000 new residential units will be built along the TECO Streetcar line in the next few years.

Continuing southbound on Franklin Street, Route 96 crosses the channel and goes past the Wyndham Harbour Hotel on its way toward the residential developments on Harbour Island.

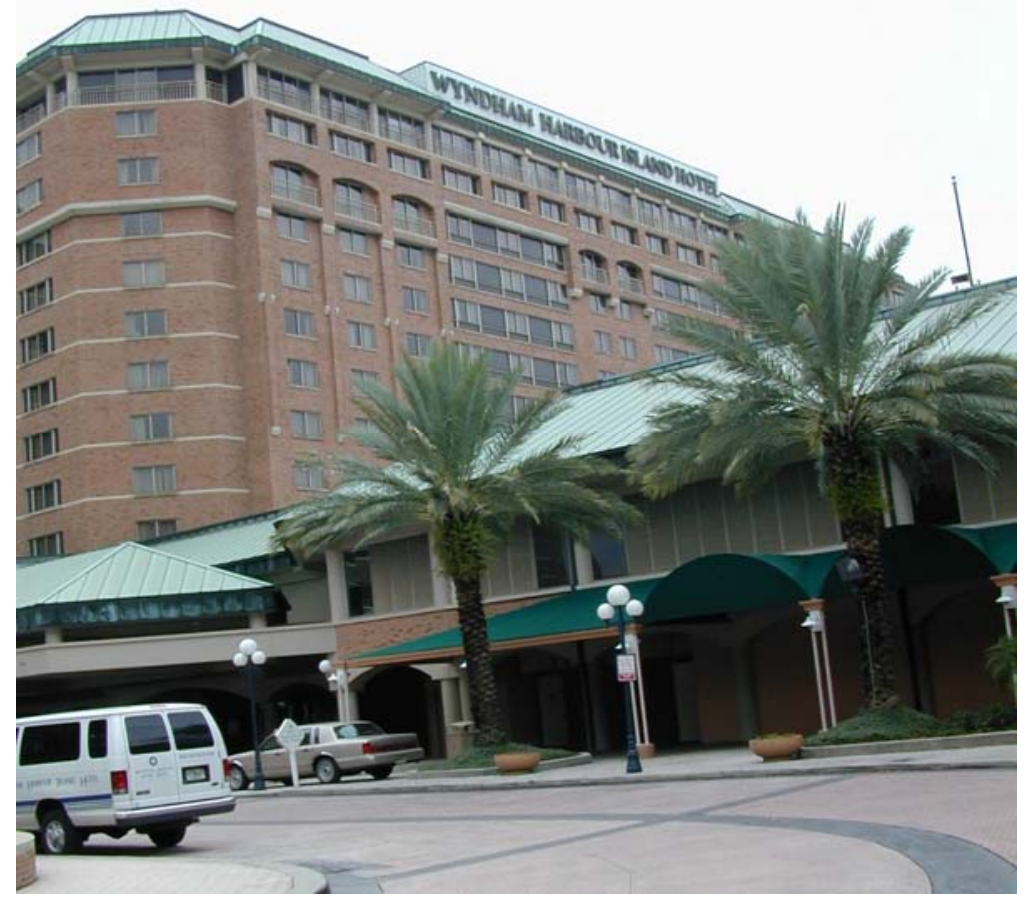

The Wyndham is a substantial hotel facility that can house smaller conferences of a few hundred people.

Route 96 then circulates through the portion of Harbour Island that is not gated, going past market rate housing of medium to high densities. This service provides very easy and direct access for residents who work downtown and do not anticipate needing a car throughout the day.

Wyndham Harbour Island Hotel is one of seven hotels in downtown Tampa served by Hartline's Route 96.

On its trip northbound, Route 96 again travels along Franklin Street to Whiting Street. Franklin Street then becomes a pedestrian only street, requiring Route 96 to take the next northbound opportunity on Florida Street, which it travels on as it goes back to its starting point at the Marion Transit Center. 


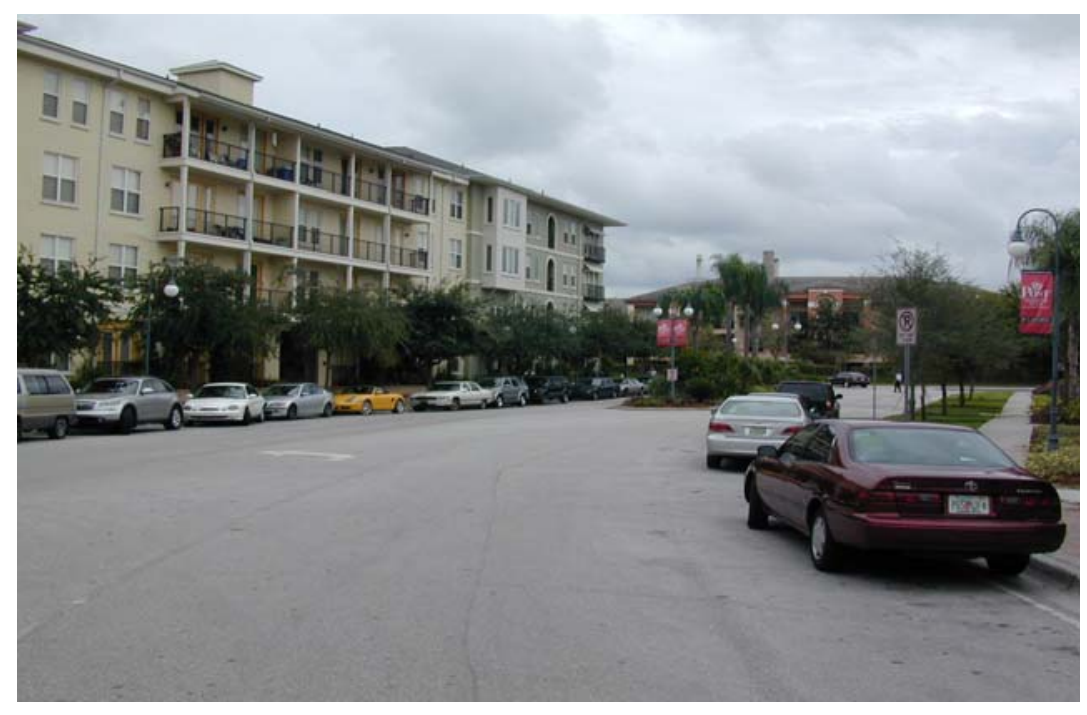

Example of residential densities on Harbour Island

While Route 96 has been in operation since 1999, a new route 98, also known as the "Hyde Park Connector", was implemented in November 2004. This route was established to connect downtown Tampa with the shopping and entertainment that is present in the Hyde Park area located about one and a half miles southwest of the Southern Transportation Center, where it connects with Route 96 and the TECO Streetcar line. The route also serves the convention center and the Wyndham hotel on Harbour Island. The route enters and leaves the downtown area via a pair of one way streets. It heads westbound on Cleveland Street and comes back into the downtown via Platt Street (see map). 


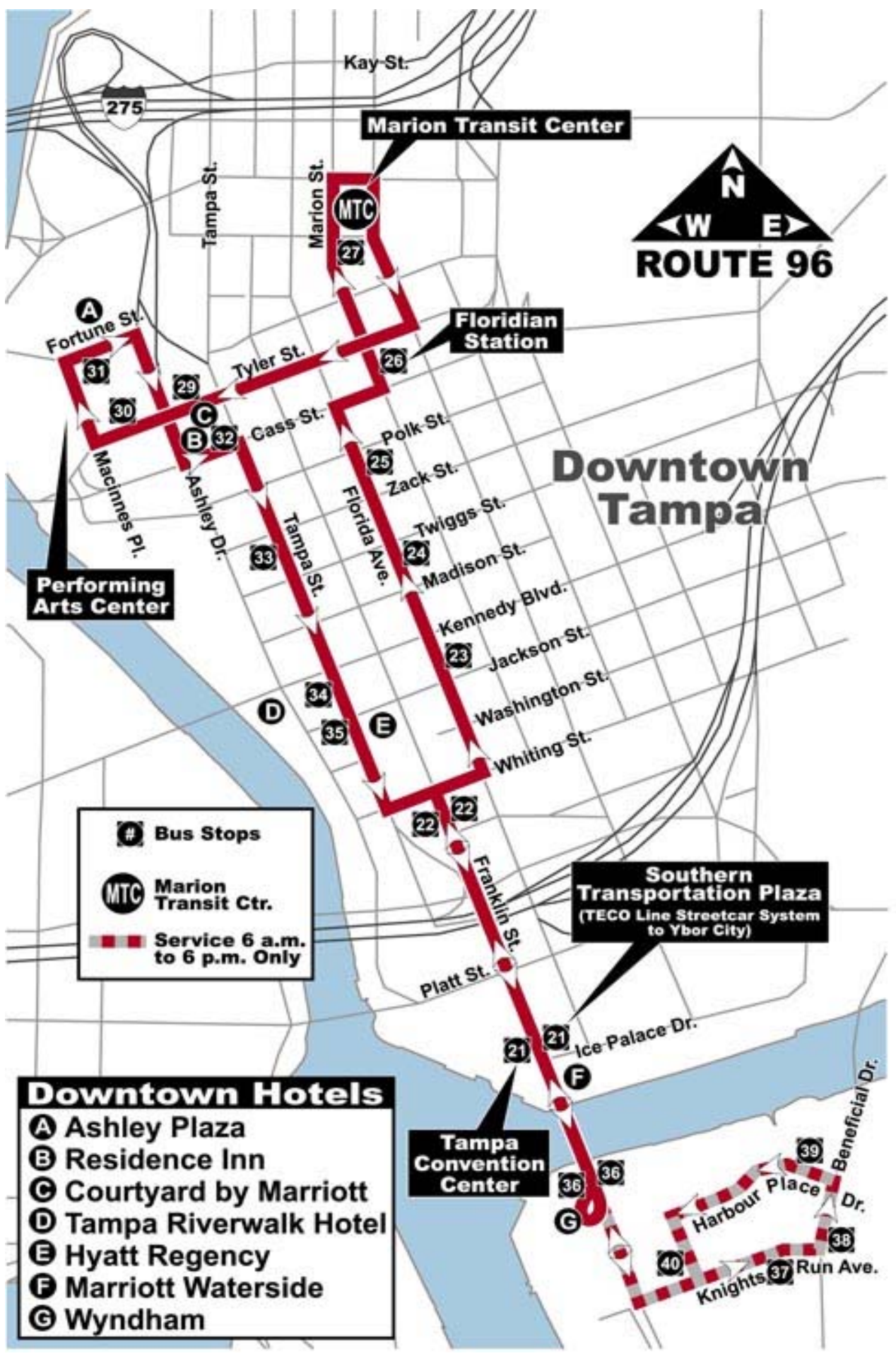


The route operates in a bi-directional manner on South Boulevard and Swann Avenue as it makes its way to Old Hyde Park Village, where there are dozens of shops, a handful of restaurants, and a movie theater complex.

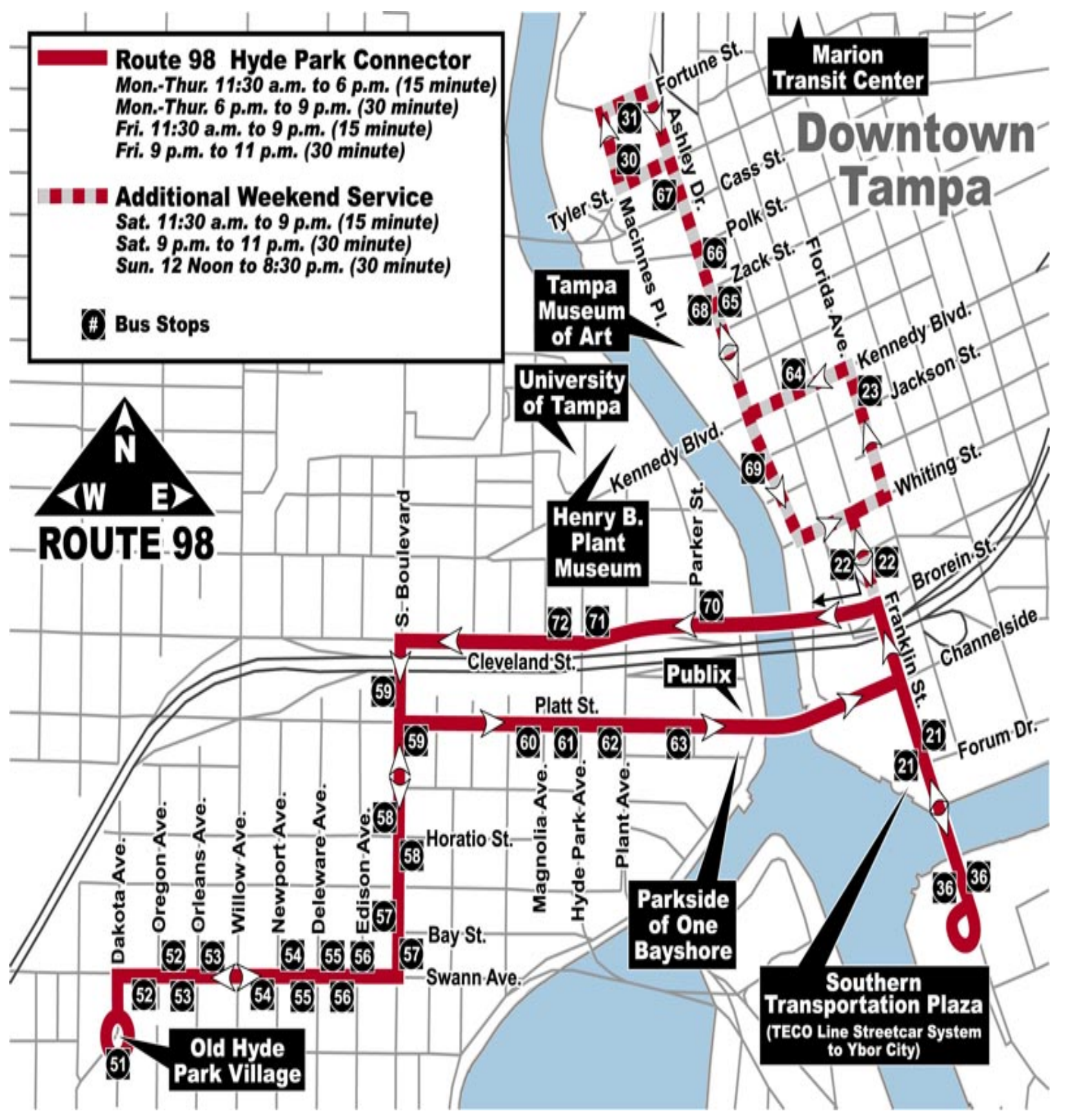




\section{Schedules}

Route 96 operates Mondays through Fridays, starting at 6 a.m. and staying in service until 9 p.m. from Monday through Thursday, and until 10 p.m. on Friday evenings. Service is provided every 15 minutes throughout all of its service days.

The schedule for Route 98 is more complex, as noted in the map above. Service is provided Monday through Thursday from 11:30 a.m. to 9 p.m. That service is provided every 15 minutes up until 6 p.m., and then every 30 minutes until 9 p.m. On Fridays, service is provided every 15 minutes from 11:30 a.m. until 9 p.m., and then every 30 minutes up to 11 p.m.

On weekends, these two routes are merged and operate under the title of Route 98. Saturdays' schedule is the same as the Route 98 as run on Fridays. On Sundays, Route 98 operates from 12:00 noon to 8:30 p.m., providing 30 minute service throughout the day.

\section{$\underline{\text { Other Services }}$}

There is one other rubber wheeled trolley that is run by Hartline in the same general area that Route 96 operates in from Mondays through Fridays. Hooters, a national chain restaurant with headquarters in Tampa, pays the expenses to operate a lunchtime shuttle through downtown Tampa from 11:30 a.m. to 2 p.m. on weekdays. This service is provided free of charge since Hooters pays all expenses, and operates every ten minutes during these limited hours. There are approximately 10 other places to eat at the Channelside location served by this bus, but the exposure provided by the advertising on the sides of the bus make it a good investment for that

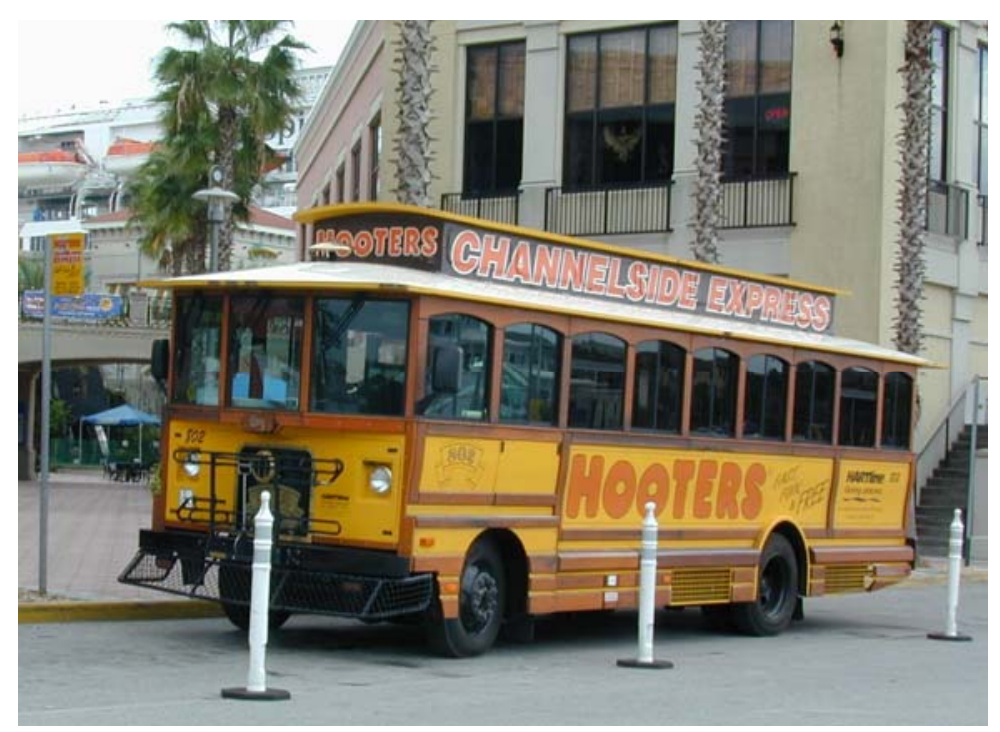

Express Lunch service operates from 11:00 a.m. to 2:00 p.m. company. This rubber wheeled trolley service provides more frequent service than Routes 96 and 98.

In addition, Hartline provides a considerable amount of fixed route service through downtown Tampa, much of which ultimately utilizes the Marion Street Transitway. From Whiting Street to the Marion Transit Center, Hartline treats the area 
between Whiting Street and the Marion Transit Center as a Fare Free Zone. Hence, just one block to the east of Florida Avenue where Route 96 runs, people can board any Hartline bus for free over the course of the approximate half mile distance between those points.

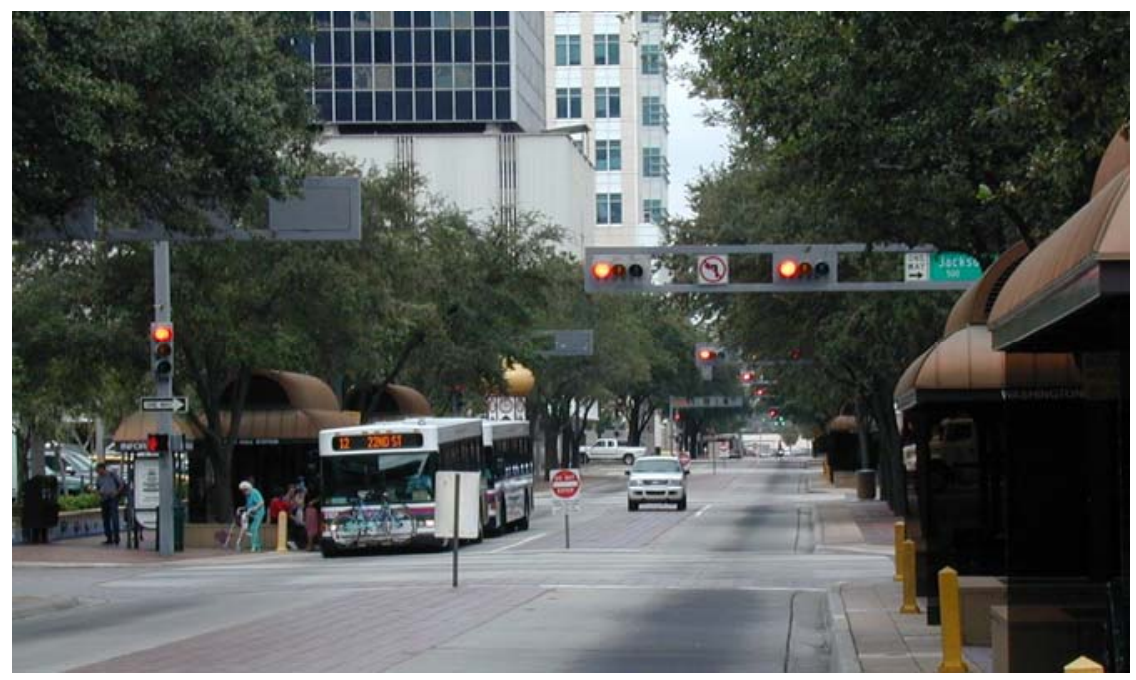

Marion St. Transitway is dedicated to transit vehicles and offers fare-free service in the downtown area.

\section{Purpose for Circulators and Markets Served}

The stakeholders of downtown Tampa believed they could accomplish a number of public purposes by providing transit circulator services in downtown Tampa with routes 96 and 98. In no particular order of importance, the following purposes are being served by the circulators:

- Provides shuttle services from hotels to the convention center and other visitor-related activities such as restaurants, shops, and art venues.

- Allows residents of Harbour Island to travel to and from downtown Tampa without the need for bringing a car into downtown.

- Allows commuters with cars to park in remote lots rather than downtown garages.

- Provides direct connections from the Marion Transit Center to most downtown destinations for those who use the Hartline regional transit services.

- Provides an inexpensive way of "seeing the city" for visitors.

- Provides customers who are in town for meetings or conventions to businesses in Hyde Park, helping economic development of that part of the city. 
- In conjunction with the Hooters Express, provides shuttle services to lunch venues for employees in the downtown area.

One might question whether there is enough distance between the hotels in the downtown area and the convention center to warrant a shuttle that is designed to make the trip easier. Many of the hotels are within a two to four block walk of the convention center. While there is no information on how many people who attend conventions use the shuttle, it is likely that conventioneers, usually dressed in business attire and/or high heels, do appreciate such a service that takes the guess work out of just how to get to the convention center, and provides an air conditioned ride on hot and muggy south Florida days and early evenings. On an average day in downtown Tampa, there are over 1,300 people attending meetings and conferences according to the Tampa Downtown Partnership, and some number of those attendees bring spouses with them. In addition, many do not have cars while they are in the downtown area, since the airport is an inexpensive taxi ride away. If five percent of the average number of conventioneers utilized the circulator, it would account for 65 passengers a day for one way trips, and perhaps twice that when considering two way trips and/or spouse usage.

The shuttle is attractive to those who live on Harbour Island and who do not have to walk long distances to access the circulator. If someone has no need for a car while they are at work, the circulator provides a very nice and inexpensive service for them, and helps to keep cars out of the downtown area. This service in turn helps to make the housing units on Harbour Island that much more attractive to buyers and sellers of residential units.

Due to the presence of the circulator, commuters who drive to work in the downtown area have a choice of parking in more remote surface lots, and can save up to $\$ 50$ a month by doing so. Parking in the more remote lots cost approximately \$30 a month, and a monthly circulator pass can be purchased for $\$ 5$. Monthly parking in the downtown garages costs approximately $\$ 80$ per month. By making these parking choices possible, it helps downtown Tampa's competitive position against other major employment centers that often offer free parking and may therefore be more attractive to employees.

\section{$\underline{\text { Facilities and Amenities }}$}

Not every circulator route stop has a bus shelter, but where they are provided they are pleasant, clean, and comfortable. Signage is also distinctive and informative. 


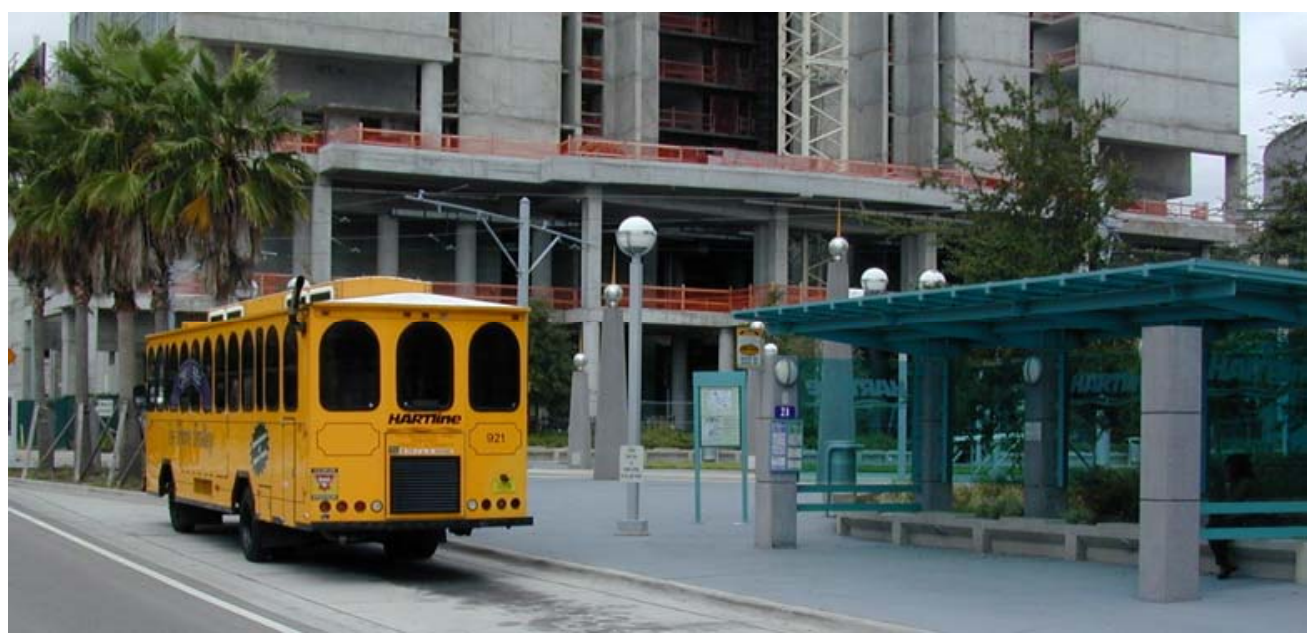

Signage

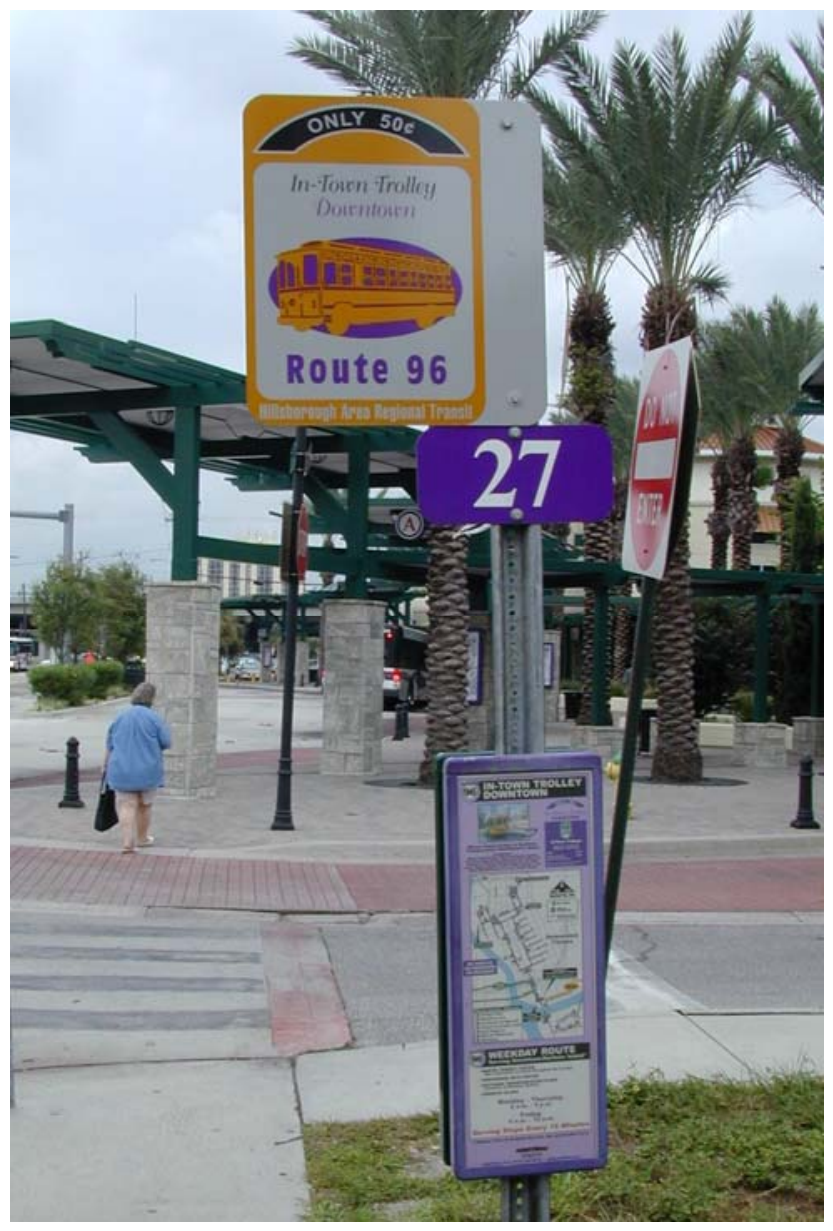

Example of Route 96 bus stop signage. 


\section{Ridership on the Circulators}

Passenger utilization of the circulators in downtown Tampa has varied since they were instituted in 1999. According to Hartline staff, annual ridership and ridership per hour on Route 96 since 2000 has been as follows:

$\begin{array}{cccc}\text { RT. } 96 & \text { RT. } 96 & \text { RT. } 96 & \text { HART System } \\ \text { Ridership } & \text { Revenue Hours } & \begin{array}{c}\text { Passengers per } \\ \text { Revenue Hour }\end{array} & \begin{array}{c}\text { Passengers per } \\ \text { Revenue Hour }\end{array}\end{array}$

$\begin{array}{lcccr}\text { FY 2000 } & 141,931 & 9,000 \text { (est.) } & 15.8 & 18.0 \\ \text { FY 2001 } & 201,953 & 8,995 & 22.4 & 16.4 \\ \text { FY 2002 } & 136,499 & 9,141 & 14.9 & 15.3 \\ \text { FY 2003 } & 90,537 & 12,105 & 7.5 & 16.0 \\ \text { FY 2004 } & 129,193 & 12,093 & 10.7 & 17.3 \\ \text { FY 2005 } & 110,281 & 10,241 & 10.8 & 18.5\end{array}$

Since the circulators operated fare-free without a farebox to record boardings in the earlier years of operation, Hartline staff is not as confident in the numbers for 2000 through 2003 as they are in the numbers of 2004 and 2005. The circulators seemed to find a market quickly, carrying almost 15,000 passengers a month within a half-year of starting service. Even though the routing of Route 96 was modified after the first six months, shifting from operations on the Marion Street Transitway to Tampa Street, the general ridership trend did not vary a great deal. While there might have been some confusion due to new routing, this change brought the service closer to major office buildings and hotels on the western portion of downtown.

According to Hartline records, ridership averaged approximately 15,000 passengers a month through the middle of 2002, varying from month to month from a low of 11,000 to a high of 20,000 per month. Such variations were often due to whether or not major conferences or events were being held at the convention center. However, in June of 2002, the route had to incorporate detours on both the north and south end of the route. Keeping ten-minute headways became difficult, causing service to be less reliable, and connections with existing transit service were disrupted. Detours were seemingly endless as major construction was going on at the I-275 and I-4 interchanges, and at the sites of the Marion Transit Center and the Southern Transportation 
Plaza. These factors made the service far less attractive to virtually everyone who had been using it. In addition, express buses that had previously dropped passengers off to connect with the circulator now entered downtown to drop passengers off within walking distance of their office buildings. According to some staff at Hartline, a new Route 97 was established aimed at serving the east side of downtown, but it siphoned off at least some of the riders that would have used Route 96. Route 97 operated for all of FY 2003, and for a few weeks of FY 2002 and FY 2004. Ridership on Route 96 hit its lowest ebb in January of 2003 at 4,190 passengers per month.

Conditions for circulator operations began to improve in the latter part of 2002. The new TECO Streetcar Line was opened in late 2002. The Streetcar Line connected with Route 96 at the Southern Transportation Plaza, providing more opportunities to access different venues in Tampa by transit. By February of 2003, the Marion Transit Center and the Southern Transportation Plaza were completed, and Route 96 was able to make smooth connections with other transit routes. One other favorable event occurred that helped Route 96 re-establish itself with passengers. The first issue of the "In Town Tampa Guide and Map” was distributed in February 2003, with a map that featured Route 96, helping to make visitors and downtown employees more familiar with the availability of the service. In October of 2003, Route 97 was discontinued which helped ridership build back up on Route 96. Ridership began to climb again, but not to levels recorded previously (though as noted above, some question the validity of the higher figures). Route 96 averaged approximately 10,700 passengers a month from March of 2003 to November of 2004.

In November 2004 a \$.50 fare was instituted, causing a predictable drop in ridership to approximately 8,700 passengers per month. Hartline and other stakeholders realized that the institution of a fare would cause ridership to drop, but they were faced with a policy dilemma. Hartline provided circulator services in communities outside of downtown Tampa, and charged $\$ .50$ for those services. It was difficult, if not impossible, to defend providing service at no cost to passengers in the downtown area, particularly when the passengers on Route 96 had considerably higher incomes than the passengers who were using Hartline's other circulator services. To lessen the impact of this considerable change in fare, Hartline allowed anyone who had purchased an All-Day pass or other type of multi-day pass to ride Route 96 at no extra fare. Since a good portion of the riders of Route 96 were also users of other Hartline services, this definitely helped lessen the impact of the fare increase. In addition, Hartline made a monthly circulator pass available to people for $\$ 5$. In this way, the people who had been parking in remote parking lots to save money on downtown parking were able to use the circulator services for what amounted to just a little more than a dime a trip, based on an average of 22 round trips 
per month. Institutions of fares of \$.25 on local shuttles in other cities (Miami Beach, Florida and Santa Barbara, California) where service had previously been provided for free caused ridership decreases of 45 percent. Hence, the 20 percent decrease in ridership experienced by Route 96 can be considered minor in comparison, particularly when the fare went from free to $\$ .50$.

The frequency of service on Route 96 had been changed a few times since its inception in 1999. At first it operated on ten-minute headway only during morning and afternoon peak hours, while operating on 20-minute headway during off peak hours. In August of 2005, it was determined that both Route 96 and Route 98 should operate on similar headways of 15 minutes. In this fashion, the services would be easier for everyone to remember, and the rubber wheeled trolleys would have a better opportunity to meet with the Streetcar Line, which also operates on 15 minute headways.

Route 98 was established in November of 2004 and as of the date of this report has been in service less than a year. When it was first started, service was provided only once every 40 minutes from the Southern Transportation Plaza to the Old Hyde Park Village shopping area. In September 2005, frequency on the route was changed to every 15 minutes, to be consistent with Route 96 and the Streetcar Line. Route 98 provides service from 11:30 a.m. to 9 p.m. Mondays through Thursdays, and from 11:30 a.m. to 11 p.m. on Friday and Saturdays. On Sundays it operates every 30 minutes from noon to 8:30 p.m.

Route 98 has carried an average of only 6.7 passengers per hour, and the peak time of usage of the route is between noon and 3 p.m. when more than 20 people per hour use the service. However, after 3 p.m., ridership decreases dramatically to an average of approximately five passengers per hour. It was hoped that this route would attract visitors who were staying downtown to travel to Old Hyde Park Village to patronize the shops and restaurants in that district just west of downtown Tampa. This apparently does occur around the lunch hour, but the route has not been successful in attracting riders during the late afternoon and evening hours. Hartline staff believe that Route 98 ends too early in the evening, making it an unattractive and unrealistic service for people to use if they intend to be out past 9 p.m.

Route 98 is supported by state grants, Hartline funding, and funds from ten private partners who hope the service will find a market, serve their interests, and make a stay in Tampa that much more pleasant for visitors and convenient for residents. The partners who support the route with funding include entities such as Old Hyde Park Village, Publix, One Bayshore (a major condominium development), and the Tampa Downtown Partnership. One odd feature of the 
route is that is does not go directly past the University of Tampa and its 3,500 students. Apparently, the university president simply did not believe that transportation in a downtown area should be funded by a university. Consequently, he declined the opportunity to contribute the \$5,000 that many partners were being asked to contribute toward the expense of operating the circulator. As a result, Route 98 was taken down other streets that traveled more directly to Old Hyde Park Village, and that had sponsors who were willing to help pay a part of the cost of the route.

There are hopes that additional private partners can be found to help pay the costs of extending the hours of service a little later into the evening, and to extend the route further west to the many shops and restaurants along South Howard. In addition, the National Hockey League strike is now over, and there will be at least 40 more games held in the evenings at the Forum, presenting more opportunities for ridership on Route 98.

\section{$\underline{\text { Lessons Learned from the Tampa Downtown Circulators }}$}

Since 1999, Tampa has been served by a number of circulators. This case study focused on Routes 96 and 98, and acknowledged the presence of the Hooters Express circulator and the TECO Streetcar Line. The longest standing circulator, now know as Route 96, has had varying degrees of success in downtown Tampa. In its earliest years of operation, this route carried over 20 passengers per hour, and outperformed Hartline's system average in that respect. Today it carries 10.8 passengers per hour, or approximately 450 passengers a day and 110,000 passengers per year. This level of productivity is approximately 60 percent of Hartline's regional transit service's productivity. The Hooters Express also carries approximately 11 passengers per hour, while Route 98 transports an average of 6.75 passengers per hour.

Downtown Tampa has a number of good things happening that help support the downtown circulators. Hartline and the local Transportation Management Association help to promote the circulators through working with transportation management coordinators among many public and private employers in the downtown area. Information on the circulators is well distributed to hotels and employers. The trolley vehicles are distinctive and generally fun to be on. Bus stops are clearly marked, informative, and distinctive. The facilities for transit users, including bus stops, shelters, and the transit centers are generally well kept and attractive.

The purpose of this chapter is not to provide specific recommendations on how the circulator services in downtown Tampa should be made more efficient. However, this report does bring to light many of the conditions that exist in other cities that have circulators that are considered successful. In those cities, there are often problems that cry out for solutions. For instance, in 
Chattanooga, Tennessee, it was recognized that air pollution was incredibly bad, and that the demand for parking was a major problem in the downtown area. In Miami Beach, traffic congestion was severe, and a relatively low income service population needed an alternative to cars as they lived and worked in a dense, mixed use environment. In Arkansas, a town that absolutely depended on tourism within its Victorian village needed to find another way for tourists to access its charms. In Coral Gables, Florida, many hundreds of employees within the downtown district needed a way to get to and from Metrorail as part of their commute to work, and they needed a service that could provide them with options to access lunch options.

In downtown Tampa, there are no conditions that cry out for circulators. There is no shortage of parking. There is no severe traffic congestion. While there are some residential developments just outside of downtown, the downtown area can hardly be called a mixed use environment at the present time. While there is a convention center and hotels, the downtown can not be described as a tourist mecca. Correspondingly, the downtown area does not yet offer an interesting walking environment where there are shops and galleries and other points of interest for visitors to explore. Transit services in Tampa and Hillsborough County are limited, and do not bring great numbers of employees downtown. Those that do use Hartline Express services can stay on their bus as it navigates on the Marion Street Transitway to get very close to their final destination.

Tampa is a still-evolving city that has a lot of activities that might attract greater use of circulator services in the future as more residential units are built and the city becomes a more mixed use environment of residents and visitors. Higher residential densities are still a few years away. Until those densities develop, it is not likely that ridership per hour figures will increase significantly on the circulators. There are some other factors that work against greater success for the circulators:

1. The street system in downtown Tampa is dominated by one-way streets, requiring Route 96 to travel southbound on one street, and then northbound on a street two blocks away. This makes the route harder to use for non-traditional transit users, and less convenient for many of the regular users.

2. A fare of $\$ .50$ is charged to use the circulators. While charging a fare is not fatal to the success of a circulator, particularly one that attracts tourists, a fare does discourage ridership. It also delays the speed of the rubber wheeled trolleys as they complete their route. In many cities, circulator services are offered free of charge, or only charge \$.25 per ride. 
3. The amount of money available for downtown circulator services is limited, resulting in a service that is offered only every 15 minutes. Fifteen minute service is simply not attractive for a lunch crowd, and it is not that attractive if the final destination of someone's trip is only a few blocks away. People might be more likely to walk a few blocks and save $\$ .50$ than wait as much as 15 minutes for a circulator to come by. It appears that downtown circulator services are much more attractive when they operate at no worse than 10 minute frequencies.

4. The Marion Street Transitway operates in a fare-free fashion from Whiting Street to the Marion Transit Center. This transitway is only one block from the northbound route of Route 96.

5. As noted earlier, the University of Tampa does not wish to support the circulator since they apparently like to tell the parents of students that the needs of students can be satisfied on their campus, and they don't believe the university should be subsidizing transit in an urban setting. This opinion is not consistent with most universities throughout the country since students are usually frequent users of transit services that are near and convenient.

6. The 98 Route does not have enough attractions in Old Hyde Park Village to generate more users from the downtown area. Perhaps if it went further west to the many restaurants and shops along South Howard Street, it might attract more riders. However, that would also require another bus to maintain 15 minute frequencies, and that money will only become available if additional private partners are willing to provide the dollars necessary to pay for the additional service.

Given all of these circumstances, one could conclude that the downtown Tampa shuttles are doing as well as they can, and might see more success in the future as residential densities increase and hours of service are added to make more trips possible for passengers. 


\section{Case Study 2:}

\section{St. Petersburg Looper}

\section{Background}

The downtown of the City of St. Petersburg, Florida is a charming area that has become a center of arts and tourism. Located on the west coast of Florida southwest of, and across the bay from, the City of Tampa, downtown St. Petersburg features no less than seven museums and 30 art galleries, interesting shops, restaurants, hotels, waterfront parks and marinas, a university campus, office activity, and increasing number of residential towers, and an employment base of approximately 20,000. The downtown area attracts four million tourists a year.

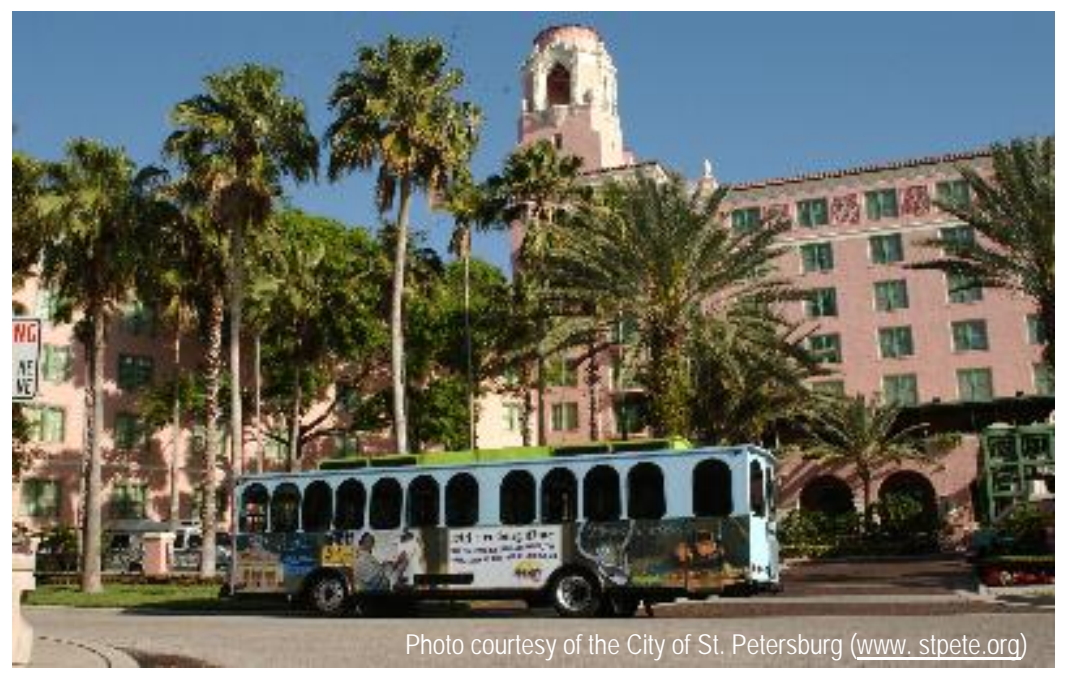

The concept of a downtown circulator, primarily for tourist purposes, has gone through a series of iterations over the past 12 years. A private company tried to succeed by running what was regarded as a "Museum Hop" by charging an all day fare of $\$ 10$, but was unable to sustain the service. The Pinellas

Suncoast Transit Authority The Looper Trolley in front of the historic Vinoy Hotel.

(PSTA) then provided a lunch time shuttle service along Central Avenue and charged \$.50 per ride, but it too failed to attract significant ridership. In 1996, the St. Petersburg Downtown Partnership created the Looper Group, Inc. as a private non-profit 501(c)(6) organization. When first started ten years ago, a single trolley served the downtown area and charged no fare. However, due to its fare-free nature, it carried too many vagrants and undesirables. Due to the need for revenue to operate and the desire to discourage the vagrants, a $\$ .50$ fare was charged and was then increased to $\$ 1.00$. Service was provided once every 30 minutes. Part of the rationale for charging the fare was that the drivers would provide information that made the service more like a guided tour of the city. 
Within the past two years, the fare was reduced to just \$.25, and service frequency was doubled to its present level of 15 minutes. The stakeholders within the city are pleased with the current status of the service. The Looper relies on assistance

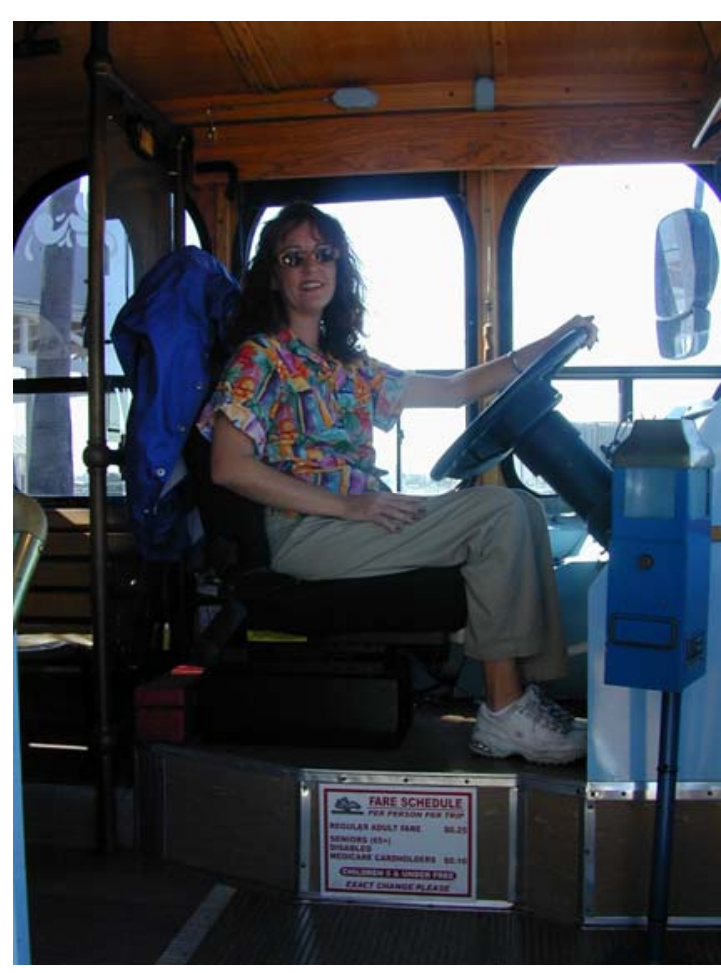

One of the colorful and cheerful operators of many kinds

from many parties, but is currently serving the purpose it is intended to do in this attractive, relaxed town.

Characteristics of the Rubber-Wheeled Trolley Service in Downtown St. Petersburg

\section{Equipment}

The Looper uses the vintage looking rubber wheeled trolley that is used in so many downtown areas throughout the country. As is the case with most of these vehicles, the seats inside are made of wood, and there are brass columns throughout the interior to give it a look quite distinct from other transit vehicles. The vehicles can seat up to 30 people, which is more than enough capacity for normal passenger loads. The Looper Group decided to sell space on the exterior of their vehicles for advertising to help pay for operating costs of the service, which makes its exterior appearance differ from many of the other rubber wheeled trolleys throughout the state. The Looper Group collects \$12,000 in revenue annually from this advertising. There are a total of five vehicles in the fleet, three of which are 35-foot enclosed diesel coaches that are used during the day, and two of which are open aired, smaller rubberwheeled trolleys that are used in the evenings and for occasional special events in the city. Two of the larger trolleys are used in the daytime service, with one held as a spare. 


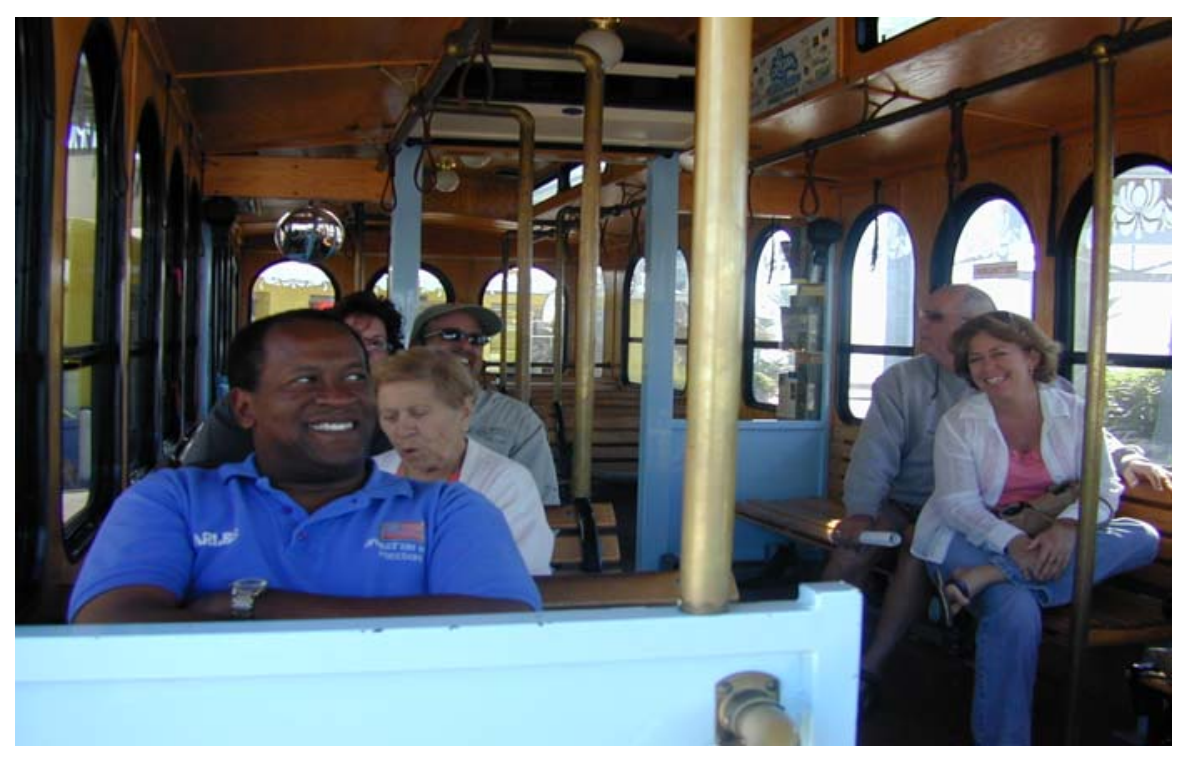

View of the interior of the Looper Trolley with passengers who are primarily tourists.

The Pinellas Suncoast Transit Authority (PSTA) owns the vehicles that were purchased through a CMAQ grant, and leases them to The Looper Group for \$1 per year.

\section{Route}

The Looper provides service through a one-way counterclockwise loop that is 4.8 miles in length. The intent of the route is to connect all of the major tourist highlights within the city to the hotels and bed and breakfasts where tourists are likely to stay. Those who are just visiting for the day can access the Looper at any of its 13 stops, but very typically they would board at the Pier for the half hour tour of the city.

There are 13 stops along the route:

1. The Pier (contains shops, eateries, and an aquarium)

2. Museum of History

3. The Vinoy Hotel

4. Museum of Fine Arts (also near retail stores, restaurants, and condominiums)

5. Baywalk (retail shops, restaurants, and movie complex)

6. A 24-story mixed use development featuring office space for Progress Energy, condominiums, and a Weston Hotel that is not yet finished

7. The Princess Martha Hotel and historic post office

8. The Arts Center (a studio to learn, create, and exhibit art surrounded by antique stores and other retail shops) 


\section{Florida Holocaust Museum}

10. Salvador Dali Museum

11. The University of South Florida

12. The Hilton St. Petersburg (with Progress Park and Major League Spring Training across the street)

\section{Hampton Inn and Suites}

While the Looper does not have a bus bay at the Williams Park transfer station for PSTA regional bus service, the stop at the Princess Martha Hotel is located just a few hundred feet away and across the street, allowing passengers to transfer relatively conveniently if they wish to access the regional transit system. A map of the Looper system is included on the following page.

\section{Schedules}

The Looper provides service every 15 minutes from 10 a.m. to 5 p.m. seven days a week. On Fridays and Saturdays, service is extended into the evenings to midnight, running every 20 minutes after 5 p.m. This clockface-based headway is relatively easy to remember and allows everyone to know that the bus will be at their stop at the same times each hour throughout the day. While 15 minutes might not be an extremely high frequency, the service is definitely not designed for typical commuters. It is for tourists with more leisurely schedules, and the 15 minute frequency is regarded as appropriate by the stakeholders in downtown St. Petersburg. Service was improved from once every 30 minutes to the present frequency of 15 minutes in December 2004. 


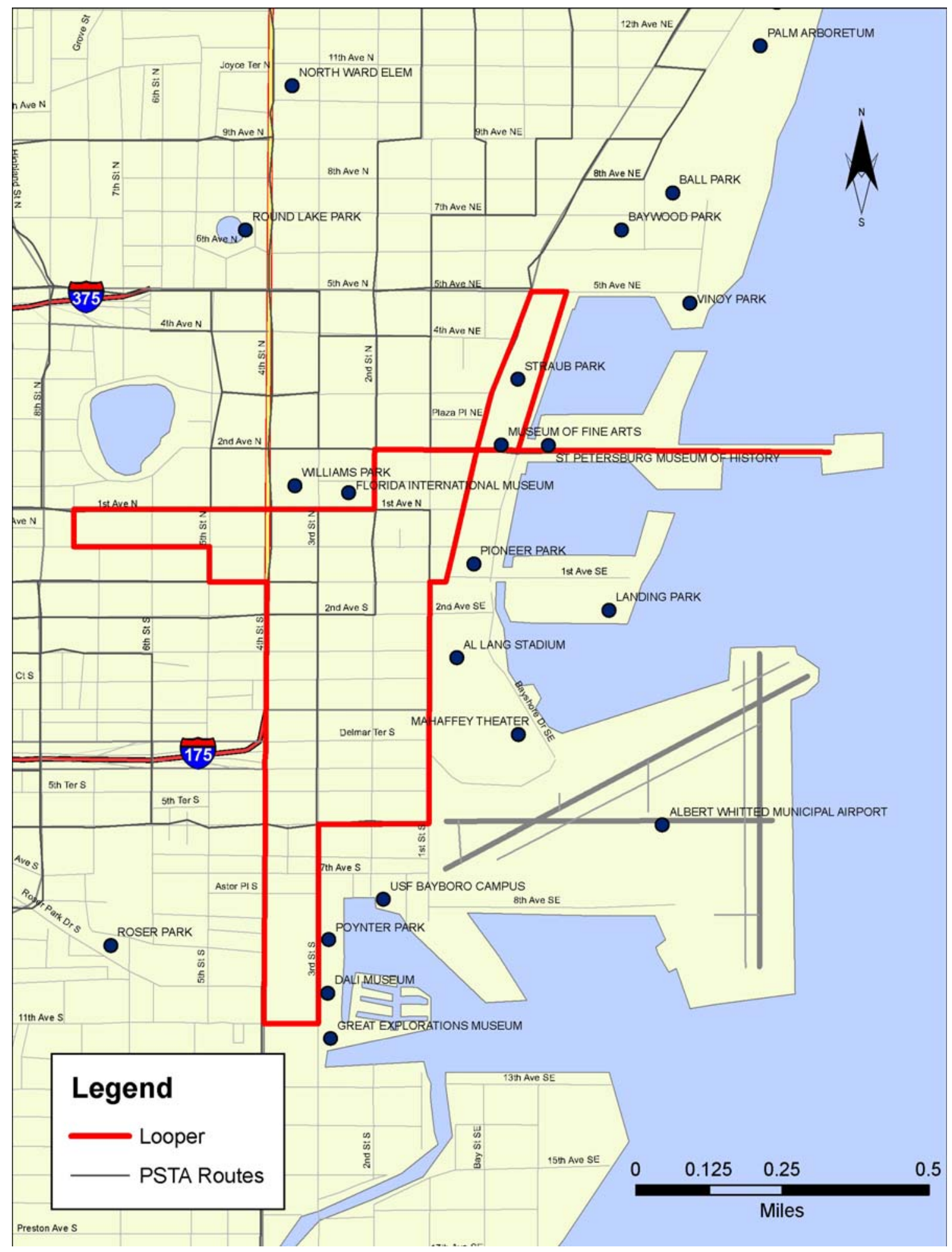




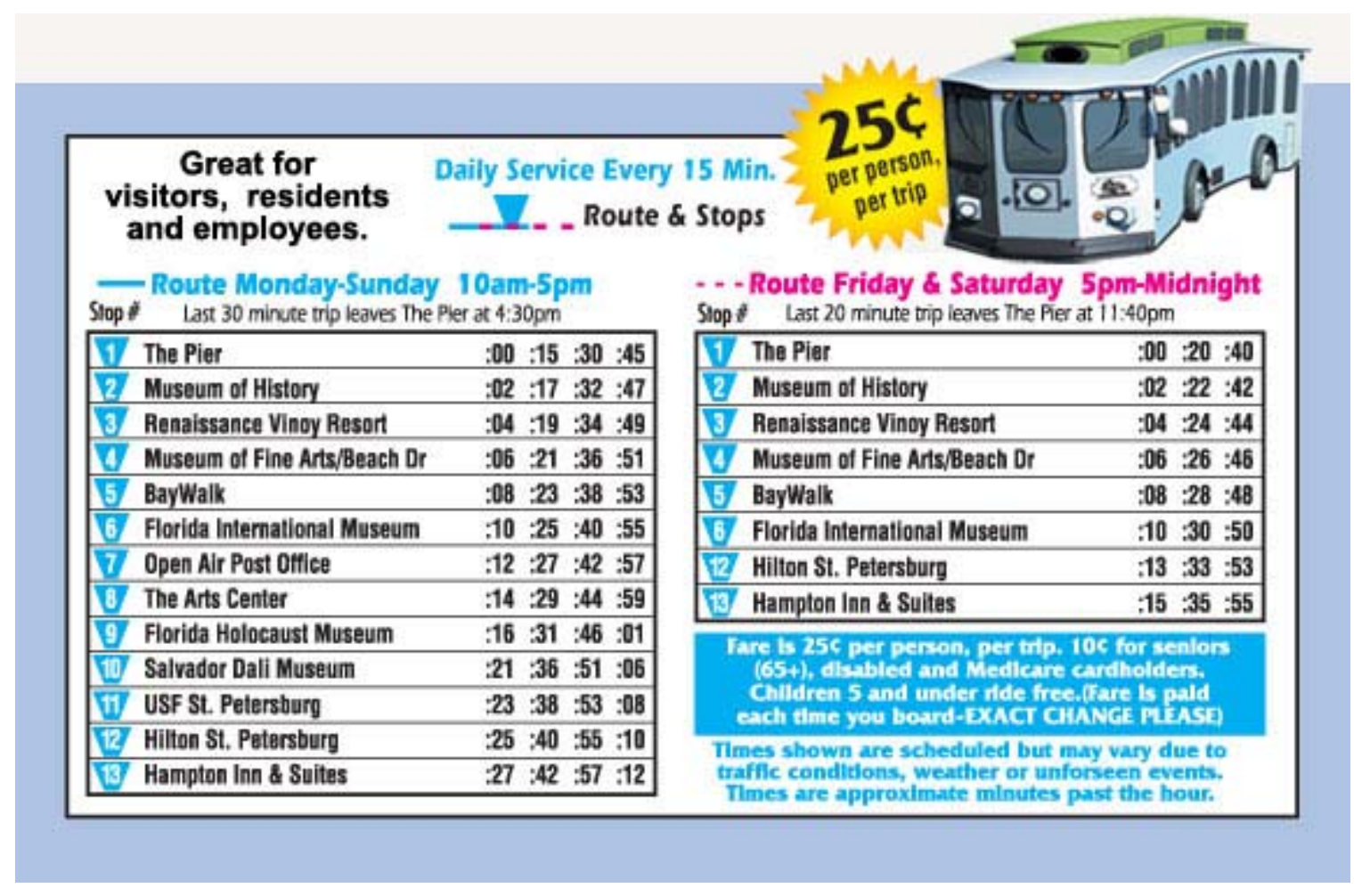

Schedule of the Looper as seen on its website.

\section{Facilities and Amenities}

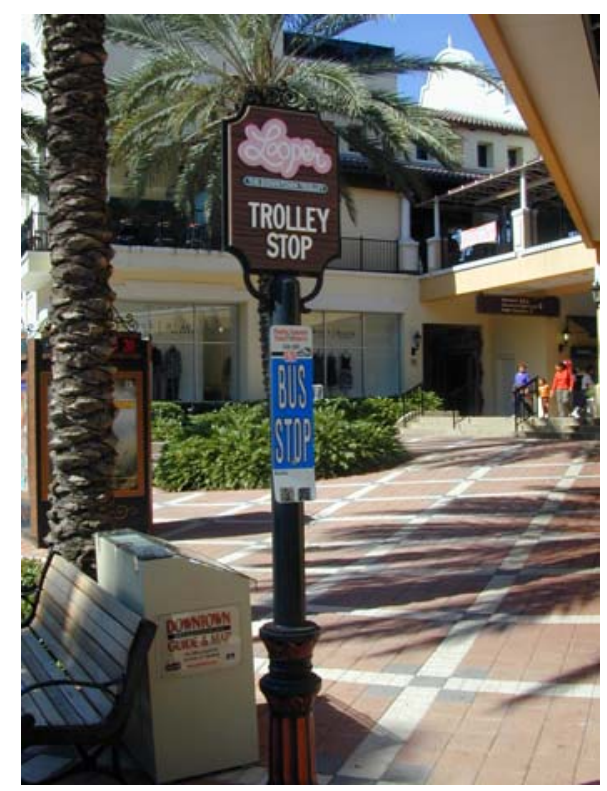

There are very few facilities associated with the Looper service with the exception of the bus stop signs that are placed at each of the 13 stops noted above. The distance between stops varies from an eighth of a mile to over a mile, since stops are based on locations that financially support the service. The entities that do support the service pay anywhere from $\$ 150$ to $\$ 600$ per month, based on their ability to pay and longevity with the system.

Bus benches are also provided where there is space in the public right of way.

Typical Looper Trolley stop sign. 


\section{Purpose of Circulators and Markets Served}

There has never been a question about the purpose of the circulator and who will use it. St. Petersburg is an employment center and the site of a branch of a major university. The regional PSTA routes serve the needs of those who commute to the downtown area for work or for classes. The Looper specializes in transporting visitors and tourists to and from the many attractions the city has to offer. Located along the waterfront of Tampa Bay, it provides a relaxing environment for regional visitors and for those from other states and countries. While more people visit in the winter than in the summer, the city remains a year-round destination for a variety of visitors.

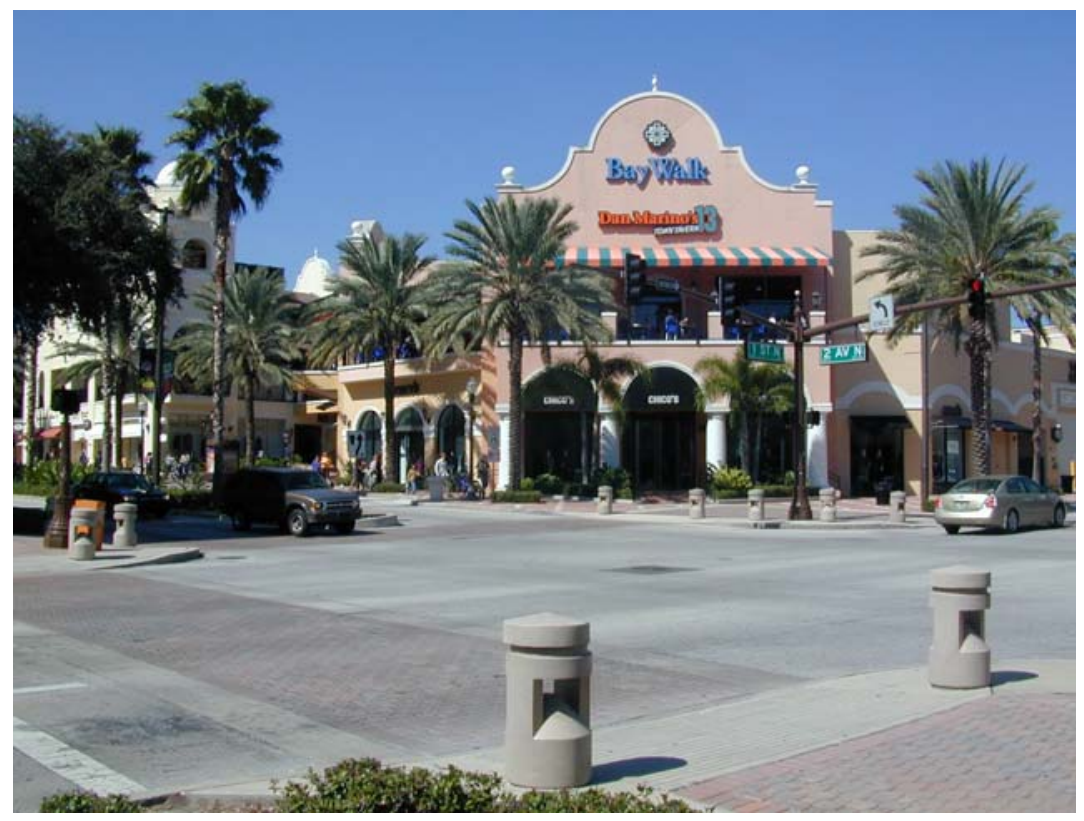

The Bay Walk stop features restaurants, shops and movies. 
The Looper is clearly designed to help St. Petersburg be a more attractive city to visit. It does not try to serve the needs of commuters, which is evident by its normal service hours of 10 a.m. to 5 p.m. A small percentage of the ridership is comprised of either local residents or students, but city officials believe that over 95 percent of the passengers on the Looper are tourists. A fifteen minute frequency is sufficient to meet the needs of most tourists who are on a more relaxed schedule. The clockface headways make it relatively easy for people to know when the next bus will arrive at any of the 13 stops.

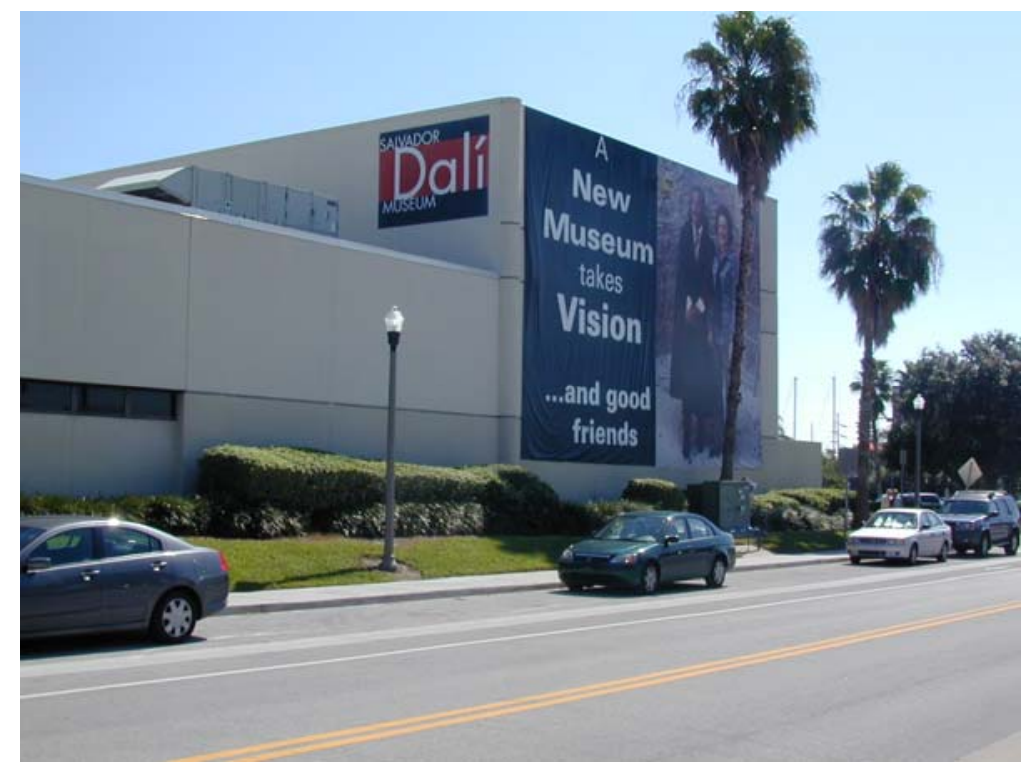

The Dali Museum is one of seven museums served by the Looper.

While there are justifications for providing circulator services in terms of reducing traffic congestion or emissions, the primary purpose of the Looper is to enhance the total experience of visitors to St. Petersburg, and thereby help the economic base of the city. The Looper has become an attraction in itself, as the operators of the trolleys provide current and historical information to passengers as they tour the city.

\section{Method of Management}

The way the Looper Service is managed is a testament to the power of partnerships between public and private organizations at various levels. The service is managed by Eric Carlson, an employee of the St. Petersburg Downtown Partnership. His primary responsibility is to oversee and manage the Looper service, though he also serves as staff for the Transportation Management Association. Funding for the Looper service comes from a variety of sources. As noted earlier, PSTA provides the vehicles by leasing them to the Looper Group for $\$ 1$ per year. That regional transit agency also provides $\$ 160,000$ per year toward the total operating expenses 
of the Looper. The Florida Department of Transportation provides a \$50,000 grant under the Commuter Assistance Program that is administered by Mr. Carlson who in addition to managing the Looper Service, also helps to promote other forms of transportation such as carpooling, vanpooling, transit, and flexible work hours in the downtown area. The St. Petersburg Downtown Partnership, comprised of over 130 businesses in the downtown area, matches the FDOT grant with $\$ 50,000$.

The City of St. Petersburg also provides important support by taking the responsibility for maintaining the fleet of vehicles used for the Looper and providing diesel fuel. Mr. Carson estimates the value of this contribution at $\$ 45,000$ per year.

While the City of St. Petersburg maintains, stores, and fuels the vehicles, The Looper Group contracts with Bay to Bay, a private charter bus company, to operate the trolleys. Bay to Bay provides the drivers, and does everything necessary in terms of drug testing, data collection, and insuring their operations. The Looper Group decided to award the contract to Bay to Bay since they provide other services along the Pier in the downtown area. The advantage to using the same company is that the two services they provide allows them to share supervision and a larger pool of drivers. Bay to Bay is paid $\$ 24.50$ per hour for their operation services. The Bay to Bay operators are allowed to accept tips.

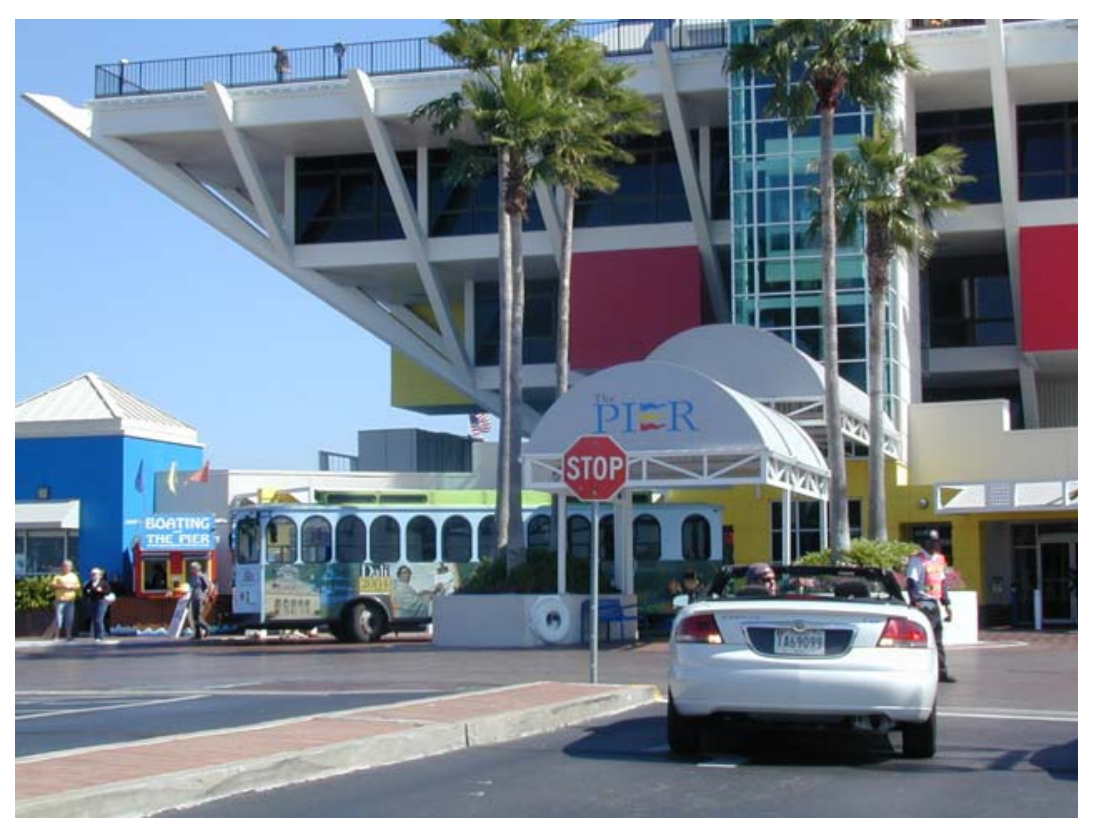

The Pier is one of the most popular tourist destinations in downtown St. Petersburg. 
They never solicit tips, but there is a visible tip jar on the dashboard of the bus next to the farebox, and people are free to put whatever amount they wish in the tip jar. This provides incentives for the operators to provide courteous, cheerful service, and to give information that will be interesting and useful to the passengers. Mr. Carson's office is located along the route, and he frequently rides the service to stay in touch with the operators and the passengers. He is convinced that the support the Looper receives from the City and PSTA is a result of the civic interests and influence of the members of the downtown Partnership. Funds are always difficult to come by for any public service, but when the leaders of the business community help to support and promote the value of the Looper, they are generally quite effective.

Additional funding for the Looper comes from those who sponsor the service and have stops on the route. These sponsors contribute approximately $\$ 50,000$ per year through their monthly assessments of between $\$ 150$ and $\$ 600$ per month. In return for their financial contributions, sponsors get a dedicated bus stop, collateral material on board the bus, a sign inside the bus with their logo, a hot link to their website from the Looper website, and the drivers say something positive about them every time the bus stops there.

Finally, the farebox contributes a small share of the total revenues of the agency. With ridership averaging approximately 5,000 passengers per month through the year, farebox revenues account for approximately $\$ 15,000$ annually.

\section{$\underline{\text { Ridership on the Looper }}$}

Everyone associated with the Looper is excited about the increases in ridership the service has experienced in the past year. In December 2004, service was increased from 30 minute frequencies to 15 minutes frequencies, and fares were reduced from $\$ 1$ to $\$ .25$. In addition, the Friday and Saturday evening service was added from 5 p.m. to midnight. Ridership for calendar year 2005 is now 131 percent higher than it was at the same point in calendar year 2004. It is impossible to determine if the increase in frequency, added evening hours, or the decrease in fare was more responsible for the substantial increase in ridership. Regardless of which factor was more prominent, in tandem the changes have produced very positive results for the Looper. 
Ridership Trends for 2004 and 2005:

$\begin{array}{llll} & \mathbf{2 0 0 4} & \mathbf{2 0 0 5} & \text { \% Change } \\ \text { January } & 3,949 & 5,125 & +30 \% \\ \text { February } & 5,357 & 7,387 & +38 \% \\ \text { March } & 6,538 & 11,772 & +80 \% \\ \text { April } & 4,530 & 8,996 & +99 \% \\ \text { May } & 4,058 & 8,771 & +116 \% \\ \text { June } & 3,600 & 7,691 & +114 \% \\ \text { July } & 2,917 & 7,017 & +141 \% \\ \text { August } & 2,314 & 5,343 & +130 \% \\ \text { September } & 1,411 & 4,399 & +211 \% \\ \text { October } & 2,636 & 4,966 & +88 \%\end{array}$

These trends appear to be consistent and sustained, with only a hurricane in September 2004 serving to cause any skew of the upward trend in ridership. Depending on the month and seasonal variation in visitors, the Looper carries between 10 and 24 passengers per hour. During the evening hours, when the southern end of the route is abbreviated and one bus provides service every 20 minutes, ridership has averaged 10 passengers an hour. Hence, all the new service has been well received, and the Looper is in the enviable position of being able to maintain close to the same farebox revenue for the year in spite of reducing fares by 75 percent.

\section{Lessons Learned from the St. Petersburg Circulator}

The Looper circulator does not try to be all things to all people. Hours of service are relatively limited (10 a.m. to 5 p.m.), and only extended on weekend evenings when visitors are most likely to be in the area. The route of the Looper "violates" the conventional wisdom often applied to downtown circulators that states they should be linear and bidirectional in order to be easy to remember. The Looper route is a one-way counterclockwise loop that is 4.8 miles long. In spite of these limited hours, a looping route, and no usefulness to commuters, ridership is relatively healthy, even though the Looper operates in an area where there is other public transit service available, and parking is generally free. Although St. Petersburg is an employment center with 20,000 employees, it is perhaps even more prominent as an area for tourists and 
visitors. The Looper has been designed to serve the interests of that market. This is further evidenced by the fact that drivers provide the services of a tour guide, and are allowed to accept tips. This provides an incentive for the operators to provide courteous, cheerful, and helpful service.

The stakeholders of the Looper circulator are delighted with the recent doubling of ridership caused by improving the frequency from 30 minutes to 15 minutes and reducing the fare from $\$ 1.00$ to $\$ .25$. Because the reduction in fares and improvements in frequency occurred at the same time, there is no way to determine how much each factored into the increases in ridership on the Looper. In at least two other cases noted in this report (Miami Beach and Santa Barbara), there was a strong relationship between fares and ridership, even when the change was minor. While a $\$ .75$ reduction is substantial, it provides more evidence that fares do affect ridership when it comes to providing local circulator service.

One of the lessons learned from the Looper experience is that partnerships can be critical to success and very useful when seeking additional financial assistance. The federal government, the city of St. Petersburg, the state (FDOT), the regional transit agency (PSTA), the business community, and the arts community all provide financial support to the Looper. Without the enthusiastic support of the business and arts community, it is questionable whether the city and regional transit agency would be as helpful as they are in supporting the Looper. 


\section{Case Study 3:}

\section{Coral Gables Circulators}

$\underline{\text { Background }}$

The City of Coral Gables is a well maintained municipality that rightfully calls itself "The City Beautiful”. According to the city's Chamber of Commerce, the population of Coral Gables is 42,765 , but its daytime employment is 49,641 . One reason for the large number of employees is the city's favorable location, being situated just four miles west of downtown Miami, and four miles south of Miami International Airport. The fact that the city is located further west of downtown Miami makes it attractive to employees who live south and west of Miami and would like a shorter commute. The proximity to the airport makes the city attractive to national and international companies. The City is often referred to as the Corporate Capital of the Americas, with more than 175 multinational corporations using Coral Gables as their Latin American headquarters. Fourteen countries maintain consulate offices in Coral Gables. It is also the home of the University of Miami, the largest private research university in the southeast United States. There is currently 6.5 million square feet of prime office space in the city, much of which is within walking distance of the Ponce de Leon Boulevard corridor, where the Coral Gables shuttle provides a high level of service.

Planning for a local circulator began in earnest in 2001, funded by a grant from the MPO. It was clear to city officials that Coral Gables was growing in popularity as an employment and shopping center, and that parking and traffic congestion was becoming a growing concern. Companies that were located in downtown Miami were interested in moving to Coral Gables to be closer to their workforce, and to be in a city with fewer urban issues and an excellent reputation for service and style. Developers of major office buildings were willing to provide attractive deals for office rentals to companies that would move away from the downtown area and relocate to Coral Gables.

While a Metrorail stop at Douglas Road provided access to much of the Coral Gables' business district, connecting Metrobus service provided by Miami-Dade Transit from that station was not as frequent as the rail service. While Metrorail provided service every 6 minutes during the peak hours, connecting bus routes provided service only every 15 to 30 minutes. According to passengers the authors of this report talked to, Metrobus service passing through Coral Gables was provided by routes that covered long distances and were not regarded as dependable due to schedule problems or breakdowns. The mayor of Coral Gables was able to convince the mayor of Miami-Dade County that a local circulator could benefit both Coral Gables and Miami-Dade 
Transit ridership. The County agreed to use part of its capital budget to purchase five new buses that would be dedicated for the service. In 2002, the residents of Miami-Dade County approved the People's Transportation Plan, which called for a half-cent general sales tax to be used primarily for public transportation. Twenty percent of the proceeds collected would be distributed to cities for public transportation purposes. A Service Development Grant from the Florida Department of Transportation helped to complete the funding necessary to launch the circulator services in November of 2003.

\section{Characteristics of the Rubber Wheeled Trolley Service in Coral Gables, Florida}

\section{Equipment}

As many other cities in the state and nation have done, Coral Gables elected to use rubber wheel trolleys for its intra-urban circulator service. There are three factors that distinguish these vehicles from most other rubber wheeled trolleys in the country. First, the original five buses purchased were hybrid-electric powered vehicles produced by E-Bus, a California-based company specializing in the manufacturing of electric buses. These vehicles are extremely quiet and produce a very low level of emissions. Coral Gables prides itself on being "The City Beautiful”, and these low-emission vehicles were consistent with the image of this city that is also known for its tree cover and parks. The second factor is that the vehicles are low floor, making the boarding and deboarding process easier and faster for passengers. The third factor is that the vehicles are relatively low capacity, seating only 20 passengers rather tightly inside a relatively narrow interior that has center facing seats in a U-shape. It appears that the city wanted interesting, pedestrian-friendly vehicles that were not intimidating and would fit in nicely with the Mediterranean theme of architecture throughout the city. However, city officials were not fully aware of just how popular the service would become and how crowded the vehicles would get. 


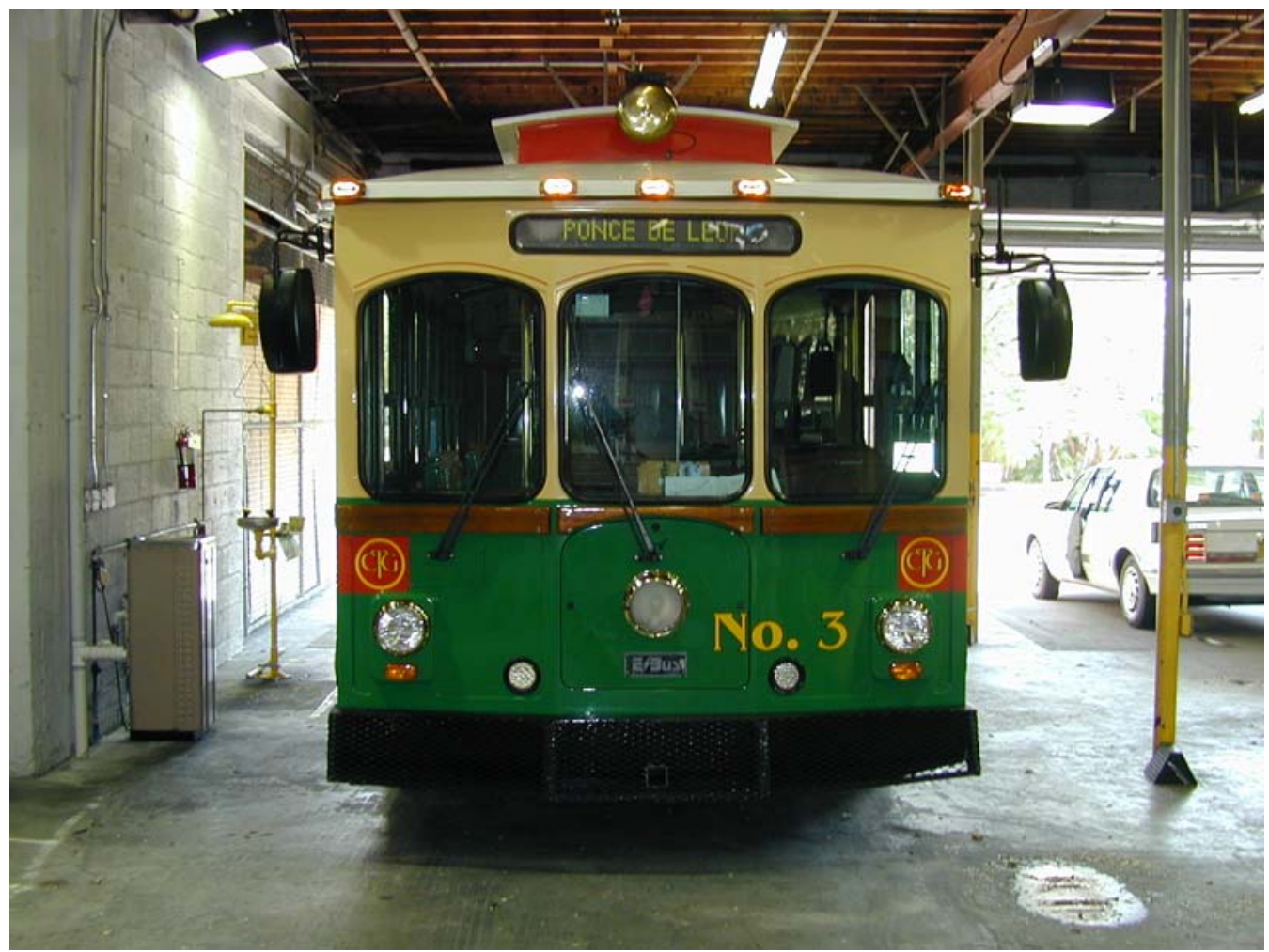

Example of 22-ft Hybrid-Electric Trolley Bus stored and maintained at City of Coral Gables Public Works Facility

The popularity of the service caused the city to lease three more vehicles to keep up with the demand for capacity from the passengers. These three leased vehicles are 35 feet long and can seat 35 passengers, and have high floors and diesel engines.

The interior of the coaches feature the wooden seats and brass columns that are not out of keeping with the early $20^{\text {th }}$ century feel of much of the city. Radio stations featuring popular music are played inside the trolleys, offering entertainment that drivers claim is well received by passengers. The service is fare-free.

\section{Routes}

Coral Gables has established two circulator routes. By far, the most prominent one is the North/South Ponce de Leon Route that runs along the major business corridor in the city. This 2.2 mile one-way route connects with Metrorail at the Douglas Road station. After leaving the Douglas Road Metrorail station, the route travels due north along Ponce de Leon Boulevard to Southwest $8^{\text {th }}$ Street (the world famous Calle Ocho). The bus then turns around and returns to the Metrorail station in a bidirectional fashion. Along the way, the route passes office buildings, 
major shopping centers, condominium towers, other shopping plazas, businesses, and restaurants. Coral Gables High School and Elementary schools are only two blocks from the northern portion of the route as well.

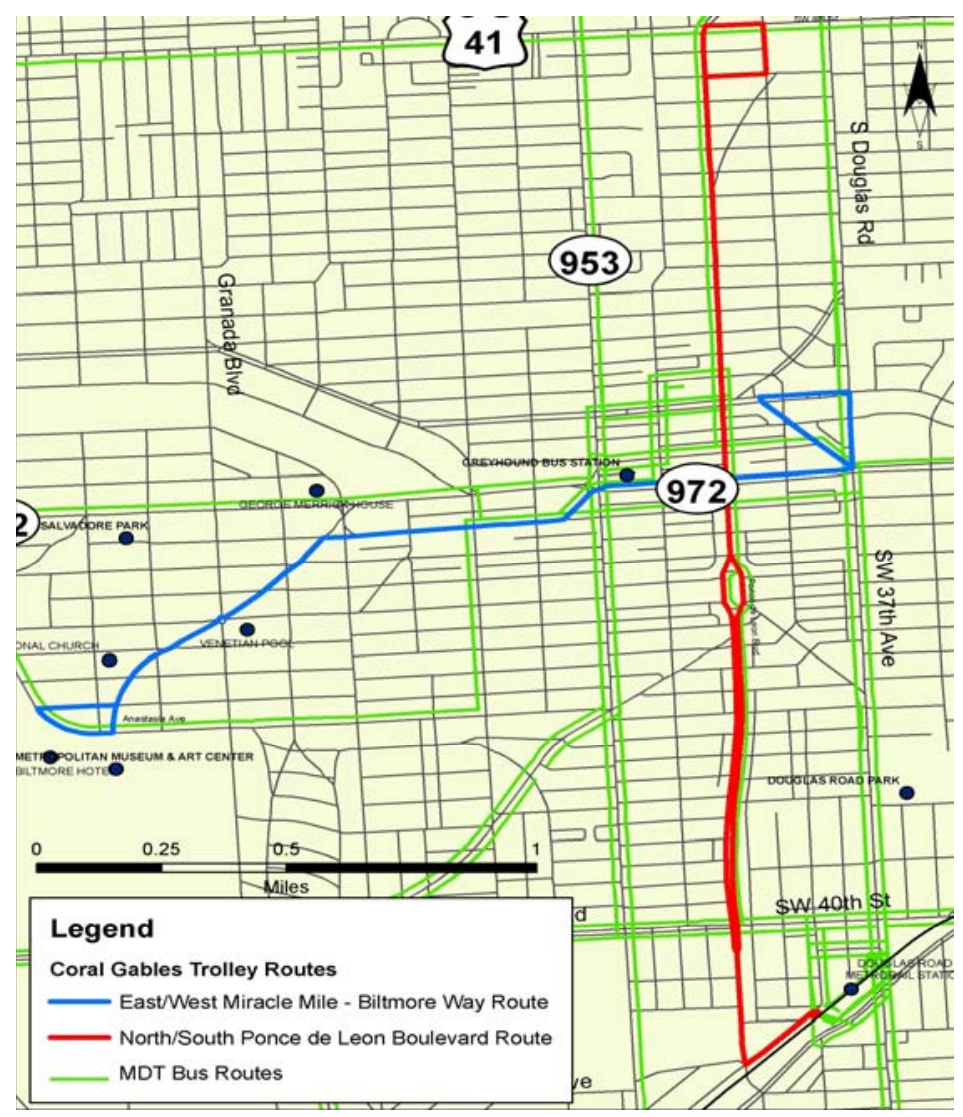

The second route established by the City of Coral Gables is the East/West Miracle Mile Twilight Route that runs along Miracle Mile (Coral Way) from Douglas Road to Anderson Road and then continues to the Venetian pool and the Biltmore Hotel. Again, this route has no odd twists and turns, nor is it made more complicated by any one-way street patterns. As is the case with the Ponce de Leon route, this route provides service in an easy-tounderstand bi-directional fashion.

\section{Schedules}

When initially implemented in November of 2003, the North/South Ponce de Leon Route ran every 15 minutes from 7 a.m. to 7 p.m. Monday through Thursday and until 10 p.m. on Friday. From 11 a.m. to 2 p.m. there was a Mid-day Express Loop between Madeira Avenue and Ponce Circle Park that was targeted to serve those going to lunch by providing four minute headways. It became clear fairly early that this loop service within a longer corridor service was a bit confusing and frustrating to passengers. People couldn't easily determine if the bus approaching them would take them only a short distance, or along the entire route. The city wisely decided to simply incorporate the vehicle hours that were being used in the lunch loop into the rest of the route to make the entire route run effectively every 10 minutes all day long. However, demand quickly began to outpace supply as ridership grew to more than 2,000 passengers per day within the first few months of operation.

The city decided to make the service demand-based rather than stick to strict clockface headways. Clearly, the major demand of the passengers was to get to and from the Metrorail station at Douglas Road. The point was to make the service meet the needs of the customers, and 
to do that service needed to be improved to once every six minutes during morning and afternoon peak hours to coincide with Metrorail schedules. The span of service on the Ponce de Leon route was also changed to operate between 6:30 a.m. and 8 p.m. to better reflect the working hour patterns of employees within the city. The City needed to add three buses to its fleet in order to meet this increased demand, with six trolleys operating on the Ponce de Leon route, and two on the Miracle Mile route during peak hours. The Miracle Mile route operates every 30 minutes from 1:30 p.m. to 8:00 p.m. Monday through Thursday and to 10:00 p.m. on Friday.

\section{Facilities and Amenities}

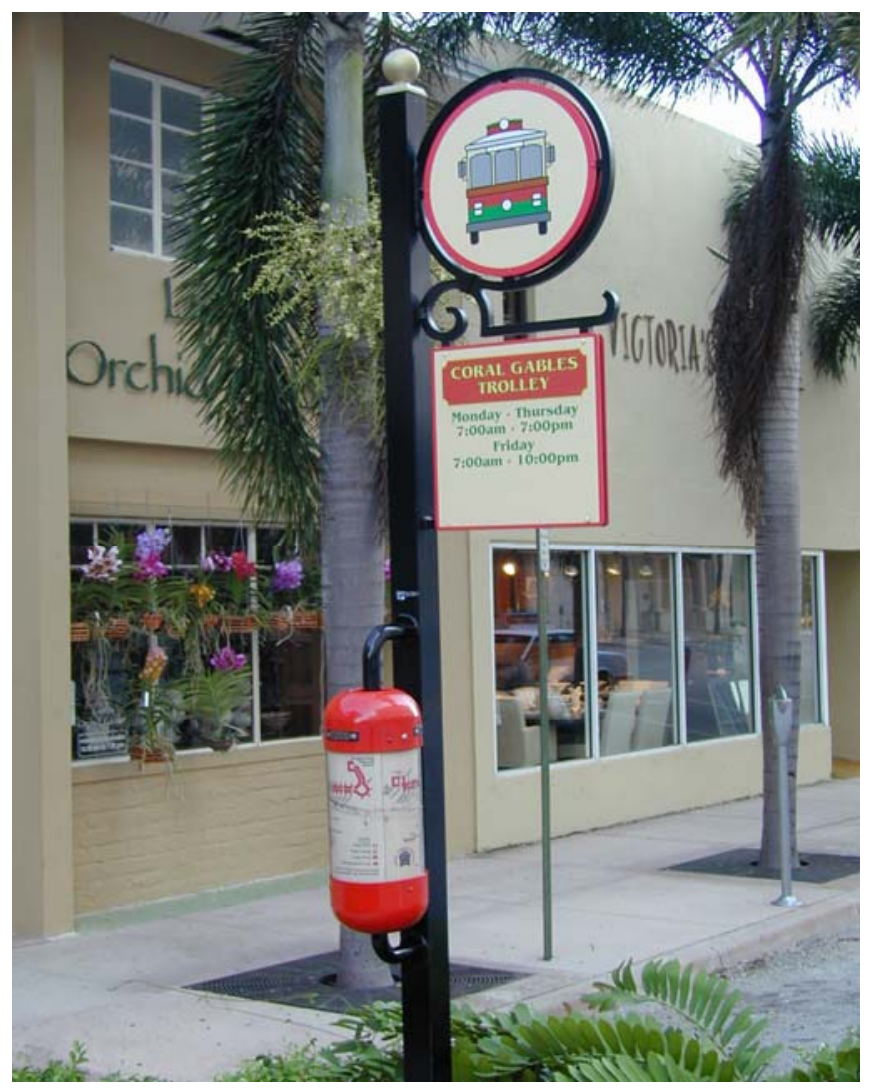

One advantage of having frequent service is that there is little need for bus shelters or benches, since circulator vehicles come by between every six and twelve minutes on the Ponce de Leon route. Passengers can generally see the next bus that is approaching during peak hours, and can wait under awnings of nearby buildings if there is rain or hot sun for the few minutes it takes for the bus to arrive.

The city has placed attractive and uniform bus stop signs at each of its many bus stops along the routes. Most stops also include information on circulator routes and schedules that is encased in tubes that are at eye level that help people immediately understand the service. In the most dense portions of the routes, bus stops are provided every block, and usually are placed no more than two blocks from each other throughout the rest of routes.

\section{$\underline{\text { Purpose of Circulators and Markets Served }}$}

The initial objective of providing the trolley service in Coral Gables was to help reduce the amount of car traffic in the downtown and provide those who worked in the area with a timely and convenient way to get to lunch and back. While the original planners of the service thought 
it would accomplish those objectives, even they were unaware of how popular the trolley would become. The following purposes are now being served by the circulators:

- It is a critical link for commuters who connect with Metrorail from the Douglas Road Station, and with Miami-Dade Metrobus service that runs east and west along SW $8^{\text {th }}$ Avenue and along Coral Way

- Students that attend both the Coral Gables High School and the Elementary School utilize the circulator since Florida schools do not provide bus service for students who live within two miles of their schools

- People use the service to access major shopping centers such as the Village of Merrick Park, a high end open air shopping mall, as well as many other businesses along or near Ponce de Leon Boulevard and Miracle Mile

- Tourists who are staying at hotels such as the Biltmore use it as a way of seeing the city and going to shops and restaurants within the city of Coral Gables

- Employees who work in the corridor can use it to get to and from lunch conveniently, making the city a more attractive and interesting place for employers and employees

- The availability of frequent, reliable, and convenient service makes using transit a more viable option for commuters, thereby minimizing traffic growth in the downtown area and making parking more available for less frequent visitors to the city

- The circulator has been cited many times by developers as part of the package that is making the city more attractive for employers to move their businesses from other areas to Coral Gables.

\section{Method of Management}

There are a variety of ways that downtown circulators are managed throughout the United States. In some cases the circulators are operated and managed by the local transit agency. In other places the director of a Transportation Management Association is responsible for contracting for the service and overseeing performance of the private contractor. This is only one part of the TMA director's job, however. In yet other cases, a municipality awards a contract and treats it as a turnkey operation where the city staff overseeing the service only gets involved when complaints are received.

In Coral Gables, the decision was made to contract for the service, but have a city employee whose sole responsibility is the success of the circulator service. The City believed that Miami- 
Dade Transit was simply too large of an agency, with almost 1,000 buses and a rail line to run, to give customized attention to trolleys within Coral Gables. Greyhound was awarded the contract to operate the service, while First Vehicle was hired to maintain the vehicles. One of the many strengths of the way Coral Gables manages the service is that they house the vehicles and the operations center in a Public Works facility within the city. This helps keep the costs low since the contractors are not responsible for the overhead associated with maintaining their own operations and maintenance facility, and the deadhead mileage for vehicles starting service is no more than a mile. The city pays Greyhound \$28 per hour to operate and supervise the trolleys, and pays First Vehicle \$25 per hour to maintain the fleet. The city provides the fuel, the cost of which is minimized due to the fact that efficient electric-hybrid vehicles constitute the majority of the fleet. The other major advantage of this arrangement is that the city's circulator manager, Mr. Ed Cox, is able to oversee and communicate directly with both the operations and maintenance personnel every hour of every day. Mr. Cox has taken the tact of approaching the service in a team fashion. He not only monitors contract compliance, he also asks how the city can help the contractors if necessary. In short, this is not a turnkey operation where the contractors are simply expected to do what they are paid to do. Mr. Cox has taken this responsibility as a personal mission in which he sees this operation as his own, and one that is critical for the success of the city.

There is a potential danger when one company is responsible for operating the buses and another is responsible for maintaining the buses. There could be finger-pointing when problems occur, with both parties blaming the other for failures in service. With the City's service manager there at all times overseeing both the operations and maintenance functions, he is able to make his own determinations if any shortcomings develop. Given his own background in running a maintenance shop and in providing charter bus service, Mr. Cox is very familiar with the issues that both contractors deal with and can get to the bottom of any disputes quickly.

One can question if operators and mechanics might not be sure who their boss is. Is it Mr. Cox, the city's manager of the service who is ever present, or is it their private company supervisor? Clearly, there is still a chain of command that is followed, and Mr. Cox works on any issues through the supervisor of each company. Every employee knows Mr. Cox, and amazingly, most passengers seem to know him as well. 


\section{Ridership on the Circulators}

The decision makers within the City of Coral Gables obviously believed in the value of providing a circulator service, or they wouldn't have pursued it. However, everyone has been astonished at the level of acceptance and utilization.

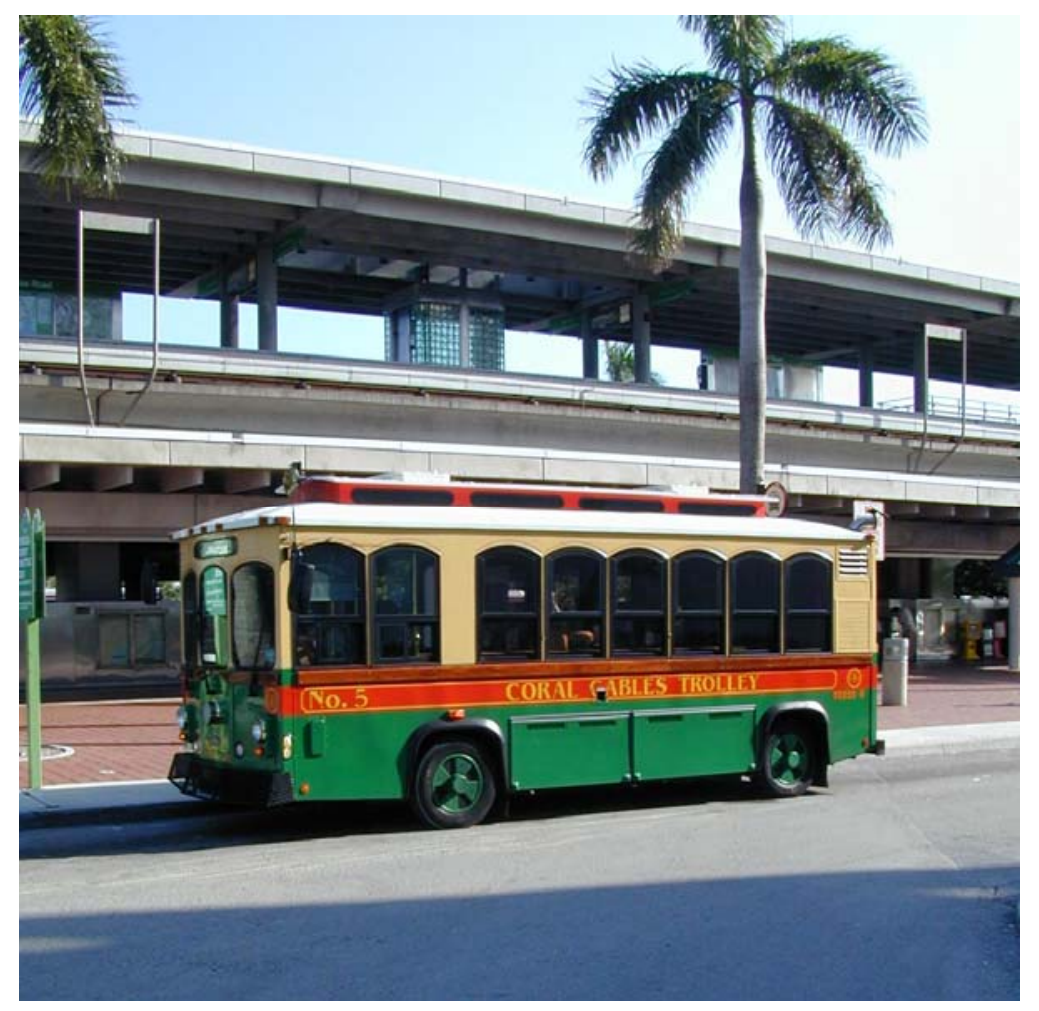

Ponce De Leon Route Connection with Metrorail.

As noted earlier, city officials anticipated a level of approximately 1,000 passengers per day. That would have represented a ridership level of approximately 17 passengers per hour, which is what the electric shuttle bus service in Miami Beach

was carrying in 2003 with five buses in service. The Coral Gables Trolley reached that level within the first seven weeks of operation. Word of mouth regarding the trolleys spread among passengers who utilized Metrorail to access their jobs in Coral Gables. Ridership grew to 1,500 passengers a day within three months of the start of service. The City had started by providing service every 15 minutes throughout the day, with a lunch hour shuttle providing service within a limited portion of the Ponce de Leon route every four minutes. Once it became clear how much demand there was for service to and from the Douglas Road Metrorail station, the city decided to modify service on the Ponce de Leon route to provide service every 10 minutes throughout the day uniformly, with no special lunchtime service. 
By the end of the first six months of service, ridership grew to 2,000 riders per day, doubling initial estimates of demand.

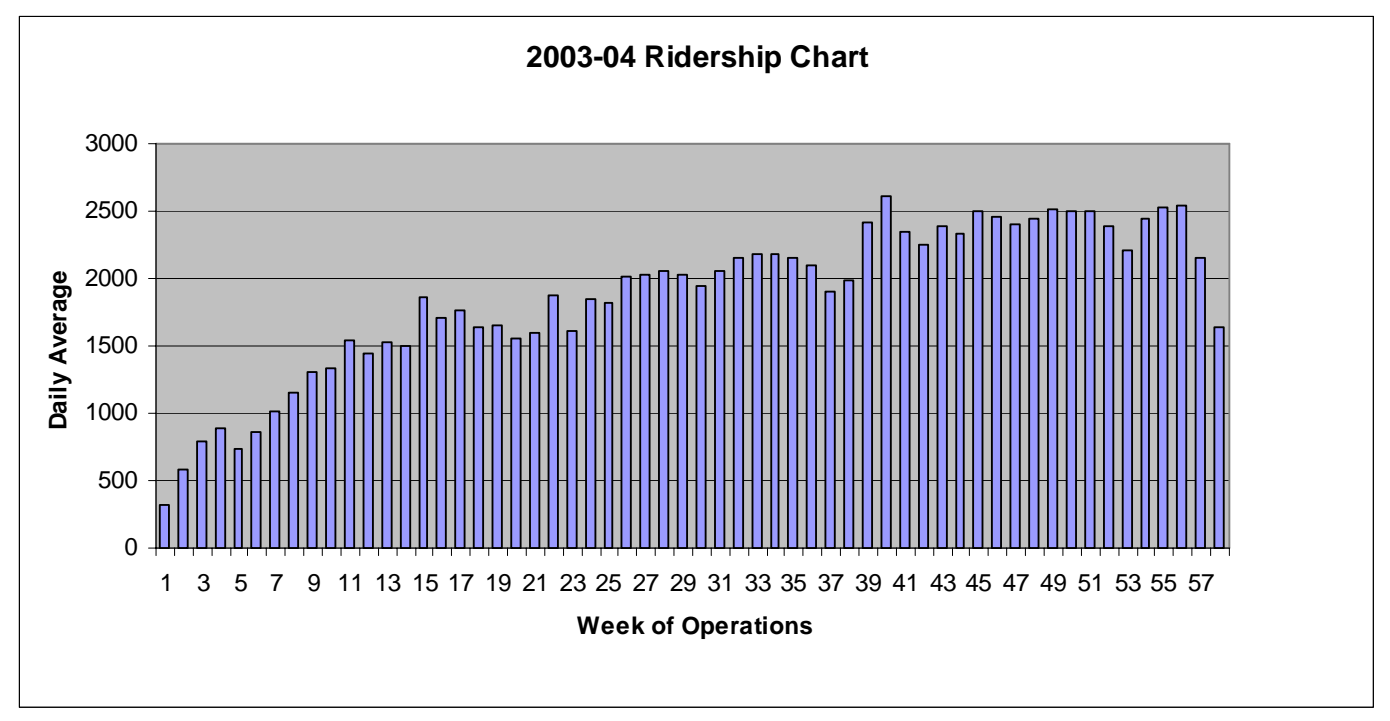

Average ridership per day by week from 11/03/03 to 12/31/04

By the end of the first ten months of service, the city had leased three more rubber wheeled trolleys to allow the provision of six-minute service during peak hours. Ridership responded by climbing to an average of 2,500 passengers per day, representing a very impressive rate of 30 passengers per hour. As more people, including students came to realize the availability of the service, ridership continued to grow throughout 2005. When school opened in August 2005, ridership started to exceed an average of 3,000 passengers a day. By the end of September 2005, the Coral Gables Trolley experienced its first 4,000+ passenger day. This level of ridership approaches 50 passengers per hour, far exceeding the average for Miami-Dade Transit's regional system of 35 passengers per hour. 


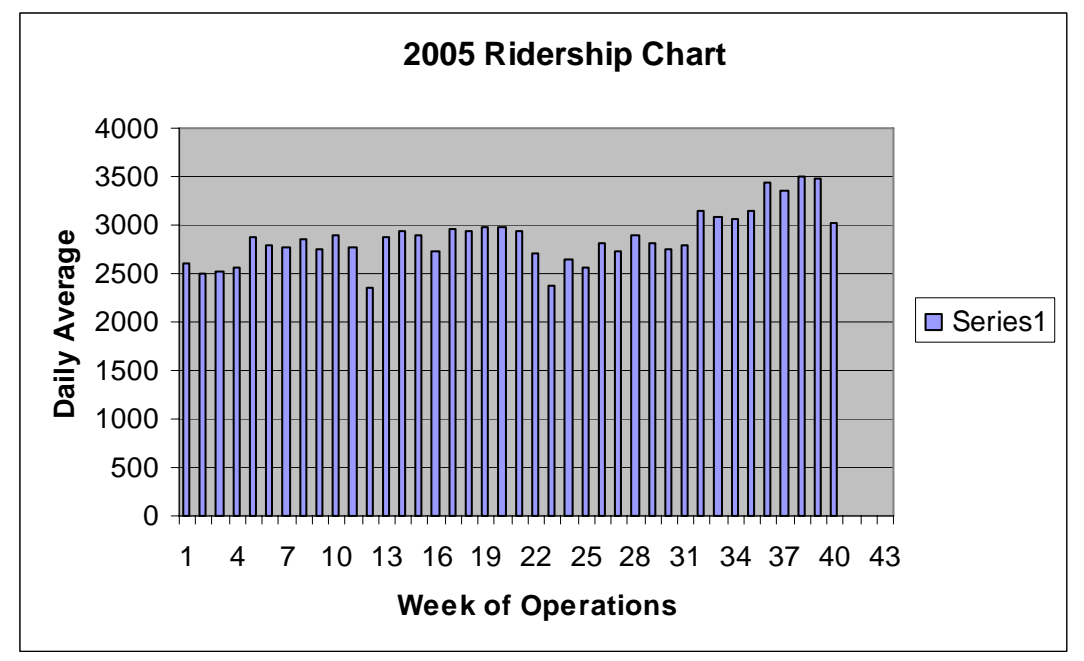

Average Ridership Per Day By Week from 01/01/05 - 10/08/05

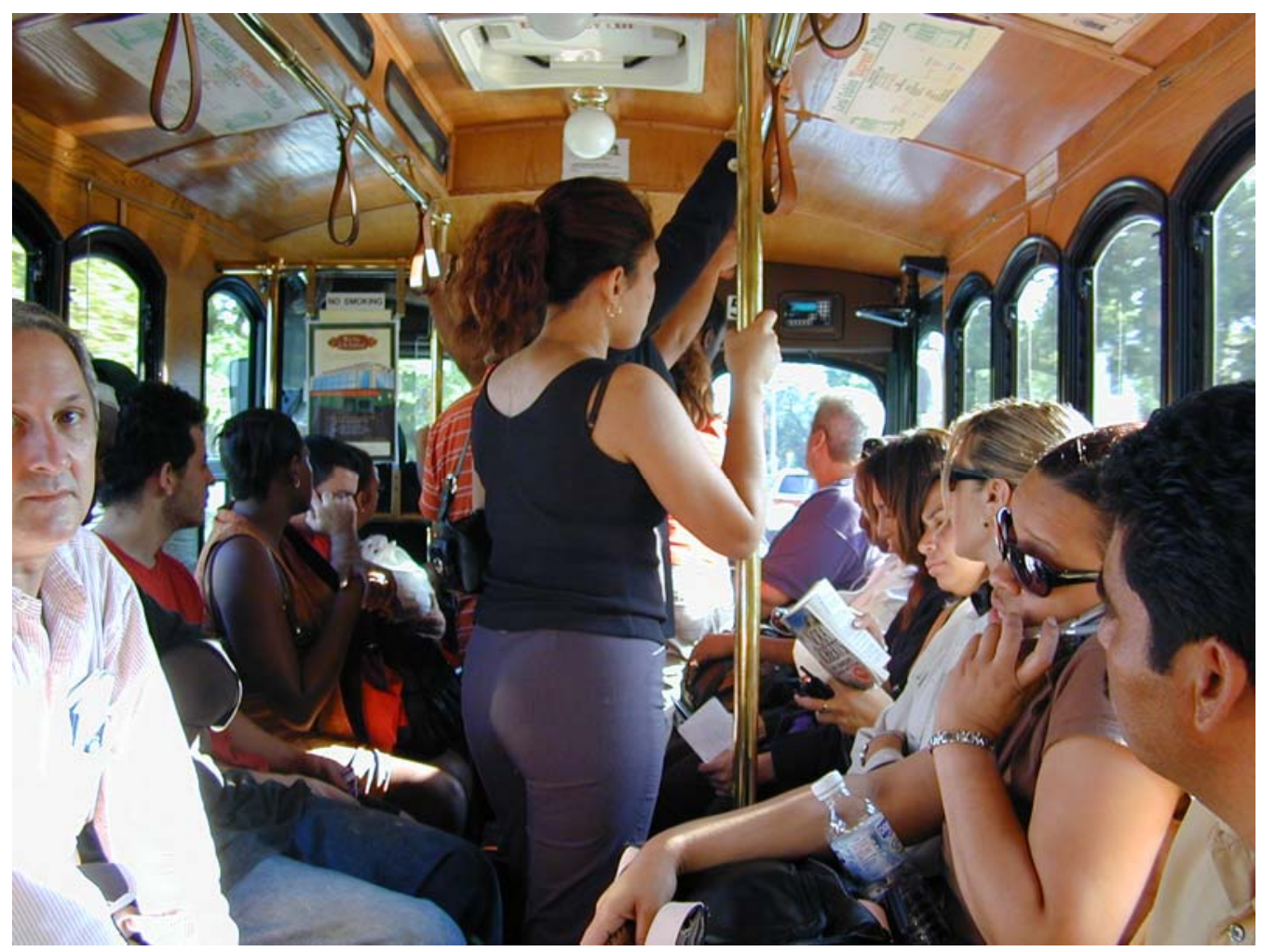

Standing-room-only passenger load on Coral Gables Trolley during afternoon peak.

Mr. Cox does not believe that additional frequency of service is needed to accommodate the demand that exists for the Trolleys. Six minute frequency during peak hours and 10 minute frequency throughout the day on the Ponce de Leon route is sufficient. He does believe larger 
buses with greater capacity are needed, and given the standing room only loads being carried on the small hybrid-electric buses, he is certainly correct. However, with 15 new major developments being planned in the corridor, including Burger King's corporate headquarters, a Hilton Hotel, and a number of $15+$ story condominium towers, even six minute frequency might not be enough during rush hours in the future. In all likelihood, given the additional passenger activity expected, at least one additional bus will probably be required to maintain the existing levels of frequency.

\section{Lessons Learned from the Coral Gables Trolley}

Coral Gables is a city that has many circumstances favorable to a successful transit circulator. It is a well run and well maintained city that sets high standards and has won many awards for its public services and policies. Over 50 percent of the city is dedicated to single family development, and another 30 percent is dedicated to public uses. It has concentrated its higher densities along just a few corridors, resulting in less than five percent of the land area contributing 46 percent of the tax base. Much of that development is along the Ponce de Leon trolley route. This has allowed the city to concentrate its circulator service along this corridor with great results. As has been noted in other studies, including "Identifying the Characteristics of Successful Local Transit Circulator Systems in Residential Areas of Southeast Florida" (CUTR December 2004) density trumps all other factors when it comes to determining ridership on transit.

In addition to this concentrated development, the Ponce de Leon route connects to the best transit service available in the county (Metrorail) at its south terminus, and to excellent bus routes in the middle of the route and at the north end of the route. Miami-Dade County is by far the most traffic-congested county in the state of Florida, and one of the most traffic-congested counties in the United States. It also offers the best alternatives to driving single occupant vehicles of any county in Florida. Hence, there are options for people to use transit, and more people are seeking this alternative if it is convenient for them to do so. The Coral Gables Trolley helps commuters finish their transit trip very easily and quickly by providing service that is timed to meet Metrorail trains at the Douglas Road station.

There are different markets served by the trolley throughout the day. In the morning, commuters and school students place a heavy demand on the service. People going to the courthouse and those who work and shop at the Village of Merrick Park use the service in the late morning. During lunch time, a good number of employees utilize the circulators to go to their restaurants of choice. In the mid-afternoon, students once again use the circulators to go home. Commuters 
complete their round trip in the latter part of the afternoon, while those who work later or wish to do some shopping after work use the service into the early evening. This constant demand from different travel markets allows the city to keep its trolleys running efficiently even at 10 minute frequencies throughout the day.

It is difficult to say just how significant the use of hybrid-electric vehicles has been to the success of the Coral Gables trolley. While no survey was taken as part of this report, casual discussions with passengers indicated that it hardly mattered that such vehicles were being used. The passengers' priority was for frequent and reliable service. There is no indication that passengers are not boarding the diesel trolleys in order to wait for the hybrid electric trolleys. In short, having an attractive and unique fleet of vehicles certainly helped to gain attention from the media which helped to make people aware of the service when it was new, but once the service was in place, passengers were far more concerned with other aspects of the service such as frequency and reliability.

The fare-free service has certainly helped ridership reach high levels. The evidence is quite clear from the experiences in Miami Beach, Florida and Santa Barbara, California that even a small fare change of going from free to $\$ .25$ can reduce ridership by approximately 40 percent. One other factor to consider is that fare-free service results in faster service, since the bus is not delayed by passengers finding change and interacting with the bus operator at each stop. If fares were charged, it is likely that travel speeds would be reduced by at least five percent, and an additional bus would be needed to maintain current headways.

There are two other factors that should be noted when reviewing the amazing success of the Coral Gables Trolley. The first is that the service is based on demand, not based on maintaining a clockface headway. When it became clear that the primary contributor to ridership on the circulator was its connection to Metrorail, the city did what it had to do to meet the expectations of its customers rather than telling its customers to accept what the city was providing. Hence, frequencies change throughout the day based on the frequencies of Metrorail, which runs every six minutes during peak morning and afternoon hours, and every ten minutes throughout the rest of the day. At these convenient frequencies, it is not important to provide detailed schedules to passengers since service is just a few minutes away. In most cases, a passenger can look down the road and see the next bus approaching their stop. While the trip on board the trolley is not particularly fast, the frequency and reliability of the service make it very popular with passengers. 
The other factor to emphasize is the method the city uses to manage the service, and the person who is managing it. The manager of the system, Mr. Ed Cox, is totally dedicated to the success of the circulator. He has no other duties that he conducts for the city, and he takes personal responsibility for ensuring that there is always a high level of customer service. Though the service is performed by private companies under contract to the city, Mr. Cox stays tuned to the radio of the trolley fleet throughout the day to stay completely aware of any changing conditions that need to be addressed. If a bus breaks down, he does everything in his power to get a replacement vehicle of some sort, even if it is a supervisor's vehicle, to go out and pick up passengers. He greets every employee each day and asks how they are and if there is anything that he can do to help them do their job. He is a firm believer in the power of communication and the importance of relationships. He understands that people need to know they are valued and appreciated, and when they are, they are more likely to want to go the extra mile with you. In addition, he rides the service and talks with passengers frequently to stay aware of their needs and desires. Consequently, he understands the service from the perspective of the employees and the passengers. While he treats all the contractors' employees as a member of a team, he is also a no-nonsense manager that demands contract compliance and professional, caring customer service.

Part of the reason Mr. Cox demands high quality service is that he knows that operating grants provided by the Florida Department of Transportation will expire within another year, which will require the city to identify another source of funds. While there is some possibility of securing funds through advertising on buses, or charging fares, Mr. Cox believes it is likely that the city will be asked to contribute a higher share of the operating expenses. He believes that the city will only do this if passengers demand that the level of service remain the same, and they will only do this if they truly value and appreciate the service based on its reliability and customer friendliness. 


\section{Findings and Conclusions}

As evidenced by the case studies and notable intra-urban circulators, there are many factors contributing to the successful implementation and operation of circulator transit service. Regardless of the urban form, operating conditions, and funding sources these services have found unique techniques to successfully provide transit service to downtown centers. Each example considered in this report applied unique solutions to address the specific conditions and objectives of the intra-urban service to meet the needs of the community.

Based on the findings of all previous tasks, several issues for consideration and strategies for success when planning and operating intra-urban transit circulators were revealed. These include the following, which are also further discussed below:

- Service goals;

- Service characteristics;

- Fares;

- $\quad$ Service delivery method;

- Connectivity;

- Identity;

- Marketing;

- Partnerships; and

- Funding

\section{Service Goals}

From the research compiled for this report, it is clear that there is no "one size fits all” approach to the successful planning and operation of intra-urban circulators. A community should not simply decide to operate a downtown circulator because another community has one, nor should it necessarily try to replicate the service characteristics from another community. What is successful in one community may not work as well in another.

A community should first determine what purpose it wants to serve, such as serving downtown workers (either for the commute trip or for mid-day services), serving as a parking garage/lot circulator, serving tourists or other visitors such as conventioneers, aiding in urban redevelopment efforts, or adding to the image or charm of a downtown area. If it is believed that a circulator system can help serve the stated purpose, service should be designed with the purpose in mind. 
While it is certainly instructive to learn from others, using resources such as this report, it is important to remember that the experiences in other communities are unique, and any characteristics or ideas that a community might want to replicate will undoubtedly need to be tailored to the needs of the community. Each example of intra-urban circulators examined in this report serves almost as a unique demonstration project on such services. Even two downtown areas that seem very similar might have drastically different results with a circulator. For example, Downtown Tampa and Downtown Coral Gables both offer circulator services. Each downtown has similar office space amounts (6.5 million square feet) and numbers of downtown workers (49,000). However, Tampa's circulator carries, on average, 11 passengers per hour, while in Coral Gables the circulator carries an average of 40 passengers per hour. A closer look at some of the unique characteristics of the downtown areas themselves as well as the transit service offered gives some understanding of the difference in the performance of the two circulators. The Coral Gables/Miami area has more transit services available, including rail transit, than Tampa, and also has a population that is historically much more accustomed to the presence and use of transit. In addition, Downtown Coral Gables has more mixed-uses (shopping, dining, entertainment, as well as financial services and other businesses) that serve as trip generators. Finally, in terms of service characteristics, the Coral Gables circulator route alignment is more linear than Tampa's, and its service is also fare-free, while Tampa charges $\$ 0.50$.

Thus, in terms of circulator system performance, it may not be very effective to compare statistics such as ridership against other communities' circulators. Rather, the community should determine how the performance will be measured, such as by comparing the results to the stated

goals or purpose. Ridership may not be the only gauge of success; relatively lower ridership numbers might be acceptable if the service is providing other benefits deemed important, such as contributing to redevelopment, improving downtown image, or providing a convenient transportation mode for area tourists or visitors. Intra-urban circulators are unique to their service areas and should be evaluated as such.

\section{Service Characteristics}

Key characteristics that make other transit modes successful, such as frequency and reliability, also are important for intra-urban circulators. Circulator trips tend to be relatively short, and so high frequencies are essential and ideally should be no more than 10 minutes. Clock-face headways are also best for the convenience of customers; however, it is also important to meet the existing demand. For example, as learned from the Coral Gables case study, the circulator in 
that city meets the local Metrorail service which, during peak periods, has headways of six minutes. Reliability of the service is also important for attracting and maintaining riders.

Relatively high levels of population and/or employment densities are also a major factor in the success of any transit mode, including circulators. In addition, a circulator will likely be more successful in an area where other forms of good transit service already exist (e.g., Downtown Tampa versus Downtown Coral Gables).

Often, the intra-urban circulator rider will be a choice rider who may not be familiar with using transit, or if a visitor, may not be familiar with the service area. Whether it is determined that a loop or a straighter route alignment is more appropriate for the service area, the route should be designed to be as easy to understand as possible. Well-placed signage along with clear and concise route schedules and maps will also help make the riding experience convenient and simple.

The circulator service should be customized to the purpose it is serving and to the character of the community in which it operates. For example, tourist-oriented circulators will necessarily have some different characteristics and amenities than a circulator designed to serve commuters primarily. A tourist-oriented circulator may serve more area hotels and attractions, and perhaps have a driver that also acts as a tour guide (e.g., the St. Pete Looper). Certainly, a downtown worker will not be interested in a tour of the local attractions during his or her commute.

If the setting is appropriate, the service can be designed to be an attraction in itself. The choice of a vehicle type to operate the service can also add to the attraction, whether it uses alternative fuel, or is designed to look like a historic trolley, etc. Of course, the vehicle type and size used should be appropriate for the service area and type of service provided.

\section{Fares}

Pricing of the circulator service is also important. In most cases, it is appropriate to have a lower fare than the primary transit service in the area, mainly because the trips tend to be relatively shorter. Some communities choose not to charge a fare at all. Fare-free service increases the convenience for the rider and also enhances the service reliability by allowing for faster boarding times. However, others charge a nominal fare, such as $\$ 0.25$ or $\$ 0.50$, either for the revenue or to discourage certain types of individuals from boarding.

There is not one correct fare policy that will work for circulators in all areas. The decision must be made locally. However, it is important to remember that, all other things being equal, the 
higher the fare, the lower the ridership. Again, each community is unique and will determine its fare structure based on existing conditions, demand, and service goals.

\section{Connectivity}

Whether a part of the primary transit service in the area or not, it is important for the intra-urban circulator to have good connections to other existing transit service as well as other modes such as pedestrian friendly areas and parking facilities. This increases the overall transit availability for the given circulator rider.

While many circulator riders may never need to transfer, connections to the rest of the local or regional transit network will increase the number of trips that could be taken by transit. For the area visitor, convenient connections to other transit modes may make it easier to get to and from the airport or to other attractions outside the downtown area (or circulator service area). For the commuter, such connections might make it more feasible to use transit for the entire work trip.

\section{Service Delivery Method}

A crucial decision for the community wanting to implement an intra-urban circulator is who will actually operate the service. There are several choices in this regard but, as mentioned previously, what works in one community may not be feasible or successful in another. Ultimately, the community will have to make its own decision based on its individual circumstances. In some areas, the local transit agency operates the circulator. In other cases, the city, other local government entity, or tourist bureau or convention center operates or contracts for the service.

Whatever the choice, there are some strategies for success that have been revealed from the research conducted for this report. It is important for the operator to be accountable for the provision of service that meets the stated goals and purpose of the circulator. Leadership from the contractor can ensure such accountability. In Coral Gables, the City hired a private company to operate its circulator, but per its contract has the service operating out of a city facility. This allows the city staff to closely monitor the performance of the operator.

With service delivery, a strong customer perspective and customer-service orientation tends to lead to success not just for intra-urban circulators, but for transit in general. It is important for the operator or contractor to work toward the stated goals for the service, and to tailor the service delivery to meet that end. 


\section{Identity}

While, as mentioned earlier, it is important for the intra-urban circulator to have good connectivity with other local and regional transit services, it is also important for the circulator to have its own identity (and yet still be easily recognized for the service it offers). In general, the appearance of the circulator vehicles, along with its signage, amenities, and printed materials, should be distinct from the other local transit service's. However, there still should be consistency among the appearance of the circulator vehicles, signs, stops, and printed materials to help make the service easy to understand and recognize.

Of course, the exact identity of the circulator service will vary according to its purpose. Careful design of the identity can work to solidify the image of the service and make it a definite part of the community in which it operates. Along with appropriate marketing efforts (discussed below) aimed at its potential riders, the circulator can become integral to the community, whether as an efficient commute or midday mode, a piece of historic charm in a redeveloping downtown, a way for visitors to get around easily and learn more about the community, or for any other unique goal or purpose held by the community.

\section{Marketing}

The marketing of intra-urban circulators is certainly important and may need to differ (perhaps significantly) from the way other transit services in the area are marketed. In some cases, wordof-mouth has been a major attractor to such circulator services.

In addition to the basic ways in which transit services are traditionally marketed, some interesting ideas emerged from the research conducted for this report, such as making the vehicle or the trip a destination or experience in itself by presenting a "fun" atmosphere. Some circulators provide music on board, or have casually-dressed drivers who may also act as a sort of tour guide (depending on the nature of the service, of course). Services targeted to visitors or convention attendees may provide video loops on televisions in area hotels, or work with concierge services to promote the service. Cities should ensure that circulator maps and basic information are included on visitor maps or brochures so potential riders can see where the circulator is in relation to local attractions and places of interest. In some places, the vehicles have a particular historic appeal, or even each have different names. Many circulators take part in promotional events or other special events, including weddings, or special "art tours” or "pub 
hops." These types of services have a value beyond the additional ridership; they serve to further solidify the circulator as a part of the community.

\section{Partnerships}

The research conducted for this report has shown the importance of local partnerships in the planning, development, and operation of intra-urban circulators. Prior to the service hitting the streets, it is beneficial to incorporate business development concerns in the early planning process. These relationships can also be fostered and continue as the service is implemented. Such partnerships can also be important for securing funding. As found in the St. Petersburg case study, partnering with local business development organizations was essential to gaining the political clout necessary to secure funding from the local transit agency to help support the Looper service.

\section{Funding}

Funding sources for intra-urban transit circulators can be generally categorized into municipal, county, other local, state, federal, and private. Farebox revenue and transit agency operating funds can contribute to the service. In addition, grants from the state and federal levels can be applied for. Other public funds can include downtown (or other attraction) parking fees, downtown property taxes, sales taxes, and general city revenues.

Private funding can result from partnerships with the business interests, such as business improvement districts (BIDs) or convention and visitors bureaus. Depending on the nature of the service, funds may also be available from museums or other cultural attractions, as well as shopping attractions. Advertising can be another source of revenue, as well as (again, depending on the nature of the service), selling the rights to naming stops, stations, or even vehicles.

It is likely that a mixture of several sources of funding will be ultimately used for any circulator service. Resources such as this report and other available literature, as well as local transit agency resources and the development of public-private partnerships, will aid communities wishing to secure adequate funding for an intra-urban circulator.

This study has developed a research synthesis by identifying key strategies for developing an intra-urban trolley/circulator system along with effective operating strategies. Because of growing interest in both large and small urban communities for a circulator system, most of which are attempting to reintroduce trolleys in downtown cores, it is important that such urban 
communities are provided with ample information on potential strategies from which to develop their own system objectives. The results of this study should be of interest to transit service providers, downtown developers and businesses, transportation professionals, transportation funding agencies that aim to improve systems currently in place, and similar others. 


\section{References}

1. Team Hartford Transport. "Downtown Hartford Circulation Project”. Technical Memorandum: Subtask 3.3.2. -Description of Existing Shuttle Services in Hartford. Prepared for The City of Hartford and The Greater Hartford Transit District. October 2000

2. The Downtown Circulator Partner Group. “Downtown Circulator Implementation Plan”. http://www.ncpc.gov/publications_press/Circulator/CirExecSummary.pdf . August 2003

3. Kimley-Horn Associates, Inc. "Local Municipal Transit Circulator Policy Study. http://www.co.miami-dade.fl.us/mpo/document/MPO_local_muni_circ_200206.pdf June 2002

4. ANA Associates. "Milwaukee Downtown Plan- Transit Connector". http://www.mkedcd.org/downtownplan/catalytic5.pdf. $\quad$ and http://www.mkedcd.org/downtownplan/execsum4.pdf. July 1999

5. Stone Consulting and Design Team, Inc. "Feasibility Report on Streetcar Transit Service as a Downtown Circulator for the Savannah Historic District and Other Locations-Draft Final Report”. http://www.catchacat.org/pdf/FinalFeasibilityReportonStreetcar.pdf. December 5th, 2003

6. Volinski, J \& Perk, V. "Miami Surface Shuttles: Feasibility Study For Transit Circulator Services in Downtown Miami Brickell, Overtown and Airport West. Prepared For Miami-Dade MPO. June 2000. http://www.cutr.usf.edu/pubs/miami_shuttlesfinal.pdf

7. Circulator Boise. http://www.compassidaho.org/trans/circulator.pdf

8. Urbitran Associates, Inc. "TCRP Report 55- Guidelines For Enhancing Suburban Mobility Using Public Transportation”. Transportation Research Board. 1999. http://gulliver.trb.org/publications/tcrp/tcrp_rpt_55-a.pdf

9. CUTR. "Electric Transit Circulator Feasibility Study”. Prepared for Miami-Dade MPO. June 2001.

http://www.co.miamidade.fl.us/mpo/docs/MPO_elec_transit_final_200106.pdf

10. ValleyRide- Boise Downtown Circulation Working Group. Boise Downtown Mobility Study- Downtown Circulation: Transit Strategies and Case Studies. http://www.valleyride.org/studiessurvey/downtownmobility/4_13_04folder/Downtown\%20Circulation_1_9_04.pdf

11. Central Salem Streetcar Feasibility Study- prepared by Nelson Nygaard Consulting and Associates, February 2005

12. Seattle Streetcar Network and Feasibility Analysis- prepared by Parsons Brinckerhoff, June 30, 2004. 


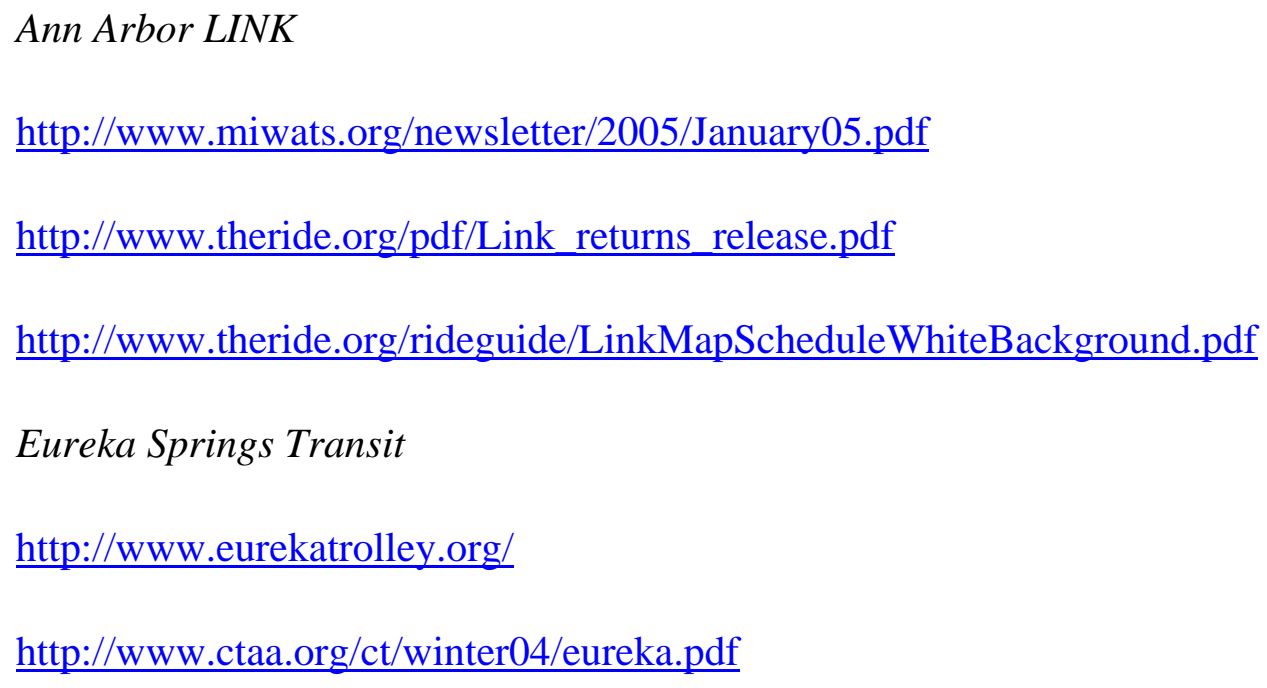

